FACUldade de Filosofia, CiÊNCIAS E LETRAS - DEPTO BIOLOGIA

NÚCLEO DE ESTUDOS EM NEUROCIÊNCIA E COMPORTAMENTO - IP

\title{
MATURAÇÃO SEXUAL, CICLOS REPRODUTIVOS E DA TEMPERATURA DO ROEDOR RABO-DE-FACHO \\ (TRINOMYS YONENAGAE, ECHIMYIDAE)
}

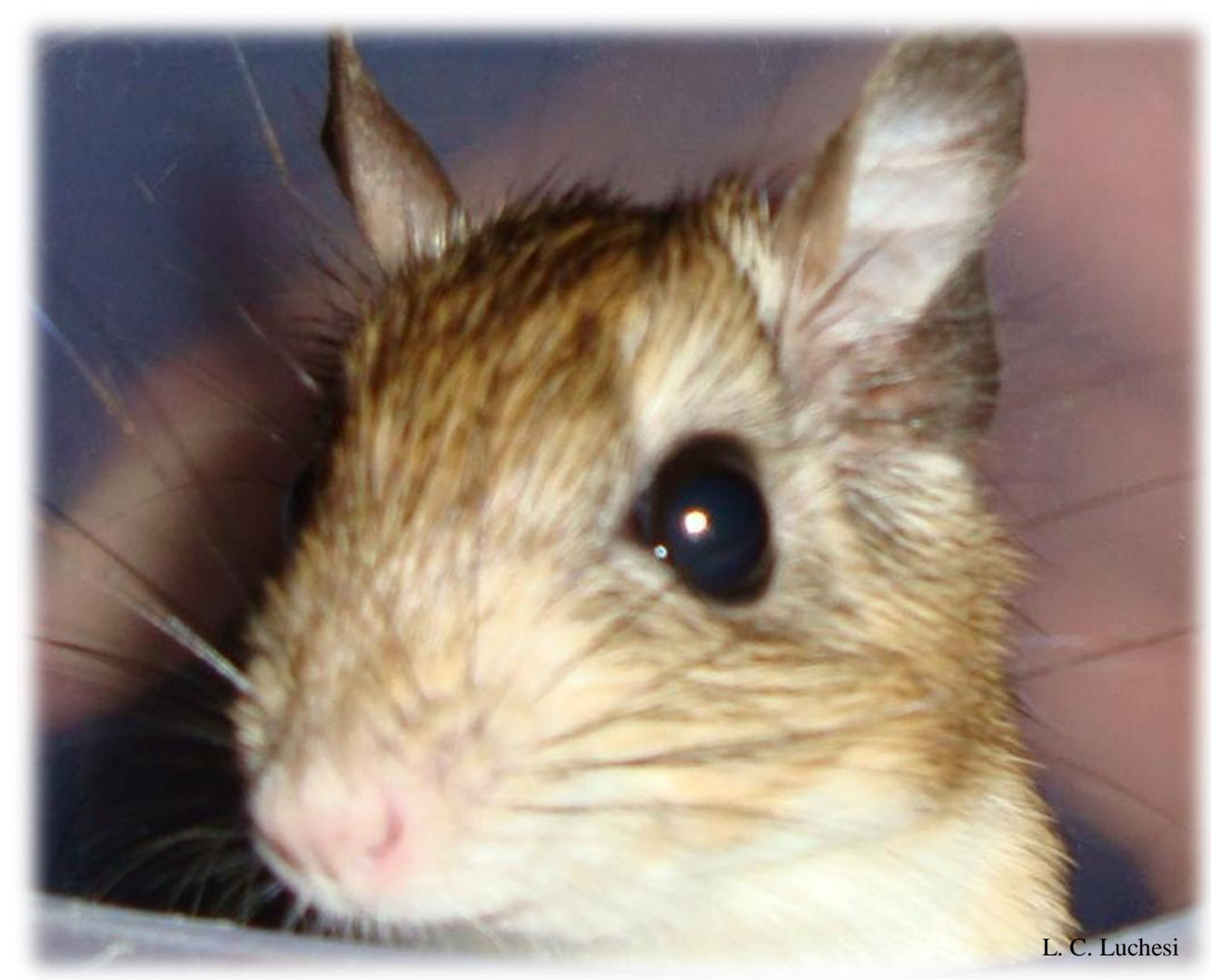


MATURAÇÃO SEXUAL, CICLOS REPRODUTIVOS E DA TEMPERATURA NO ROEDOR RABO-DE-FACHO (TRINOMYS YONENAGAE, ECHIMYIDAE)

Dissertação apresentada ao Instituto de Psicologia da Universidade de São Paulo (USP) para obtenção do título de Mestre em Neurociências e Comportamento.

Área de concentração: Neurociências e comportamento

Orientadora: Prof. Dra ${ }^{\mathrm{a}}$ Elisabeth Spinelli de Oliveira 
AUTORIZO A REPRODUÇÃO E DIVULGAÇÃO TOTAL OU PARCIAL DESTE TRABALHO, POR QUALQUER MEIO CONVENCIONAL OU ELETRÔNICO, PARA FINS DE ESTUDO E PESQUISA, DESDE QUE CITADA A FONTE.

Catalogação na publicação Biblioteca Dante Moreira Leite Instituto de Psicologia da Universidade de São Paulo

Luchesi, Lilian Cristina.

Maturação sexual, ciclos reprodutivos e da temperatura no rabo-defacho (Trinomys yonenagae, Echimyidae) / Lilian Cristina Luchesi; orientadora Elisabeth Spinelli de Oliveira -- São Paulo, 2010.

$106 \mathrm{f}$.

Dissertação (Mestrado - Programa de Pós-Graduação em Psicologia. Área de Concentração: Neurociências e Comportamento) Instituto de Psicologia da Universidade de São Paulo.

1. Rabo-de-facho (roedores) 2. Maturidade sexual 3. Ciclo estral 4. Ritmos biológicos (animal) 5. Temperatura do corpo I. Título. 


\section{FOLHA DE APROVAÇÃO}

\section{Lilian Cristina Luchesi}

Maturação sexual, ciclos reprodutivos e da temperatura no roedor rabo-de-facho (Trinomys yonenagae, Echimyidae)

Dissertação apresentada ao Instituto de Psicologia da USP para obtenção do título de Mestre em Neurociências e comportamento.

Aprovada em:

\section{Banca Examinadora}

Prof $^{a}$. Dr ${ }^{\mathrm{a}}$ Elisabeth Spinelli de Oliveira Depto de Biologia da FFCLRP/USP, Rib. Preto

Prof. Dr. Pedro Luis Bernardo da Rocha

Depto de Zoologia do IB/UFBA, Salvador

Prof. Dr. Luciano Freitas Felício

Depto. De Patologia da FMVZ/USP, São Paulo

Prof ${ }^{a}$. Dr ${ }^{\mathrm{a}}$ Miriam Mendonça Morato de Andrade

Depto de Ciências Biológicas da FCL/UNESP, Assis

Prof. Dr. José Lino Oliveira Bueno

Depto. De Psicologia e Educação da FFCLRP/USP, Rib. Preto 
Dedico a minha família, meus pais Lilian Ap. Sacutti Luchesi e Layr Luchesi Jr. e ao meu irmão André Marcel Luchesi, por estarem sempre por perto aguentando todas as dificuldades e alegrias desse projeto de minha vida. Amo vocês! 
Sou grata todos os dias a Deus, que criou tudo o que aqui está me permitindo estudar e conhecer cada vez mais os mistérios desse mundo, do qual fazem partes os roedores mais fofos, os rabo-de-

facho.

À Profa. Dra. Miriam Andrade que confiou em minha capacidade e me apresentou à Beti para que eu pudesse seguir meu sonho de fazer pesquisas.

À Profa. Dra. Elisabeth Spinelli de Oliveira por me aceitar em seu laboratório e que acabou se tornando mais do que minha orientadora. Obrigada, me considero uma pessoa de muita sorte! A Universidade de São Paulo e ao NeC pela oportunidade de cursar a pós-graduação. À Fundação de Amparo à Pesquisa do Estado de São Paulo, FAPESP, pela bolsa que permitiu que eu seguisse com meu objetivo de cursar o mestrado.

A meus pais, Layr Luchesi Jr. e Lilian Ap. Sacutti Luchesi, que me trouxeram a esse mundo e são os responsáveis por hoje eu ser quem sou. E a toda a minha família que me ajudou, e ajuda sempre que preciso na confiança de que o investimento não será em vão.

Agradeço todos os dias por ter vocês em minha vida! Ao pessoal do LECO que sempre me lembra que é possível trabalhar em equipe. Formamos uma bela equipe, unida não só na vida profissional! Em especial às meninas do laboratório que não são apenas parceiras de trabalho, mas as melhores amigas que alguém poderia ter Lais Ruiz Cantano e Larissa Dias, que me dão uma mãozinha nos afazeres do laboratório sempre que é preciso. Mesmo quando isso inclui dormir! Vocês são muito especiais! As amigas, velhas e novas, que me receberam em São Paulo quando precisei de um lugar para dormir e seguir as tarefas da pós-graduação Camila Huffenbaecher, Fernanda Luccas, Aline e Vivian. Se não fosse por vocês não sei como teria sido minha jornada. A todos os outros que me ajudaram de alguma forma nessa trilha, nas conversas, passeios, discussões e viagens me ajudando a entender a vida e a ciência como parte dela.

E é claro, aos Trinomys yonenagae, que me deixaram acompanhar suas vidas, que foram tiradas da Caatinga há muito tempo, para que eu possa dar a minha pequena contribuição à necessidade do homem de entender o mundo a sua volta. 


\section{RESUMO}

LUCHESI, L. C. Maturação sexual, ciclos reprodutivos e da temperatura no roedor rabo-de-facho (Trinomys yonenagae, Echimyidae). 2010. 106p. Dissertação (Mestrado) Instituto de Psicologia - NeC - Universidade de São Paulo, São Paulo, 2010.

Os ratos-de-espinho são abundantes nas florestas úmidas Neotropicais. Trinomys yonenagae (RocHA, 1995) constitui uma exceção entre as espécies do gênero por habitar o campo de dunas fixas da Caatinga, ser colonial e fossorial. Tanto o ambiente seco, como a socialidade e o hábito fossorial podem alterar o padrão reprodutivo das espécies. Diante do fato desses roedores serem coloniais, por exemplo, espera-se a influência de co-específicos (fêmeas ou machos) no ciclo estral. Estudos-piloto na natureza e em cativeiro mostraram que a fase de diestro pode ocorrer com a vagina aberta, um fato que merece ser mais investigado, já que se considera que a abertura vaginal ocorra somente durante a transição da fase proestroestro. O objetivo deste trabalho é, portanto, o de estudar aspectos dos ritmos reprodutivos infradianos (ciclo estral e gestação) e circadiano (temperatura corporal) em rabos-de-facho, mantidos em cativeiro, alojados individualmente, e pareados com fêmeas e com machos. Nesses grupos são caracterizados os esfregaços e o estado de abertura da vagina, buscando conhecer aspectos da fisiologia reprodutiva, tais como, a idade de maturidade sexual (cap. 1), a relação entre a fase do ciclo estral e o estado vaginal (cap. 2), e as características da citologia esfoliativa durante a gravidez (cap. 3). Os dados da citologia são correlacionados com o padrão comportamental durante o acasalamento, caracterizando a existência de estro pós-parto (cap. 3). Analisa-se ainda a distribuição de todos os nascimentos ocorridos ao longo de dez anos. O ritmo de temperatura corporal das fêmeas é aferido a partir de acompanhamento da temperatura retal com uso de termômetro digital durante 72h (cap. 4). Embora de maneira geral Trinomys yonenagae siga os padrões reprodutivos de outros membros da família Echimyidae, tais como, gestação longa (90d), ninhadas pequenas (média de 2 filhotes) e maturidade sexual tardia (ao redor dos 90d) é possível identificar a influência de co-específicos (dominância entre fêmeas) no ciclo estral. Este ciclo parece ser espontâneo, do tipo poliéstrico, com fases muito curtas de proestro e estro $(<24 \mathrm{~h})$. A condição vaginal não é um bom indicativo de atividade reprodutiva (ocorre abertura no diestro e na gravidez); a presença do macho não garante fecundação; também se confirma a ocorrência de estro pósparto, igualmente breve. O comportamento de acasalamento é elaborado, o que é esperado de espécies com estro curto ou de vida social e subterrânea. A distribuição dos nascimentos não é sazonal, confirmando dados de campo. Quanto ao ritmo de temperatura corporal, ele é 
circadiano com picos noturnos e com relação positiva de fase com o ritmo de atividade/repouso, o que segue o padrão geral de roedores.

Palavras-chave: estro pós-parto; gestação; paleodeserto da Caatinga; ritmo circadiano de temperatura; Trinomys yonenagae 


\begin{abstract}
LUCHESI, L. C. Sexual maturity, reproductive cycles and the temperature in the torch-tail rodent (Trinomys yonenagae, Echimyidae). 2010. 106p. Dissertação (Master) Instituto de Psicologia - NeC - Universidade de São Paulo, São Paulo, 2010.
\end{abstract}

Spiny rats are among the most numerous group of mammals in Neotropical rainforests. Trinomys yonenagae (ROCHA, 1995) is an exception because it is colonial, fossorial and inhabits the semiarid Caatinga. The dry environment and the underground and colonial life styles are known to affect reproductive patterns. So it is expected, for example, that social life may influence the estrous cycle especially through the presence of conspecific (females and males). It is considered that vaginal opening occurs only during the estrus. Previous field studies or in captivity have shown the unexpected occurrence of vaginal opening and diestrus, a fact that deserves further investigation. The aim of this work is verify the reproductive infradian rhythms (estrous cycle and pregnancy) and the circadian body temperature rhythm, in T. yonenagae kept individually or in pairs (male-female and femalefemale) in captivity. In these groups vaginal smears and the presence of the vaginal membrane is studied aiming to characterize aspects of its reproductive life, such as, the age of sexual maturity (chapter 1), the relationship between the vaginal opening and the phase of the estrous cycle (chapter 2), and the smear cytology during pregnancy (chapter 3). The cytological data are correlated with the mating behavioral, characterizing the post-partum estrus (chapter 3 ). All birth that occurrence during 10 years are analyzed. The body temperature rhythm is measured during $72 \mathrm{~h}$ by rectal temperature with a digital thermometer (chapter 4 ). Although Trinomys yonenagae follows the reproductive patterns of other members of Echimyidae, such as prolonged gestation( 90d), small sized litter (mean of 2) and delayed sexual maturity (around 90d), it is possible to identify the influence of conspecifics (female dominance) upon the estrous cycle. This cycle seems to be spontaneous, poliestric, having very short proestrus and estrus phases $(<24 \mathrm{~h})$. The vaginal condition is not a good indicative of the reproductive status (vaginal opening may occur during the diestrus phase and the pregnancy); the presence of males does not guarantee pregnancy. We also confirm the occurrence of post-partum estrus, which is also short-lived. The mating behavior is complex, which is expected in species were the duration of estrus is short, or in species of social and subterranean life. The birth distribution is non seasonal, which is in agreement with field data. The body temperature rhythmicity is circadian with peaks at night; and shows a positive phase relationship with the rest/activity rhythm, both cycles follow the pattern known for other nocturnal rodents.

KEY-WORDS: Trinomys yonenagae; post-partum estrus; circadian body temperature rhythm; gestation, sand dune fields in the Caatinga 


\section{ÍNDICE DE FIGURAS}

Figura 1 Distribuição das principais famílias de roedores da América do Sul pertencentes ao clado Caviomorpha

Figura 2. Distribuição geográfica dos roedores da família Echimyidae na América do Sul segundo Mares \& Ojeda (1982)

Figura 3. a) Exemplar de T. yonenagae macho $(\mathrm{m}=130 \mathrm{~g})$; b) Pais com filhotes de $T$. yonenagae

Figura 4 Filogenia proposta por Lara \& Patton (2000) com os três clados para o gênero Trinomys. Trinomys yonenagae está destacado no clado 2 que tem espécies ligadas a ambientes com vegetação xérica

Figura 5 Em destaque a entrada da toca de T. yonenagae, feita em solo arenoso e com vegetação próxima em que há predomínio de cactácea e bromeliáceas

Figura 6 Localização do núcleo Supraquiasmático no SNC de Ratus novergicus em destaque

Figura 1.1 Fêmea de Trinomys yonenagae com o orifício vaginal fechado (VF)

Figura 1.2 Idade em que ocorreu a $1^{a}$ abertura vaginal em fêmeas de Trinomys yonenagae mantidas em cativeiro $(n=9)$. $O$ traço horizontal indica o valor da média

Figura 2.1 Estados vaginais (a) e fases do ciclo estral (b) de fêmeas pareadas com fêmeas (grupo A) durante o $1^{\circ}$ semestre de observação

Figura 2.2 Estados vaginais (a) e fases do ciclo estral (b) de fêmeas alojadas em gaiolas individuais (grupo B) durante um ano de observação

Figura 2.3 Estado vaginal (a) e fases do ciclo estral (b) em fêmeas pareadas com machos $(n=4$ a 5) fora do período de gravidez

Figura 2.4 Estados vaginais (a) e fases do ciclo estral (b) na fêmea nulípara (1CF) durante um ano de observação

Figura 3.1. Evolução da massa corporal das fêmeas de Trinomys yonenagae em 15 semanas de observação ( $\mathrm{n}=8$ episódios)

Figura 3.2. Estados vaginais das fêmeas grávidas durante os três meses de gestação $(n=5) \quad 64$

Figura 3.3. Fases do ciclo estral observadas nas fêmeas grávidas durante os três meses de gestação $(n=5)$

Figura 3.4. Esfregaço vaginal com espermatozóides da fêmea 6CF em janeiro de $2009 \quad 68$

Figura 4.1 Oscilação de temperatura nas fêmeas do grupo A $(\mathrm{n}=8)$ de Trinomys yonenagae em 24 horas. A barra preta representa a fase de escuro

Figura 4.2 Oscilação de temperatura nas fêmeas do grupo B $(n=8)$ de Trinomys yonenagae em 24 horas. A barra preta representa a fase de escuro

Figura 4.3 Oscilação de temperatura das fêmeas de Trinomys yonenagae $(\mathrm{n}=16)$ em 24 horas. A barra preta representa a fase de escuro 


\section{SUMÁRIO}

INTRODUÇÃO

Trinomys yonenagae: Rodentia (Hystricognathi, Echimyidae) 13

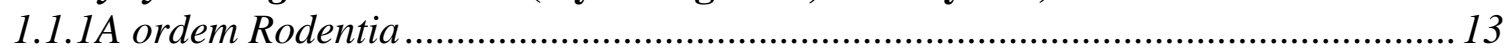

1.1.2 Trinomys yonenagae (Rocha, 1995): roedor da Caatinga..................................... 14

1.1.2.1 O ambiente da Caatinga: o paleodeserto à margem oeste do São Francisco 17

1.1.4. Trinomys yonenagae em estudos de contexto evolutivo ......................................... 19

2.1.1 Ritmicidade biológica: evolução, tipos, osciladores, definições e propriedades ... 21

2.1.2 A cronobiologia de T. yonenagae ............................................................................24

2.1.2.1 Padrão circadiano 24

2.1.2.2 Padrão infradiano 25

OBJETIVOS GERAIS $\quad 27$

MATERIAL E MÉTODOS

$\begin{array}{ll}\text { 4.1 Animais } & 27\end{array}$

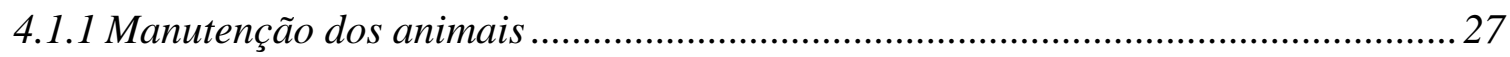

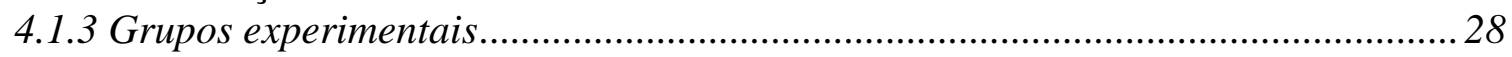

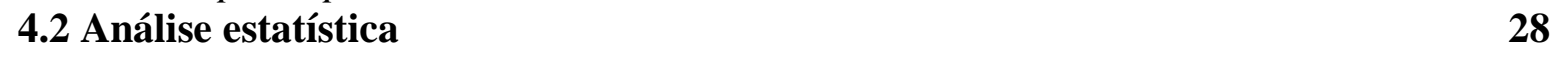

CAPÍTULO I - IDADE DA ABERTURA VAGINAL EM TRINOMYS YONENAGAE 29

1.1 Introdução $\quad 29$

$\begin{array}{ll}1.2 \text { Objetivos } & 30\end{array}$

1.3. Material e Métodos

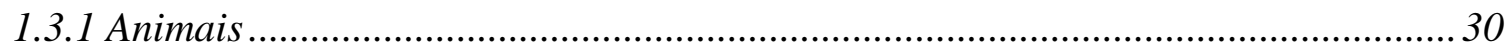

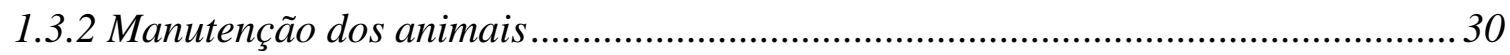

1.3.3 Procedimento e equipamentos do acompanhamento da maturidade sexual............31

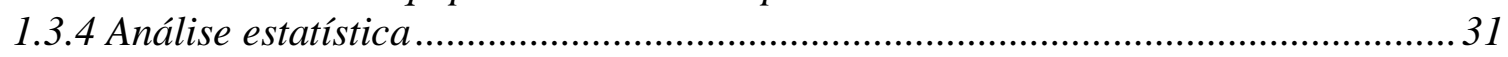

1.4. Resultados $\quad 32$

1.5. Discussão $\quad 33$

CAPÍtUlo II - CiClo ESTRAL E ESTAdo VAGINAL EM TRINOMYS YonenaGAE 37

$\begin{array}{ll}2.1 \text { Introdução } & 37\end{array}$

2.2 Objetivos $\quad 39$

2.3 Material e métodos $\quad 40$

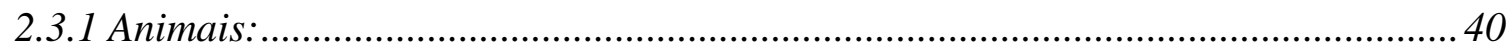

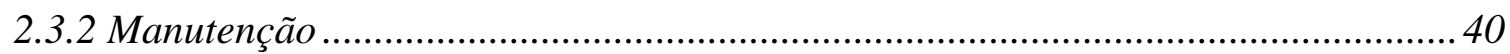

2.3.3 Procedimento e equipamentos dos estudos do ciclo estral.......................................40

2.3.3.1 A coleta do esfregaço vaginal 41

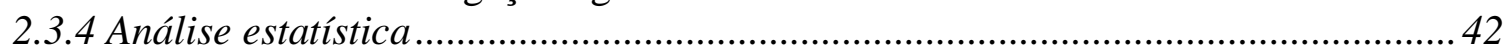

2.4 Resultados $\quad \mathbf{4 2}$

2.4.1 Os estados vaginais ............................................................................................... 42

2.4.2 Características gerais do ciclo estral de Trinomys yonenagae .............................. 43

2.4.2.1 Ciclo estral das fêmeas alojadas em duplas (grupo A) 44

2.4.2.2 Ciclo estral das fêmeas alojadas em gaiolas individuais (grupo B) 47

2.4.2.3 Ciclo estral nas fêmeas alojadas com machos (grupo C) 49

2.5 Discussão $\quad 51$

2.6 Bibliografia $\quad 54$

CAPítulo III - GeStaÇÃo e ACASAlamento em TRinomys yonenaGaE 56

3.1 Introdução $\quad 56$

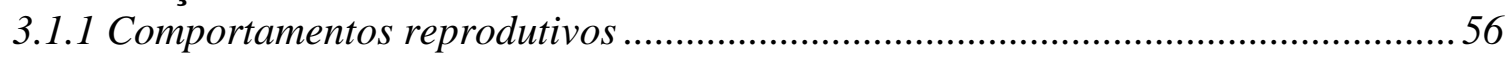




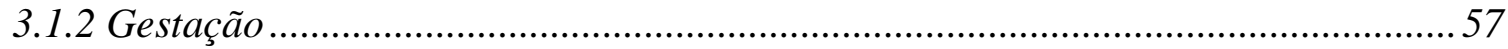

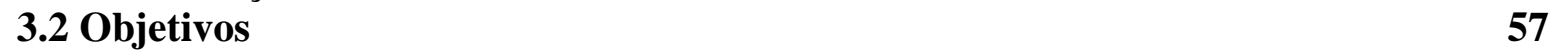

3.3 Material e Métodos $\quad 57$

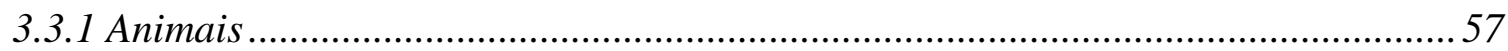

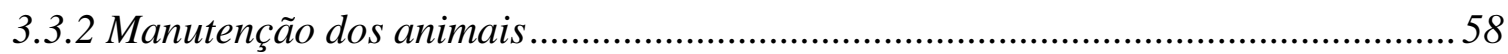

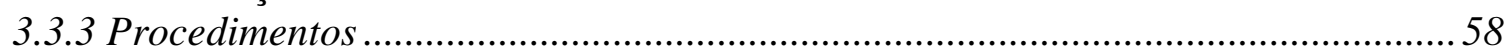

3.3.3.1 Procedimentos e equipamentos dos estudos das características da gestação 58

3.3.3.2 Procedimentos e equipamentos dos estudos do padrão do comportamento $\begin{array}{ll}\text { reprodutivo } & 59\end{array}$

3.4. Resultados $\quad 59$

3.4.1 Gravidez em Trinomys yonenagae ........................................................................5

3.4.1.2 Ganho de peso durante a gestação $\quad 61$

3.4.2 Nascimentos durante o desenvolvimento do estudo ..................................................62 62

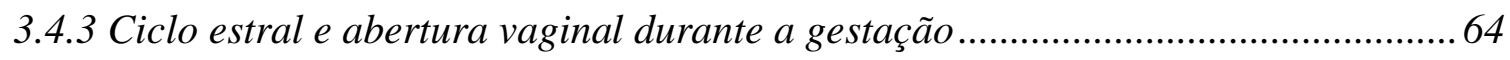

3.4.4 O padrão de acasalamento ................................................................................... 65

3.4.4.1 Maturação sexual e reprodução da fêmea 080398 (6CF) 67

$\begin{array}{ll}3.5 \text { Discussão } & 68\end{array}$

$\begin{array}{ll}\text { 3.6 Bibliografia } & 71\end{array}$

CAPÍtUlo IV - RITMO DE TEMPERATURA CORPORAL

$\begin{array}{ll}4.1 \text { Introdução } & 73\end{array}$

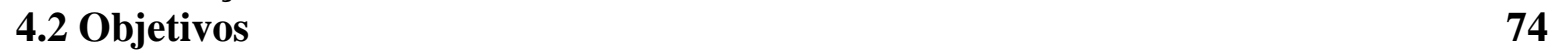

4.3 Material e Métodos $\quad \mathbf{7 4}$

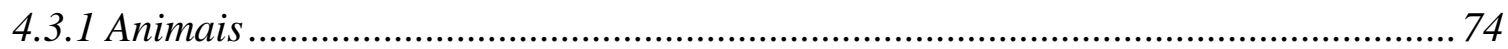

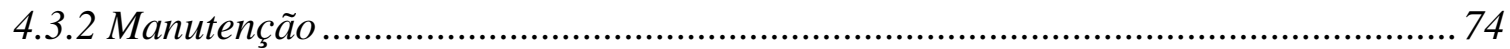

4.3.3 Procedimento e equipamentos do estudo do ritmo de temperatura corporal .......... 74

4.3.4 Análise dos dados ............................................................................................. 75

4.4 Resultados $\quad \mathbf{7 5}$

4.4.1 Ritmo de temperatura nos dois grupos de fêmeas ............................................... 75

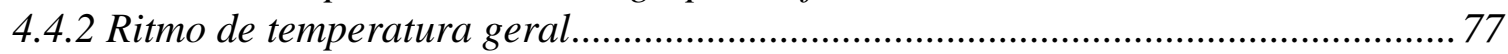

$\begin{array}{ll}\text { 4.5 Discussão } & 77\end{array}$

$\begin{array}{ll}\text { 4.6 Bibliografia } & 80\end{array}$

CONCLUSÕES FINAIS $\quad 81$

BIBLIOGRAFIA $\quad 83$

$\begin{array}{ll}\text { AneXos } & 90\end{array}$ 


\section{INTRODUÇÃO}

Esta dissertação trata do estudo da caracterização temporal de fenômenos fisiológicos que são de fundamental importância para a sobrevivência das espécies. Aqui, a espécie em questão é um roedor que é peça-chave em um ambiente especial da Caatinga, o das dunas da margem esquerda do Rio São Francisco, na Bahia. Serão abordadas duas questões pertinentes para a compreensão da biologia deste mamífero, que é de pequeno porte e com possíveis ancestrais de florestas úmidas: a da reprodução e a da temperatura corporal.

\section{Trinomys yonenagae: Rodentia (Hystricognathi, Echimyidae)}

\subsubsection{A ordem Rodentia}

A ordem Rodentia apresenta mais de 2.000 espécies distribuídas em uma grande diversidade de famílias e gêneros, representando uma entre cada quatro espécies de mamíferos. A ordem está dividida em subordens segundo critérios anatômicos. Considerando as diferenças no arco do zigomático e no músculo masseter (ver WOOD, 1948; WILSON e REEDER, 2005) ela é dividida em três subordens: Sciuromorpha (como os esquilos), Myomorpha (ratos e camundongos) e Hystricomorpha (capivaras e pacas). Seguindo o critério da mandíbula a ordem divide-se em Sciurognathi (esquilos, ratos e camundongos) e Hystricognathi (paca, cutia). Alguns roedores são ainda tanto histricomorfos como histricognatas (ver MARTIN, 1992). Mais recentemente outras denominações têm sido propostas (ver CARLETON e MUSSER, 2005), mas nesta dissertação será utilizada a nomenclatura clássica, como citada pelos autores da bibliografia.

Os histricognatas encontrados na América do Sul são denominados de Caviomorpha (ver WoOD, 1984 e figura 1). Este é um grupo muito diversificado com representantes de tamanhos variados, desde 7 até $150 \mathrm{~cm}$ de comprimento cabeça-corpo (ver MACDONALD, 1984). Esse é também considerado o grupo de roedores mais antigo a colonizar a América do 
Sul, quando esse continente ainda estava isolado das Américas Central e do Norte, o que poderia explicar a presença de espécies de caviomorfos nos mais diversos ambientes sul americanos. A colonização é um evento considerado controverso há mais de 100 anos, portanto, existem várias teorias a respeito da origem dos caviomorfos neste continente (ver Martin, 1992; LuCKetT \& HARTEMBERGUer, 1985, NowAK, 1999). Alguns de seus representantes são a paca (Agouti paca), a capivara (Hydrochoerus hydrochaeris), a cotia (Dasyprocta aguti), a cobaia (Cavia porcellus) e o rabo-de-facho (Trinomys yonenagae).

Figura 1 Distribuição das principais famílias de roedores da América do Sul pertencentes ao clado Caviomorpha

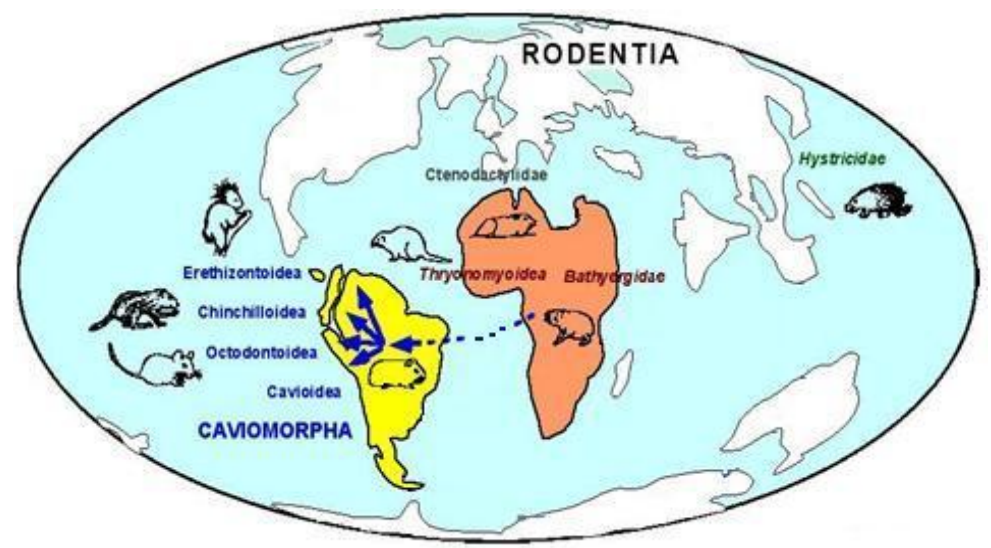

Considera-se que os caviomorfos sejam os primeiros roedores a colonizar a América do Sul. A rota em azul representa a hipótese mais aceita da origem africana dos Caviomorfa. Figura retirada e modificada de Huchon e Douzery, $2001^{1}$

\subsubsection{Trinomys yonenagae (Rocha, 1995): roedor da Caatinga}

Os ratos-de-espinho (Echimyidae) formam o mais abundante grupo de mamíferos nãovoadores nas florestas úmidas e a distribuição da família na América do Sul encontra-se na figura 2 (retirada de MARES \& OJEDA, 1982). O grupo é de interesse já que permite estudos comparativos de espécies filogeneticamente próximas, mas que vivem em ambientes distintos entre si como as florestas neotropicais e a caatinga.

\footnotetext{
${ }^{1}$ Huchon, D; Douzery, E. J. P. From the Old World to the New World: A Molecular Chronicle of the Phylogeny and Biogeography of Hystricognath Rodents. Molecular Phylogenetics and Evolution, v. 20, n. 2, pp. 238-251, 2001.
} 
Figura 2. Distribuição geográfica dos roedores da família Echimyidae na América do Sul segundo Mares \& Ojeda (1982)

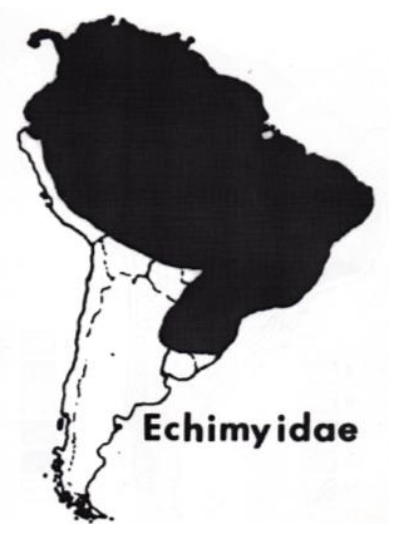

Inicialmente o rato-de-espinho Trinomys yonenagae (figura 3) foi descrito como pertencente ao gênero Proechimys, e subgênero Trinomys por RocHA, 1995 a partir de espécimes coletados em 1991, no paleodeserto de dunas fixas localizado na margem oeste do rio São Francisco, no domínio morfoclimático da Caatinga (BA) (RODRIGUES, 1991; ROCHA, 1992, 1995). A região de $7.000 \mathrm{~km}^{2}$ abriga uma fauna com altos índices de endemismos (RoDRIGUES, 1996) e presentemente é conhecida como “Área de Preservação Ambiental das Dunas e Veredas do Médio Rio São Francisco", de acordo com o Centro de Recursos Ambientais da Bahia. Estudos ecológicos mostraram que a espécie é endêmica desses campos de dunas e a única representante de mamíferos de pequeno porte da área (RocHA, 1992).

Posteriormente a espécie passou a ser denominada Trinomys yonenagae (RocHA, 1995) quando a monofilia do táxon Proechimys foi revista e Trinomys foi elevado ao status de gênero (LARA et al, 1996; LARA \& PATTON, 2000; GALEWISK et al, 2005). 
Figura 3. a) Exemplar de $T$. yonenagae macho $(\mathrm{m}=130 \mathrm{~g})$; b) Pais com filhotes de $T$. yonenagae
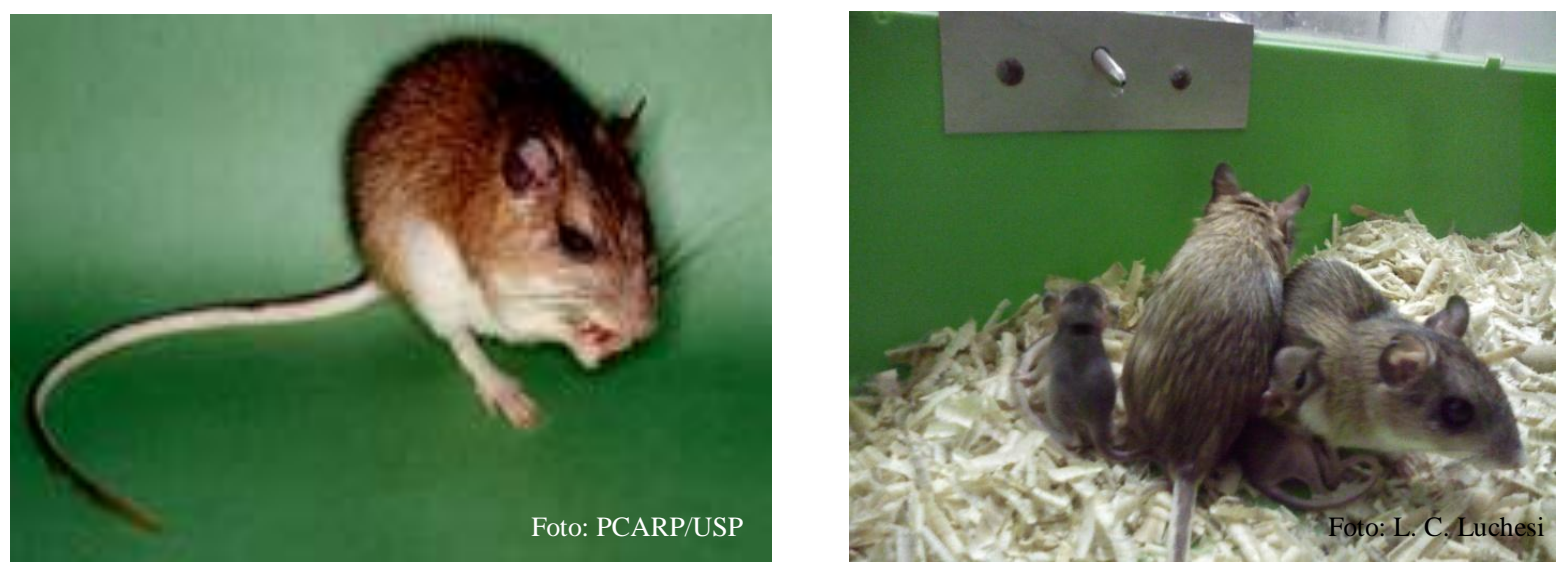

O gênero Proechimys predomina na Amazônia e os Trinomys são restritos ao leste do Brasil (GALEWSKI et al, 2005). Considera-se que Trinomys possui três clados distintos (LARA \& PATTON 2000) que estão em concordância com a distribuição vegetal, sendo um deles distribuído ao longo das matas da costa sudeste, um encontrado nas florestas semi-decíduas internas e o terceiro relacionado à vegetação xérica, ao qual pertence T. yonenagae (figura 4).

Figura 4 Filogenia proposta por Lara \& Patton (2000) com os três clados para o gênero Trinomys. Trinomys yonenagae está destacado no clado 2 que tem espécies ligadas a ambientes com vegetação xérica

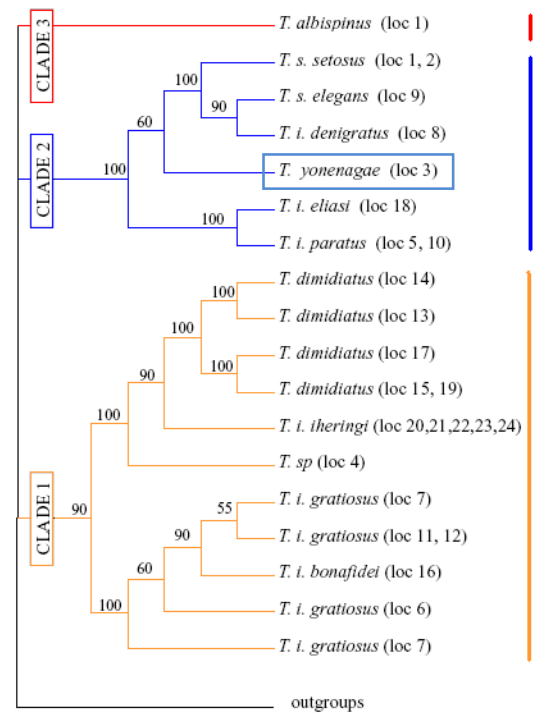


Hipóteses sobre a história evolutiva da Caatinga (VIVO, 1997) indicam que a espécie T. yonenagae, apesar de viver no semi-árido, provavelmente tem um ancestral de ambiente florestado úmido, o que é refletido em aspectos de sua fisiologia, como o balanço hídrico, que em muitos aspectos é semelhante às espécies de mata, diferente do que seria esperado para espécies de ambientes secos (OLIVEIRA et al 1995; MENDES, 1998; SCHMIDT-NIELSEN, 1964).

\subsubsection{O ambiente da Caatinga: o paleodeserto à margem oeste do São Francisco}

A Caatinga, um bioma brasileiro, localizada na região nordeste do Brasil, em uma área de aproximadamente 700 mil $\mathrm{Km}^{2}$ sendo uma das três regiões semi-áridas da América do Sul. É caracterizada por um regime escasso e irregular de chuvas, um alto grau de radiação solar, a mais alta variação de temperatura e a mais baixa umidade relativa do ar no Brasil (AB'SABER, 1970; REIS, 1976). As marcações ambientais podem ser observadas por dois períodos distintos: um de chuvas que acontece no verão entre dezembro e julho, podendo variar de um a seis meses dependendo da região e chamado localmente de inverno - e o de seca, que se inicia em julho e pode durar de sete a onze meses por ano, chamado localmente de verão (RochA, 1992, ver site $\mathrm{IBGE}^{2}$ ). A temperatura média anual na região está entre os $25^{\circ} \mathrm{C}$ e $27^{\circ} \mathrm{C}$ (NEVES, 1999). O dia apresenta-se com aproximadamente $12 \mathrm{~h}$ de claro e $12 \mathrm{~h}$ de escuro, com variação ao redor de uma hora de $11 \mathrm{~h} 29 \mathrm{~min}$ a $12 \mathrm{~h} 46 \mathrm{~min}$ de fase de claro, entre o dia mais curto e mais longo do ano (comunicação pessoal Freitas, J. N.S. a partir de dados sobre a duração do primeiro dia de cada mês durante um ano).

Na estação de chuvas ocorre o processo de alimentação das sub-bacias hidrográficas da região, o período conhecido como "a chegada do rio" se inicia em dezembro. A partir de junho ou julho os rios chegam ao término do período de correnteza, indicando que após a

\footnotetext{
${ }^{2}$ Fonte: IBGE. Disponível em: <ftp://geoftp.ibge.gov.br/mapas/tematicos/mapas_murais/clima.pdf>. Acesso em: 04 mar. 2010. Dados apresentados são referentes a cidade de Barra localizado a cerca de 50km, o ponto metereológico mais próximo do campo de dunas onde são encontrados os espécimes de T. yonenagae.
} 
cessação das chuvas ainda há uma alimentação residual das águas da superfície. Após este período os rios não correm mais pela Caatinga alimentando os lençóis freáticos (AB'SABER, 1974

As dunas de areia onde são encontrados os Trinomys yonenagae podem chegar a 100m em relação ao nível do rio (RODRIGUES, 1991), sendo que as diferenças entre os cumes e vales atingem valores entre 10 e 30m de altura (RocHA, 1992). O padrão climático é o da Caatinga, sendo os meses mais secos do ano de abril a outubro (RoCHA, 1992). Segundo relatos de moradores de Xique-xique, cidade localizada à margem direita do rio, o mês de agosto é o mais seco (comunicação pessoal).

A vegetação é esparsa e rasteira, formada na sua maior parte por arbustos e árvores de pequeno porte $(1,5 \mathrm{~m}$ a $2,0 \mathrm{~m})$, podendo-se observar frequentemente a presença de bromeliaceas e cactaceas próximas as tocas de Trinomys yonenagae (figura 5) (ver RocHA, 1992).

Figura $5 \mathrm{Em}$ destaque a entrada da toca de $T$. yonenagae, feita em solo arenoso e com vegetação próxima em que há predomínio de cactáceas e bromeliáceas

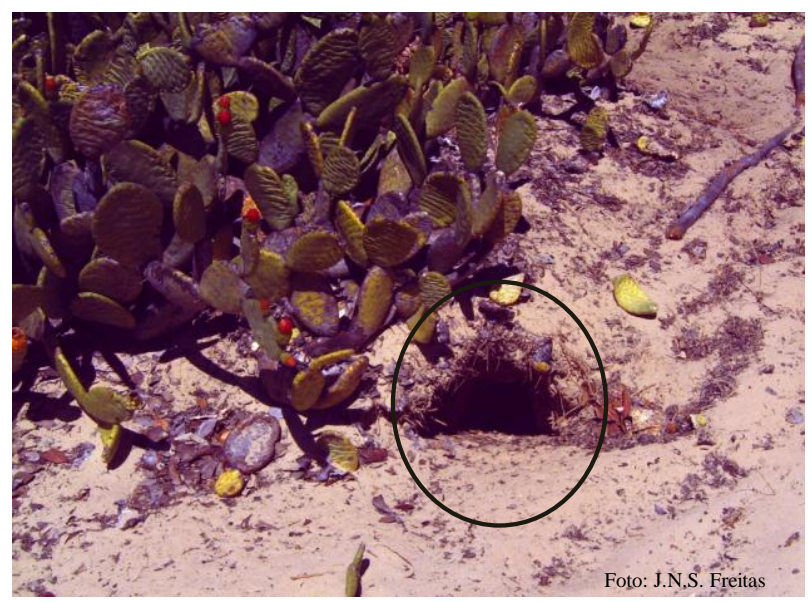




\subsubsection{Trinomys yonenagae em estudos de contexto evolutivo}

Estudos do balanço de ingestão, alimentar e hídrico (SPINELLI OLIVEIRA et al, 1995; MENDES, 1998), e de parâmetros respiratórios e metabólicos (BARROS et al, 1998), indicam que T. yonenagae não se diferencia marcadamente de outras espécies de Trinomys que habitam florestas úmidas. Com relação à capacidade de concentrar urina $T$. yonenagae não apresenta convergência com outros roedores de deserto (SPINELLI OLIVEIRA et al, 1995; Mendes, 1998, SchmidT-NiElsen, 1964). Tanto T. iheringi (da Mata Atlântica) como o T. yonenagae apresenta, por exemplo, taxa de metabolismo basal mais baixa do que ratos de linhagem Wistar (BARROS et al, 1998), o que pode ser considerado uma exaptação importante para a sobrevivência de T. yonenagae na Caatinga.

Com relação à morfologia, no entanto, há convergência de T. yonenagae com roedores de deserto: o tamanho do corpo e a massa corporal são reduzidos, a bula timpânica é inflada, a pelagem é críptica (relativamente mais clara), as patas posteriores são compridas, e a cauda alongada apresenta um pincel de pêlos na extremidade. Essa última característica é responsável pelo seu nome popular, rabo-de-facho, e é importante na estabilização da locomoção bípede no substrato arenoso (RoCHA, 1992; 1995 Rocha et al, 2007).

Dados de campo descrevem o rabo-de-facho como fossorial (senso HILDEBRAND, 1985): esse roedor é o único do gênero que constrói e mantém galerias relativamente profundas e extensas onde passa o dia, e durante a noite forrageia no ambiente aberto das dunas (RochA, 1992). Estudos no cativeiro mostram significativas diferenças na freqüência de cavar, independentemente do sexo, idade e massa corporal dos indivíduos, assim como capacidade de enterrar sementes (food hoarding) e depois recuperá-las (MARCONATO, 2003).

Do ponto de vista comportamental $T$. yonenagae também difere de outras espécies silvícolas do mesmo gênero e dos Proechimys (FreItas, 2003, 2008; MANAF, 2000, 2005; 
MANAF \& SPINELli OliveIRA, 2000; MANAF et al, 2003a, 2003b), cujas espécies são consideradas terrestres, solitárias e territoriais (KLEIMAN, 1974; BERGALLO, 1995).

Ainda com relação à socialidade os rabos-de-facho apresentam um padrão agregado de distribuição de adultos nas dunas (RochA, 1992; SANTOS, 2004). Estudos em cativeiro confirmam a existência de uma organização comunal caracterizada por um grande repertório de comportamentos afiliativos, que inclui cuidado parental e aloparental, e alta tolerância intra-específica com baixa agressividade (MANAF, 2000, 2005; MANAF et al, 2003; MANAF \& SPINELli OliveIRA, 2000; FreitAs et al, 2003). Os dados também indicam um papel social diferenciado das fêmeas, tanto em estudos de campo (SANTOS, 2004; FrEITAS et al, 2008) como em cativeiro (MANAF, 2000; MANAF \& SPINELLI OLIVEIRA, 2009).

Em Trinomys há a presença de uma complexa glândula anal de cheiro (GC) (MANAF \& SPINELli OLIVEIRA, 2006; MANAF et al, 2003b). Esta glândula parece ser uma plesiomorfia de ratos-de-espinho eumisopinos já que várias espécies do clado (Trinomys albispinus, $T$. iheringi, Proechimys cayennensis, Thrichomys apereoides e Clyomys bishop) apresentam uma GC com características morfológicas semelhantes às do rabo-de-facho.

T. yonenagae utiliza a comunicação olfativa pela GC durante interações diádicas com um co-específico desconhecido, independentemente do sexo, mas não durante a exploração de ambiente desconhecido. Esse sinal é parte de uma seqüência de comportamentos afiliativos envolvidos com o reconhecimento de indivíduos ou classes de indivíduos, e com a redução da agressividade (MANAF \& SPINELli OLIVEIRA, 2006; MANAF et al, 2003b).

Diante disso, atualmente T. yonenagae é uma das espécies mais conhecidas entre os equimídeos principalmente por ser adequada a estudos da interação entre ambiente e filogenia, possibilitando comparações evolutivas com outras espécies próximas de habitat distinto (BARRos et al, 1998; FREITAS et al, 2003, 2008, 2010; FONSECA, 1998; MANAF, 2000, 2005; MANAF \& Spinelli Oliveira, 2000, 2006, 2009; MANAF et al, 2003a, 2003b; 
MARComini, 2004; MARComini \& Spinelli OliveiRA, 2003; MARConAto, 2003, Mendes, 1998; MoneiA, 2004; Ribeiro, 2004; Rocha, 1992, 1995; SPINELli OliveIRA, 2003; SANTOS, 1997, 2004).

Este conjunto de dados a respeito de $T$. yonenagae permite a elaboração de hipóteses relacionadas a aspectos de importância para a sobrevivência da espécie e que ainda não foram objetos de estudos. A irregularidade climática é considerada por autores como Mares e colaboradores (1981) como um fator excludente de seleção direcional para certas características, como a habilidade de concentrar urina, principalmente para animais de vida curta. No entanto, dados recolhidos em cativeiro (SPINELli DE OliveIRA e MANAF, em preparação) indicam que $T$. yonenagae vive mais do que outros roedores de mesmo tamanho, em um ambiente com estabilidade do ciclo claro-escuro ao longo do ano. A hipótese do presente trabalho é que a espécie não mostraria sazonalidade em seus padrões rítmicos de reprodução, ou seja, que não haveria variações significativas nas taxas de nascimento ao longo do ano.

\subsection{Os ritmos biológicos}

2.1.1 Ritmicidade biológica: evolução, tipos, osciladores, definições e propriedades

A presença de ciclos é reconhecida desde grupos basais como o das cianobactérias (KONDO, 2000) e fungos (IwASAKI, 2000), até grupos de organismos estruturalmente mais complexos, como de plantas e animais. A origem desta ritmicidade tem sido analisada a partir do nível molecular, e hoje se sabe que não há uma similaridade entre os genes responsáveis por ela nas cianobactérias, fungos e animais. Isso é uma indicação de que os mecanismos de ritmicidade apareceram de forma independente pelo menos duas vezes nas diferentes formas de vida (YounG, 2000). 
Os eventos fisiológicos, bioquímicos e comportamentais de origem endógena, que são recorrentes em intervalos definidos de tempo, são chamados de ritmos biológicos. Esses ritmos expressam-se como: a) ritmos circadianos, caracterizados por período de $24 \pm 4 \mathrm{~h}$ $($ circa $=$ cerca de; dies $=$ dia $)$, por exemplo, o ritmo de atividade/repouso de duas espécies de roedores silvestres equimídeos (MARCOMINI, 2003); b) ritmos ultradianos, que apresentam período menor de 20h, por exemplo, o padrão de atividade eletro-encefálico em mamíferos; c)

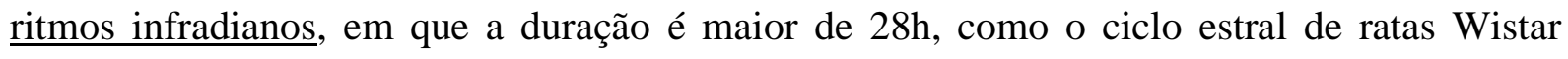
(Rattus norvegicus) que é de quatro a cinco dias (para definições ver MoORE-EDE et al. 1982).

Dentre os osciladores de ritmos circadianos nos mamíferos encontram-se os Núcleos Supra-Quiasmáticos do Hipotálamo (NSQ) (figura 6), e o putativo “Oscilador arrastável pelo alimento" ou "FEO" (Food Entrainable Oscillator) (ESCOBAR et al, 1998; DíAZ-MuÑOz et al, 2000; ver GOLOMBEK et al, 2003; DAVIDSON, 2006).

Figura 6 Localização do núcleo Supraquiasmático no SNC de Ratus novergicus em destaque
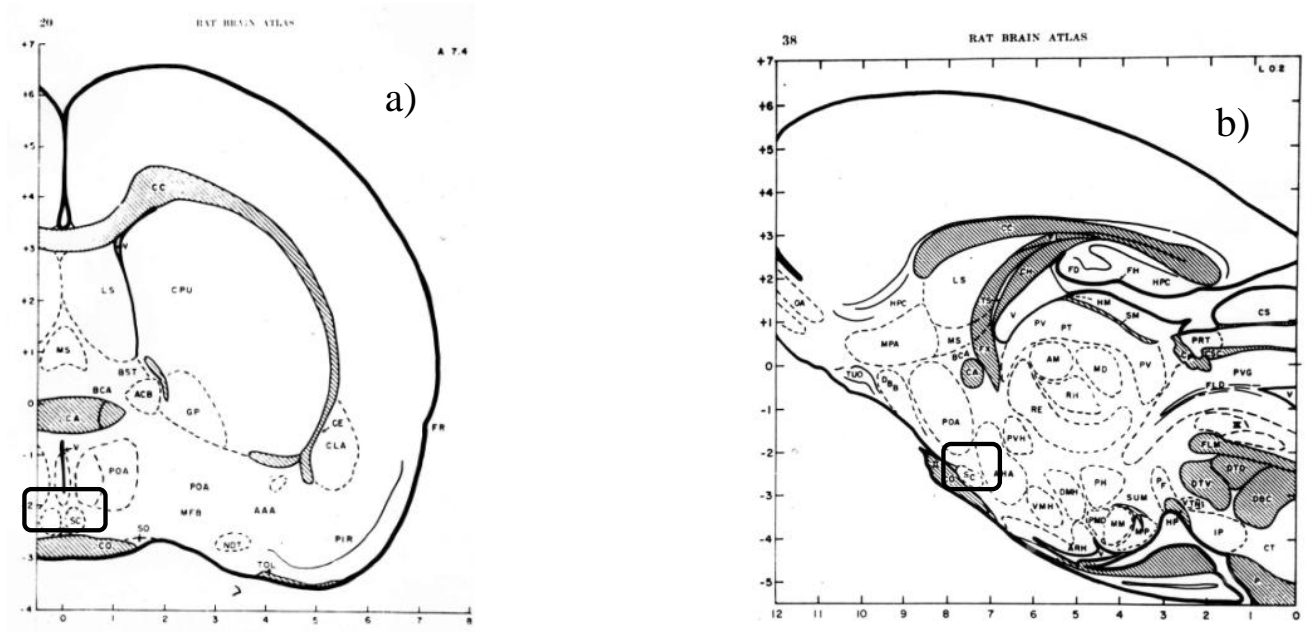

a) Corte frontal; b) corte sagital. Encéfalo de rato destacando o NSQ em vermelho. Figuras retiradas e destacadas de Groot, J. De. The rat forebrain in Stereotaxic coordinates, 1959.

O funcionamento coordenado de células, tecidos ou órgãos - regido por sistemas de organização temporal, presentes em todos os seres vivos - apresenta ritmicidades que se 
originaram de pressões seletivas relacionadas aos ciclos geofísicos, e refletem interações dos ambientes externos e internos das diferentes formas de vida, que possibilitaram ajustes antecipatórios às oscilações ambientais periódicas (PERRY \& SPINELLI OLIVEIRA, 2010). Através dessas interações com o meio externo ocorre o ajuste dos ritmos endógenos aos fenômenos cíclicos ambientais, um fenômeno chamado de arrastamento. Quando oscilações externas são eliminadas, como por exemplo, em condições experimentais de iluminação constante, não se observa o fenômeno de arrastamento e os ritmos biológicos observados dessa forma são denominados de ritmos em livre-curso (ver MACDONALD, 1995; MARQUES et al. 2003) o que permite conhecer a periodicidade de um ritmo independente de suas relações com o meio externo.

Entre os parâmetros estimados em cronobiologia, destaca-se ainda a acrofase, que se refere ao horário de pico de um ciclo circadiano, ajustado por métodos estatísticos a uma curva senoidal. Por exemplo, no ritmo de atividade/repouso, a acrofase é o horário do dia onde ocorre o pico de atividade.

A periodicidade de um ritmo, ou seja, o intervalo de tempo em que ele leva para reiniciar é dada pela frequência do chamado oscilador, ou de um conjunto de osciladores e, no ritmo arrastado, à ação sincronizadora de alterações ambientais cíclicas, denominadas zeitgeber ou sincronizador(es) externo(s) (ASCHOFF, 1951, 1954 apud ROTENBERG et al, 2003). O ciclo claro/escuro é um zeitgeber fótico e a rotina de uma sociedade, nas espécies sociais, é um zeitgeber não-fótico ou social (ver MARQUES et al, 2003).

Membros da comunidade com os quais as espécies sociais dividem o tempo e o espaço influenciam o padrão de atividade nas relações com parceiros sexuais, competidores, predadores, presas e parasitas (revisão MiSTLBERGER \& SKENE, 2004). Além de o contato social fornecer pistas temporais para o desenvolvimento do indivíduo, ele também contribui na ontogenia do repertório comportamental de uma dada espécie (VARLINSKA et al, 1999). 
Dado o alto grau de socialidade nos rabos-de-facho espera-se encontrar influencia de co-específicos nos padrões rítmicos da reprodução nessa espécie em animais alojados juntos.

\subsubsection{A cronobiologia de T. yonenagae}

\subsubsection{Padrão circadiano}

Estudos em T. yonenagae mantidos em cativeiro - em condições de ciclo C/E 12:12, luzes acesas às $18 \mathrm{~h}$ - mostram um claro padrão circadiano de atividade/repouso, apresentando atividade predominante na fase de escuro e acrofase às 00:36h, sem diferenças significativas entre os sexos (MARComini, 2004, MARComini \& Spinelli Oliveira, 2003). Esses dados confirmam o padrão noturno de atividade que é encontrado na maioria dos roedores. No entanto, a comparação com outros equimídeos, um filogeneticamente mais próximo (Trinomys albispinus minor) e outro mais distante (Thrichomys apereoides), indica diferenças na distribuição da atividade, que é intermitente na primeira espécie e bimodal na segunda.

Nos rabos-de-facho foi também possível observar um alto grau de sincronização, tanto da atividade como do repouso, o que pode indicar a presença de um zeitgeber social nessa espécie, não excluindo a possibilidade de haver um zeitgeber fótico (MARCOMINI \& SPINELLI OLIVEIRA, 2003), uma vez que foi observado um comportamento antecipatório de atividade precedendo a fase de escuro (MARCOMINI, 2004). Como T. yonenagae é também uma espécie de hábitos fossoriais seria esperado um relaxamento da pressão seletiva de caráter fótico, o que não parece ter ocorrido.

Embora seja conhecida a relativa hipotermia de T. yonenagae em condições normais (BARROS et al, 1998) considera-se importante caracterizar o padrão rítmico de sua temperatura corporal, já que em mamíferos ele segue uma ritmicidade circadiana. Além disso, pergunta-se qual é a relação temporal entre temperatura corporal e atividade nos rabos-de- 
facho, que vivem em um ambiente cuja temperatura diurna na superfície das dunas alcança valores próximos a $60^{\circ} \mathrm{C}$, e oscila de 30 a $33^{\circ} \mathrm{C}$ nas galerias subterrâneas (RoCHA, 1992).

\subsubsection{Padrão infradiano}

O sucesso reprodutivo apresenta estreita ligação com a capacidade de sobrevivência das espécies. Especialmente para as fêmeas, vários aspectos da reprodução podem ser cíclicos: os níveis hormonais, as citologias vaginal, uterina e mamária, a ovulação e a abertura e fechamento vaginal. Também o nascimento de filhotes pode ser sazonal em várias espécies de mamíferos. Em geral essas ritmicidades são infradianas, com períodos muito variados. Por exemplo, a gestação em roedores histricomorfos pode ter duração média de 53 a 250 dias (WEIR, 1974).

Existem poucas informações sobre a biologia reprodutiva em roedores de vida subterrânea, embora esse aspecto seja de importância fundamental para todos os organismos. A maior parte dos estudos trata da reprodução em espécies da família Bathyergidae, com poucos dados referentes a outros clados. Essa lacuna é especialmente crítica nos equimídeos, daí a importância de estudos com espécies dessa família, como os rabos-de-facho, o que está presentemente proposto nesta dissertação.

Para o levantamento de hipóteses é importante se salientar que o ambiente fossorial dificulta o uso do zeitgeber fótico, tendo importância outras pistas temporais como temperatura, regime de chuvas e dieta para o arrastamento dos ritmos das espécies de vida subterrânea (BENNETT et al 2000). Neste contexto o alto nível de afiliação encontrado no rabo-de-facho apóia a importância do zeitgeber social nessa espécie. No ambiente fossorial há também o desafio da identificação de possíveis parceiros por pistas sensoriais que não sejam a da comunicação visual. Nesse aspecto, o rabo-de-facho apresenta alta capacidade de comunicação olfativa (MANAF et al, 2003b) e sonora, inclusive através do tamborilar (MANAF \& Spinelli OliveIRA, 2000; Neves, 2007). 
Também deve ser considerado que nas espécies sociais o tempo de acasalamento dos roedores de vida subterrânea é mais prolongado, provavelmente em decorrência da segurança encontrada nas tocas. Em geral, nesses casos a iniciativa da corte é da fêmea (JARVIS, 1991; BennetT \& JARVis, 1988b apud BenNetT et al 2000). Como este dois aspectos da biologia dos rabos-de-facho não estão descritos eles também serão objeto de estudo neste trabalho.

Com relação à citologia vaginal estudos-piloto foram conduzidos no campo e em cativeiro (Oliveira SpINELli, et al, 1997; MONEIA 2004) com o objetivo de iniciar a caracterização de parâmetros reprodutivos em fêmeas de rabos-de-facho. Os resultados no campo (OliVEIRA SPINELLI, et al, 1997) mostraram que todas as fêmeas examinadas com a vagina aberta estavam em diestro e não em proestro ou estro, como seria esperado da literatura da literatura de roedores (STOCKARD \& PAPANICOLAU, 1919).

Para vários autores a vagina aberta é indicativa de atividade reprodutiva, ou seja, da presença de estro ou proestro (ver WEIR, 1974). Consequentemente, em estudos de ecologia com acompanhamento de populações de roedores no campo, a avaliação das condições reprodutivas dos indivíduos é normalmente feita a partir de evidências indiretas, tais como, a presença de sinais de lactação, de embriões palpáveis, palpação dos testículos e o critério "grau de abertura da vagina". Considera-se, portanto, que face aos resultados obtidos até o momento é necessário aprofundar o estudo da condição vaginal nos rabos-de-facho em situações experimentais controladas e suas relações com o ambiente e/ou indivíduos.

Os dados obtidos em cativeiro com amostragem aleatória indicam que a atividade cíclica é espontânea; o padrão é do tipo poliéstrico com as quatro fases; sendo o diestro a fase de maior duração; a cópula parece acontecer no proestro; a presença do macho não assegura a gravidez. Finalmente, é necessário ter cautela na utilização da abertura da membrana vaginal como indicativo de atividade reprodutiva até que sejam realizados estudos complementares 
com amostras feitas em intervalos regulares e ao longo do ano (SPINELLI OLIVEIRA et al, 2007).

\section{OBJETIVOS GERAIS}

Os objetivos gerais deste trabalho são, portanto, de estudar em cativeiro aspectos da cronobiologia da reprodução de fêmeas de T. yonenagae, de maneira a caracterizar a periodicidade do ciclo estral e identificar possíveis influências de co-específicos; identificar a idade de maturidade sexual; caracterizar o padrão comportamental de fêmeas e machos no acasalamento; aprofundar os conhecimentos no padrão de gestação nesta espécie e caracterizar o ciclo de temperatura corporal, ainda desconhecido.

\section{MATERIAL E MÉtodos}

\subsection{Animais}

São estudados 72 indivíduos adultos e filhotes de T. yonenagae sendo, 49 fêmeas e 22 machos. Destes, 67 são nascidos no Biotério de Roedores Silvestres (LECO) da FFCLRPUSP, de pais que foram coletados no paleodeserto de dunas fixas, Ibiraba, BA $\left(10^{\circ} 48^{\prime} \mathrm{S}\right.$, $42^{\circ} 50^{\prime} \mathrm{W}$ ) (licença IBAMA n. 129/98) e cinco deles coletados nessa mesma localidade.

\subsubsection{Manutenção dos animais}

Os animais são mantidos e estudados em salas isoladas da influência luminosa ambiental, relativamente livres de ruídos externos, no Biotério de Roedores Silvestres, que conta com sistema de renovação de ar (Springer, Carrier modelo Slit, on a cada 6h), temperatura controlada $\left(24,0 \pm 2,0^{\circ} \mathrm{C}\right)$, ciclo claro - escuro invertido (12h E: $\left.12 \mathrm{~h} \mathrm{C}\right)$, luzes acesas às 02:00h, e luminosidade de 130 (Claro) e três Lux (Escuro). A alimentação consiste de ração para roedores (Nuvilab CR-1 para ratos e camundongos, Nuvital Nutrientes Ltda., 
Brasil) e água ad libitum, complementada semanalmente com vitamina oral (Hemolitan Pet, Vetnil Ind. Com. de Produtos Veterinários LTDA, Brasil; também vitamina C - Vitavet C Vetnil Ind. Com. de Produtos Veterinários LTDA, Brasil) e/ou ração para papagaios (Nutripássaros, Ebúrneo \& Monteiro Com. LTDA, Brasil), sementes de girassol e frutas frescas da estação.

O acondicionamento dos animais é feito em caixas de propileno tamanho-padrão $(30 \times 40 \times 16 \mathrm{~cm})$ ou em gaiolas do tipo duna $(38 \times 64 \times 29 \mathrm{~cm}$ Ferplast Pet Products, Itália), no caso dos casais, forradas com dois centímetros de maravalha. A limpeza e pesagens são feitas semanalmente pelo mesmo indivíduo.

\subsubsection{Grupos experimentais}

As fêmeas adultas foram divididas em diferentes grupos experimentais. O detalhamento será apresentado no início de cada capítulo da forma como se segue.

I- Idade da abertura vaginal (AV) $n=9$

II- Ciclo estral e estado vaginal (EV) $n=26$

III- Gestação e acasalamento $n=14$

IV - Temperatura corporal $n=16$

\subsection{Análise estatística}

Todos os procedimentos estatísticos foram efetuados através do programa "SPSS" (versão 12.0) e o nível de significância ( $\alpha$ ) adotado é de 5\% (ver ZAR, 1996).

A análise do padrão do ritmo de temperatura corporal foi feita pelo ajuste dos dados a uma curva co-seno através do software Cossana (BENEDITO-SILVA, 1996). Os horários apresentados referem-se ao horário do Zeitgeber (ciclo claro-escuro do Biotério) assim 0h ZT corresponde ao início da fase de claro (02:00h) e 12h ZT ao início da fase de escuro (14:00h). 


\section{CAPÍTULO I - IDADE DA ABERTURA VAGINAL EM TRINOMYS YONENAGAE}

\subsection{Introdução}

Em mamíferos é possível observar uma membrana vaginal que mantém o orifício fechado até a puberdade e durante o período não reprodutivo. Esta membrana foi primeiramente apontada por Gallois (1812) e mais tarde descrita por Stockard e Papanicolau (1919) em Cavia porcellus, um roedor caviomorfo, sendo denominada por esses autores de vaginal closure membrane.

Em várias espécies de histricomorfos, grupo que inclui os caviomorfos da América do Sul, esta membrana parece se romper imediatamente antes ou durante o primeiro período do estro e pouco antes do parto, em fêmeas grávidas (WEIR, 1974). Nesse sentido, o momento do primeiro episódio de abertura vaginal (AV) também é tido como o início da puberdade em várias espécies de mamíferos, incluindo os histricomorfos. Weir (1973b) relatou a presença da membrana vaginal no roedor equimídeo Proechimys guairae que fecha completamente o orifício vaginal e só se apresenta perfurada no período de estro ou no parto.

Entre os pesquisadores de campo, como em Bergallo (1995), a membrana representa um parâmetro importante para a classificação do estado reprodutivo das espécies.

Ojeda e colaboradores (1984) estudando a puberdade em ratas da linhagem Wistar, um murídeo, roedor filogeneticamente distante dos caviomorfos, descreveu a presença de membrana vaginal que mantém o orifício vaginal fechado até o momento em que atingem a puberdade (30-35 dias de vida) marcada também pelo primeiro episódio de estro. Nesses roedores após o evento de $\mathrm{AV}$ a vagina permanece constantemente aberta.

A constituição desta membrana é muito variável podendo ser desde uma secreção mucosa até a formação de um tecido que fecha todo o orifício vaginal. Kelly e colaboradores (1927, apud Weir, 1974) estudando a constituição da membrana vaginal em Cavia porcellus relataram que esta é uma camada de tecido conjuntivo que fecha completamente o orifício 
vaginal. Em Octodon degus esta membrana é frágil e se rompe facilmente quando sofre pressão (WEIR, 1974) podendo se tornar parcialmente perfurada durante o ciclo e fechando novamente até que se abra em um episódio de estro.

O período em que o orifício vaginal permanece aberto varia entre as diferentes espécies, podendo permanecer aberto apenas por algumas horas ou por até 13 dias consecutivos, como em Lagostomus maximus (WEIR, 1974); e tem relação direta com a duração do ciclo estral. Essa membrana apesar de conhecida há mais de um século não é muito estudada e sua relação com o ciclo reprodutivo em muitas espécies ainda necessita de maiores esclarecimentos.

\subsection{Objetivos}

O objetivo desde experimento é identificar a idade em que ocorre o $1^{\circ}$ episódio de abertura vaginal no roedor Caviomorpha Trinomys yonenagae, o que pode ser usado como um indicador do início da maturidade sexual.

\subsection{Material e Métodos}

\subsubsection{Animais}

Nove fêmeas de Trinomys yonenagae que nasceram no Biotério de Roedores Silvestres (LECO) da FFCLRP-USP. A descrição dos animais encontra-se no Anexo 1.

\subsubsection{Manutenção dos animais}

Todos os filhotes de uma mesma ninhada foram alojados juntamente com os pais em gaiolas do tipo duna até os três meses de vida quando foram separados. As fêmeas foram então alojadas em caixas individuais de propileno tamanho-padrão em sala livre da influência dos machos. 


\subsubsection{Procedimento e equipamentos do acompanhamento da maturidade sexual}

As observações do estado vaginal ocorreram a partir do $20^{\circ}$ dia de vida, quando as fêmeas ainda estavam alojadas com os pais, até o momento do $1^{\circ}$ evento de abertura vaginal (AV). As observações ocorreram em intervalos de dois a sete dias e seguiram procedimentos estabelecidos anteriormente pelo laboratório (OLIVEIRA SPINELLI, 1997; SPINELLI et al, 2007). A fêmea era colocada em um tubo de plástico e imobilizada pela mão da pesquisadora que segurava a cauda, por entre os dedos indicador e médio, o que expõe a região genital por uma das extremidades do tubo. Em seguida era aplicada uma pressão sobre a papila genital verificando se ocorria ou não a $\mathrm{AV}$. O estado vaginal era classificado de acordo com os critérios da tabela 1.1, e em seguida anotado em uma planilha. Em parte das fêmeas $(n=3)$ foi feito o esfregaço vaginal no momento da verificação da AV (selada ou aberta propriamente dita).

Tabela 1.1: Classificação dos estados vaginais das fêmeas de Trinomys yonenagae em cativeiro

\begin{tabular}{lll}
\hline Estado vaginal & Código & Descrição \\
\hline Aberta & A & $\begin{array}{l}\text { Orifício vaginal visível em qualquer grau de abertura } \\
\text { (desde pontual a total) }\end{array}$ \\
& & Orifício vaginal coberto por uma secreção mucosa que se \\
Selada & S & Orompe ao se aplicar pressão \\
& & Orifício vaginal obliterado por membrana e que permanece \\
Fechada & fechado mesmo sob pressão
\end{tabular}

\subsubsection{Análise estatística}

A média da idade em que ocorreu o primeiro episódio de abertura vaginal foi obtida a partir dos dados individuais de cada fêmea e um gráfico de dispersão é apresentado para representá-las segundo Zar (1996). 


\subsection{Resultados}

O reconhecimento do sexo em $T$. yonenagae recém nascidos é feito pela distância entre a papila genital, muito pronunciada nessa espécie, e o orifício anal. Em fêmeas esta distância é significantemente menor do que em machos; a vagina encontra-se totalmente fechada e é imperceptível ao olho nu (figura 1.1). A aparência da região vaginal é de continuidade com a da papila, ou seja, é glabra e rósea.

Figura 1.1. Fêmea de Trinomys yonenagae com o orifício vaginal fechado (VF)

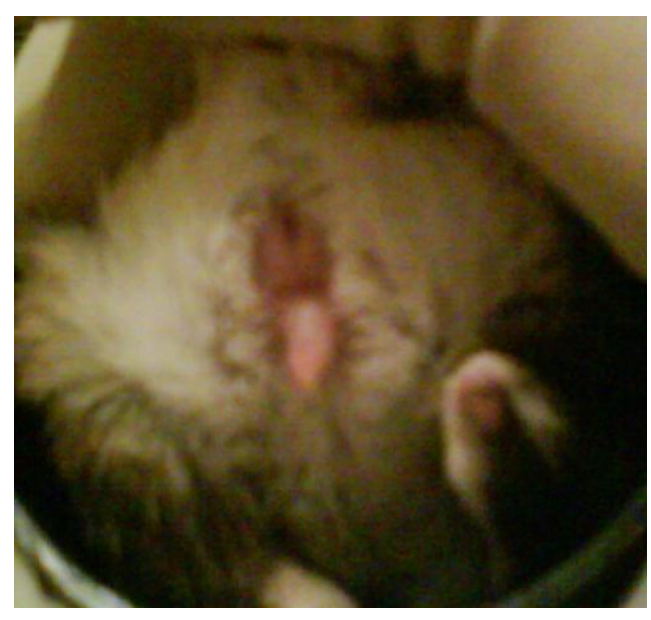

Este estado permanece até que é possível observar uma depressão longitudinal de cinco mm, no máximo, que com o passar do tempo torna-se mais visível, até o momento da sua ruptura pelo toque, o que caracteriza o estado de AV. Em $89 \%$ das fêmeas houve coincidência da ruptura com a produção de muco, ou seja, essas fêmeas apresentaram o estado de vagina selada. Somente em uma única fêmea a AV pode ser caracterizada como "aberta" no momento da verificação. A partir daí as fêmeas não mostram um padrão regular do estado vaginal, que pode variar entre aberto, fechado e selado, como será tratado no capítulo 2.

Nas fêmeas em que o esfregaço pode ser coletado em seguida à verificação da abertura a fase do ciclo era de diestro. 
Na figura 1.2 observa-se que a maioria das fêmeas dessa espécie apresenta AV por volta dos três meses de vida $(92,0 \pm 17,7$ dias), ou seja, seis fêmeas tiveram a primeira ocorrência de AV entre os 90 e 100 dias e as outras três fora desse período. Uma delas foi a fêmea a abrir mais cedo e que estava com 61 dias de vida, ainda alojada com os pais. A mais velha estava com 121 dias de vida, já alojada em gaiola individual e em sala livre da influência de machos. A terceira fêmea a apresentar AV fora do período dos três meses de vida estava com 75 dias de vida ainda alojada na gaiola com os pais (Tabela 2 Anexo 1).

Figura 1.2. Idade em que ocorreu a $1^{\mathrm{a}}$ abertura vaginal em fêmeas de Trinomys yonenagae mantidas em cativeiro $(n=9)$. $O$ traço horizontal indica o valor da média.

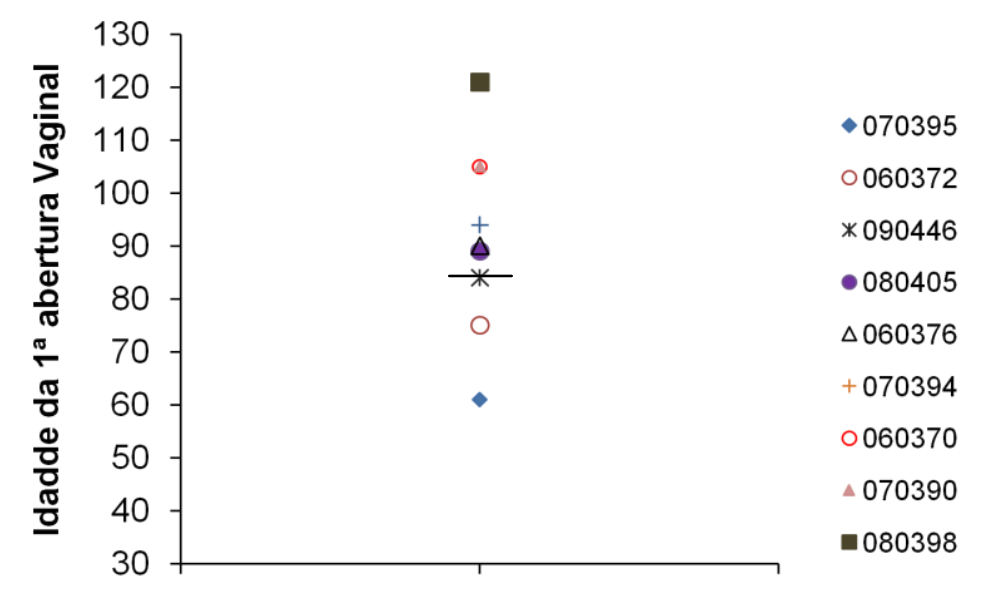

\subsection{Discussão}

Trinomys yonenagae apresenta uma membrana vaginal que parece ser uma continuação do tecido epitelial da papila genital, fechando completamente o orifício vaginal em recém nascidos e jovens. Os dados mostram que a $1^{\text {a }}$ ocorrência de abertura vaginal (selada ou aberta propriamente dita) mostra-se bem variável, aparecendo entre 61-120 dias de vida. O valor da média, de três meses, é semelhante ao encontrado para Proechimys guairae, 
outro membro dos caviomorfos equimídeos, no qual a abertura vaginal ocorre aos 95,2 $\pm 7,5$ dias (WEIR, 1973b).

Em Octodon degus, membro da superfamília Octodontoidea, a qual também os gêneros Proechimys e Trinomys pertencem, a maturação sexual pode ocorrer entre 63 a 180 dias de vida tomando-se a primeira concepção como referencial (WEIR, 1974).

Em Cavia aperea, um roedor caviomorfo cavídeo, relativamente distante dos equimídeos, a ocorrência da primeira abertura vaginal é ao redor de 58,6 dias segundo Rood e Weir (1970). Entretanto, Trillmich (2000) observou que o início da vida reprodutiva pode ocorrer entre 30-40 dias de vida.

A comparação entre os caviomorfos sugere que há bastante variação entre as espécies e que a filogenia pode ser um fator determinante do momento da $\mathrm{AV}$, já que gêneros próximos parecem ter padrão semelhante.

Em roedores miomorfos como Rattus norvegicus, linhagem Wistar, a AV ocorre por volta dos 30 dias de vida (OJEDA et al, 1984 e 1985) e está dissociada da gestação. A primeira gestação nesses ratos pode ocorrer não concomitante ao primeiro episódio de vagina aberta, já que a idade adulta é atingida aos 90 dias de vida, dois meses após a AV.

Em Trinomys yonenagae, o primeiro evento de vagina aberta também parece estar dissociado da gestação, que ocorre ao redor dos 110 dias de vida (ver capítulo 3), um mês após a idade em que acontece a AV. Embora a amostra seja pequena a coleta do esfregaço vaginal, revelando a fase de diestro, não aponta uma associação entre a primeira AV e o estro. O conjunto dos dados indica que nos rabos-de-facho há uma fase de puberdade que se inicia com a AV, mas onde o estro/gravidez estão ausentes.

O momento de AV é considerado o início da vida reprodutiva em várias espécies de mamíferos (WEIR, 1974). Os resultados obtidos no presente trabalho são indício de que a maturidade sexual ocorre de forma tardia na superfamília a qual Trinomys pertence, seguindo 
o padrão dos Caviomorpha, se comparada a outros roedores da subordem mais estudada, a Sciurognatha, a qual pertence o murídeo Wistar e grande parte dos roedores estudados. 


\subsection{Bibliografia}

Bergallo, H. G. Comparative life-history characteristics of two species of rats, Proechimys iheringi and Oryzomys intermedius, in an Atlantic Forest of Brazil. Mammalia, v. 59, n. 1, pp. 51-64, 1995.

Kelly, G. L.; PAPANicOlaOU, G. N. The mechanism of the periodical opening and closing of the vaginal orifice of the guinea-pig. American Journal of Anatomy, v. 40, pp. 387-411.

Oliveira SPinelli, E.; SAntos, J. W. A.; MAnAF, P.; Rocha, P. L. B. Utilização da técnica de esfregaço vaginal para o estudo de uma população de Proechimys yonenagae (Rodentia:

Echimyidae). In: XII Reunião Anual da Federação de Sociedades de Biologia Experimental - FeSBE, Caxambu: 1997, p. 276.

RoOD, J. P.; WeIR, B. J. Reproduction in female wild guinea pigs. Journal of Reproduction and Fertility, v. 23, pp. 393-409, 1970

SPINELli OliVeIRA, E.; PeRry, S. F.; MONEA, N. M.; BARBOSA, F. L.; LuCHESI, L. C. Does vaginal opening coincide with reproductive activity in a dune-living spiny rat? In:

Comparative Biochemistry and Physiology Part A: Molecular \& Integrative Physiology, n. 148, Suplement 1, S22, 2007.

STOCKARD, C. R.; PAPANICOLAU, G. N. The vaginal closure membrane, copulation, and the vaginal plug in the guinea-pig, with further considerations of the oestrous rhythm. Biological Bulletin, v. 37, pp. 222-245, 1919.

TRILLMICH, F. Effects of low temperature and photoperiod on reproduction in the female wild guinea pig (Cavia aperea). Journal of Mammalogy, v. 81, n. 2, pp. 586-594, 2000.

WEIR, B. J. Reproductive characteristics of hystricomorph rodents. Symposium of Zoological Society of London. n. 34, pp. 265-301, 1974.

Another hystricomorph rodent: keeping casiragua (Proechimys guairae) in captivity. Laboratory Animals, v. 7, pp. 125-134, 1973b.

OJeDA, S. R.; URbanski, H. F.; Ahmed, C. E. The onset of female puberty: Studies in the rat. Recent Progress in Hormone Research, v. 42, pp. 385-442, 1984.

URBANSKI , H. F.; OJEDA, S. R . The Juvenile-Peripubertal Transition Period in the Female Rat: Establishment of a Diurnal Pattern of Pulsatile Luteinizing Hormone Secretion.

Endocrinology, v. 117, pp. 644-649, 1985.

ZAR, J. H., Biostatistical analysis. 3 ed., New Jersey: Prentice-hall. Inc., 1996, 662p. 


\section{CAPÍTUlo II - CiClo ESTRAL E ESTADO VAGINAL EM TRINOMYS YoNENAGAE}

\subsection{Introdução}

Uma vez tratado sobre os aspectos relativo à maturidade sexual e da abertura e fechamento do orifício vaginal passar-se-á ao ciclo estral, propriamente dito.

A alternância hormonal, morfológica e comportamental de fêmeas não antropóides (NA) é denominada de ciclo estral, e o período de receptividade sexual que coincide aproximadamente com a ovulação, é chamado de estro (ver ECKERT, 1998). As fêmeas podem apresentar essa fase reprodutiva de uma vez ao ano (chamado de ciclo estral monoéstrico) a várias vezes (ciclo poliéstrico). Quando a atividade cíclica é contínua as fases são denominadas de diestro, proestro, estro e metaestro (ver item 2.3.3.1) e há grande variação quanto à duração de cada fase e do período do ciclo entre diferentes espécies. Nos mamíferos não-poliéstricos, que não apresentam atividade contínua pode ocorrer ainda a fase de anestro, caracterizada pela involução reversível do aparelho reprodutivo como um todo.

O eixo hipotálamo-hipófise-gonadal, integrado a outras estruturas límbicas, coordena estes ciclos reprodutivos. E sabe-se que duração do ciclo também é variável, estando este sob influência de variações ambientais como ciclo claro/escuro e estações do ano. Em ratos Wistar, um murídeo, o período é de quatro dias e as estações não parecem ter influência direta sobre o período. Em Cavia porcellus, um caviomorfo, assim como Trinomys yonenagae, o período é de 16 dias (Avery, 1925; Asdell, 1964) e de 22 dias em Proechimys guairae (WEIR, 1973b).

Em roedores, é conhecida a participação de osciladores circadianos no controle do ciclo estral e da sazonalidade reprodutiva. Em camundongos (Mus musculus), a exposição à feromônios do macho arrasta o ciclo estral da fêmea. Ocorre também a sincronização do ciclo estral de fêmeas de ratos e hamsters (Mesocricetus spp) quando alojadas juntas. 
As variações deste ciclo, ainda podem ser interpretadas como resultado da sazonalidade na oferta e qualidade do alimento, do fotoperíodo e temperatura ao longo do ano (BRONSON 1989). Segundo o mesmo autor, uma mesma espécie de mamífero pode reproduzir diferentemente dependendo da latitude, sendo poliéstrica em latitudes baixas e apresentando uma época definida para a reprodução em latitudes maiores. Populações do roedor africano Mastomys natalensis apresentam diferenças sexuais nas respostas às condições ambientais, sendo que os machos ficam mais tempo ativos durante o inverno do que as fêmeas (BRONNER et al, 1988). Tobin e colegas (1994) observaram que o rato Rattus rattus, no Havaí, apresentou reprodução ao longo de todo ano, com pico de capacidade reprodutiva durante o mês de abril. Bergallo (1995), estudando duas espécies de roedores da Mata Atlântica filogeneticamente distantes, verificou que o rato-de-espinho (Proechimys iheringi) tem pico reprodutivo durante o verão, enquanto o cricetídeo (Oryzomys intermedius) não apresenta esta tendência, reproduzindo ao longo de todo o ano.

O ciclo estral pode ainda ser dividido em dois tipos: espontâneo e induzido. Se a ovulação ocorre independente da presença ou de qualquer estímulo de um macho, o ciclo é chamado espontâneo, mas em algumas espécies a ativação do corpo lúteo depende de sinais provenientes do macho (ver ECKERT, 1998). O ciclo é dito induzido quando é necessário algum estímulo provindo do macho para que a ovulação aconteça, seja, odorífero, visual (como a presença dele), ou mecânico (como a cópula), como o reportado por Touma e colaboradores (2001) em Cavia aperea (preá).

O estado vaginal, como discutido no capítulo 1 também pode ser usado como um critério da atividade reprodutiva em trabalhos de campo, considerando-se a vagina perfurada como indicativo de estro (WEIR, 1974; ver, entre outros, BERGALLO 1995) em algumas espécies. Considera-se após a cópula a vagina é fechada por uma secreção que depois dá lugar à nova membrana que a manterá fechada até o próximo período de estro ou pré-parto. 
Uma das metodologias mais usadas na caracterização do ciclo estral é a técnica de esfregaço vaginal (colpocitologia ou citologia esfoliativa) por ser não-invasiva, de alto grau de confiabilidade e de fácil execução/custo. Entre os roedores histricognatas, incluindo os Caviomorpha, esta técnica foi utilizada, por exemplo, por Barbosa e colaboradores (2007) para caracterização das células encontradas em capivaras (Hydrochoerus hydrochaeris) e por Touma e colaboradores (2001) em preás e cuis.

Há uma variação do padrão reprodutivo em roedores histricomorfa/histricognatas (WEIR, 1974), mas estudos prévios realizados neste laboratório (LECO) indicam que a ovulação em Trinomys yonenagae é espontânea (SPINELLI OLIVEIRA et al, 2007; LUCHESI et al 2008).

\subsection{Objetivos}

Os objetivos deste experimento são:

Determinar o período do ciclo estral e a duração das fases das fêmeas de $T$. yonenagae em três situações experimentais diferentes, fêmeas pareadas com fêmeas; pareadas com machos e solitárias. Espera-se que a freqüência de proestro e estro seja maior nas fêmeas do grupo pareado com machos (ver NELSON, 1995);

Verificar a relação da presença ou não de membrana vaginal nas diferentes fases do ciclo nos mesmos grupos experimentais. Tem-se como hipótese que a condição de vagina aberta seja acompanhada da fase de proestro ou estro e que em relação às fêmeas pareadas com macho, as fêmeas pareadas com fêmeas apresentem maior freqüência do estado de vagina fechada $(\mathrm{VF})$. 


\subsection{Material e métodos}

\subsubsection{Animais:}

Foram estudados o ciclo estral e o estado vaginal de 26 fêmeas divididas em três grupos (descrição dos indivíduos Anexo 2):

A) Seis duplas de fêmeas $(\mathrm{n}=12)$, sendo metade formada por irmãs de ninhada (duplas 13) e a outra por não-irmãs (duplas 4-6);

B) Oito fêmeas alojadas em gaiolas individuais $(\mathrm{n}=8)$;

C) Seis fêmeas alojadas em casal com seis machos $(n=6)$.

\subsubsection{Manutenção}

Os animais dos grupos A e B foram mantidos em gaiolas individuais de propileno e os casais do grupo $\mathrm{C}$ em gaiolas do tipo duna, em salas de alojamento/experimentação em condições descritas na parte introdutória.

\subsubsection{Procedimento e equipamentos dos estudos do ciclo estral}

$\mathrm{O}$ esfregaço vaginal (EV) foi feito de acordo com protocolos de rotina em nosso laboratório (OliveIRA SPINELl, 1997; SPINELli, 2007). A observação do grau de abertura vaginal (AV) foi feita imediatamente antes do EV por observação direta do animal. A classificação do grau de AV e a sua relação com o EV, ao longo do tempo, foram realizadas de acordo com o critério da tabela 1.1 (capítulo 1).

Inicialmente foram feitas coletas em dias intercalados, sempre no mesmo horário, na última hora de claro (entre 12h30min e 14h), em fêmeas mantidas previamente por um mês na situação experimental, já que dados de caviomorfos indicavam que o ciclo, e suas fases, possivelmente seria longo. Este protocolo foi usado por quatro meses e neste período de tempo a frequência das fases de proestro e estro foi pequena, indicando que em rabos-de- 
facho provavelmente a duração das fases de atividade sejam curtas. Com o objetivo de aumentar a possibilidade de detecção de proestro e estro mudou-se o protocolo de coleta do EV no quinto mês. A partir desse ponto, a coleta foi diária (entre 11h e 12h). Ainda buscandose aumentar o número de observações de proestro e estro no segundo semestre, o grupo de fêmeas alojadas em gaiolas individuais (grupo B) e aquelas alojadas em casal (grupo C) tiveram seu EV e AV observados em dias e horários aleatórios no período de escuro.

\subsubsection{A coleta do esfregaço vaginal}

A coleta do EV foi feita individualmente por lavagem da vagina usando-se uma gota de solução de cloreto de sódio 0,9\% (Darrow Lab. S. A., RJ, Brasil) aplicada através de ponteiras plásticas descartáveis para pipeta, volume aproximado de $50 \mu \mathrm{l}$, com sucção da lavagem e sua imediata colocação em lâmina para esfregaço e análise ao microscópio óptico. As fases do ciclo estral foram identificadas de acordo com critérios histológicos. Quatro fases são identificadas: fase de proestro - presença de células epiteliais pavimentosas (podendo

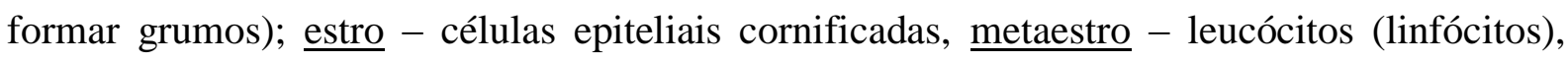
células epiteliais e cornificadas, e diestro - leucócitos (linfócitos), muco e algumas células epiteliais. (LONG Evans, 1922; Dellias, 1973; OliveIRA SPINELli et al, 1997). Quando necessário foi feita a fixação e coloração do esfregaço com solução alcoólica Azul de Toluidina (5\%). Os esfregaços foram secos por 15 minutos a $37^{\circ} \mathrm{C}$, corados por $5 \mathrm{~min}$, retornando por mais 15 minutos à estufa e acondicionados para posterior análise e registro fotográfico. 


\subsubsection{Análise estatística}

Os semestres apresentados serão aqueles de acordo com o início do experimento, sendo o $1^{\mathrm{o}}$ semestre equivalente aos meses de março a agosto de 2008 e o $2^{\circ}$ de setembro de 2008 a fevereiro de 2009.

Todos os procedimentos estatísticos foram efetuados através do programa "SPSS" (versão 12.0) e o nível de significância $(\alpha)$ adotado foi de $5 \%$.

O teste do $\chi^{2}$ foi usado para comparar a frequência dos diferentes estados de AV no grupo de fêmeas mantidas em gaiola individual com o grupo das fêmeas mantidas em duplas do mesmo sexo em sala isolada da presença de machos. O número de fêmeas para este teste foi igualado para oito em cada condição por sorteio das integrantes do grupo A, que era composto por 12 fêmeas (6 duplas).

\subsection{Resultados}

\subsubsection{Os estados vaginais}

Durante os quatro primeiros meses de coletas em dias alternados, acompanhando os três grupos experimentais, foi possível observar a ocorrência dos três estados vaginais. A tabela 2.1 mostra as ocorrências e a porcentagem relativa de AV nos três grupos experimentais.

É possível observar que independente da condição de alojamento da fêmea o estado vaginal de maior ocorrência é o selado, sendo mais observado no grupo das fêmeas em casal (grupo C com $82 \%$ das ocorrências), seguido pelo grupo das fêmeas isoladas (grupo B com $62 \%$ ) e pelas duplas (grupo A com 52\%). A maior porcentagem de vagina aberta (VA) foi no grupo C (11\%), seguido do grupo B (5\%) e das fêmeas do grupo A (3\%) em sala isolada de macho. Isto indica que o grupo que apresentou menor atividade reprodutiva, de acordo com 
este critério, foi o grupo das fêmeas pareadas com o mesmo sexo e o de maior atividade foi o constituído por casais (Tabela 2.1).

Tabela 2.1. Freqüência de eventos (E) e porcentagem (\%) de abertura vaginal (AV) em Trinomys yonenagae por coletas feitas em dias alternados e diariamente durante cinco meses de observação

\begin{tabular}{cccccccc}
\hline \multirow{2}{*}{ Grupo } & \multicolumn{9}{c}{ Estado AV } & \multirow{2}{*}{ Total } \\
\cline { 2 - 6 } & \multicolumn{2}{c}{ Fechada } & \multicolumn{2}{c}{ Selada } & \multicolumn{2}{c}{ Aberta } & \\
\hline $\begin{array}{c}\text { A dupla } \\
(\mathrm{n}=6)\end{array}$ & 506 & 45 & 582 & $\mathbf{5 2}$ & 28 & 3 & 1116 \\
$\begin{array}{c}\text { B isolada } \\
(\mathrm{n}=12)\end{array}$ & 243 & 33 & 461 & $\mathbf{6 2}$ & 40 & 5 & 744 \\
$\begin{array}{c}\text { C casal } \\
(\mathrm{n}=5)\end{array}$ & 16 & 7 & 193 & $\mathbf{8 2}$ & 26 & 11 & 235 \\
\hline
\end{tabular}

TOTAL 2095

* Fêmeas em casal fora do período de gravidez; Fechada (F); Selada (S); Aberta (A).

Na comparação estatística entre os grupos $A(n=8$ para o teste) e B $(n=8)$ apenas para os quatro primeiros meses, em que a coleta ocorreu em dias intercalados o teste do $\chi^{2}$ mostrou diferença quanto à ocorrência dos estados vaginais observados $\left[\chi^{2}=46,9107, \mathrm{df}=2, \mathrm{p}=\right.$ 0,00001], ou seja, a AV das fêmeas mantidas em duplas era diferente da AV das alojadas em gaiolas individuais, em sala isolada da presença de machos ocorrendo com maior frequência o estado fechado no grupo A.

\subsubsection{Características gerais do ciclo estral de Trinomys yonenagae}

As observações do ciclo estral em roedores rabo-de-facho foram feitas nos três grupos de fêmeas. Neles pode-se ver que o ciclo tem fases de duração variada, o que está mostrado na tabela 2.2. Em 18 oportunidades as fêmeas tiveram o EV coletado duas vezes no mesmo dia para tentar melhorar a estimativa da duração das fases do ciclo estral, permitindo reforçar que a fase de proestro tem em média um dia de duração e o estro algumas horas. $\mathrm{O}$ 


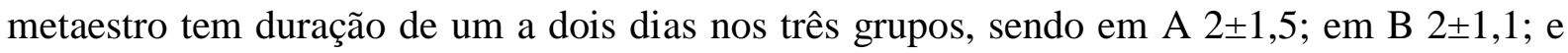
em C 1 $1 \pm 0,3$ dias. A fase de diestro é a de maior duração nos três grupos de fêmeas, variando de 15 a 36 dias dentre aquelas que apresentaram alternância das fases do ciclo estral, embora as fases de P, E, M, e D possam ser reconhecidas na maioria dos indivíduos (tabelas 2.3 e 2.5).

Tabela 2.2. Duração das fases do ciclo estral em Trinomys yonenagae $(\mathrm{n}=26)$

\begin{tabular}{ccccc}
\hline Grupo & Fase & $\begin{array}{c}\text { Duração } \\
\text { (dias) }\end{array}$ & $\begin{array}{c}\text { Duração } \\
\text { média }\end{array}$ & Eventos \\
\hline A & $\mathrm{P}$ & 1 & 1 & 12 \\
duplas & $\mathrm{E}$ & 1 & $<1$ & 4 \\
$(12)$ & $\mathrm{M}$ & $1-4$ & $2 \pm 1,5$ & 33 \\
& $\mathrm{D}$ & $17-20$ & $\#$ & 560 \\
\hline B & $\mathrm{P}$ & $1-3$ & $1 \pm 0,7$ & 49 \\
isoladas & $\mathrm{E}$ & 1 & $<1$ & 7 \\
(8) & $\mathrm{M}$ & $1-5$ & $2 \pm 1,1$ & 39 \\
& $\mathrm{D}$ & $15-30$ & $\#$ & 923 \\
C & $\mathrm{P}$ & 1 & 1 & 7 \\
Casal $*$ & $\mathrm{E}$ & 1 & $<1$ & 4 \\
$(6)$ & $\mathrm{M}$ & $1-2$ & $1 \pm 0,3$ & 12 \\
& $\mathrm{D}^{\$}$ & $15-36$ & $\#$ & 496 \\
\hline
\end{tabular}

Fases: Diestro (D), Proestro (P), Estro (E), Metaestro (M). Entre parênteses o número de fêmeas por grupo. \$ muito variável; * fora da gravidez

\subsubsection{Ciclo estral das fêmeas alojadas em duplas (grupo A)}

As fêmeas alojadas em duplas tiveram seu ciclo estral acompanhado apenas durante o primeiro semestre de observações (março-agosto).

Uma comparação qualitativa das fases em cada dupla indica que uma das fêmeas exerce influência sobre o ciclo estral da outra (tabela 2.3). As fases indicativas de atividade reprodutiva $(\mathrm{P}, \mathrm{E}, \mathrm{M}$ e $\mathrm{T})$ são numericamente maiores em uma das fêmeas de cada dupla. Uma das duplas (dupla 1) é excepcional: uma fêmea apresentou vagina selada ou aberta em 
99\% das observações (tabela 2.4), entretanto, permaneceu grande parte do tempo em diestro; a sua companheira de caixa permaneceu todo o tempo de observação com a vagina fechada (em destaque na tabela 2.4).

Assim, ocorre proestro ou estro, em pelo menos uma fêmea de cinco das seis duplas. A fase de estro é observada em uma das fêmeas de duas duplas (4 e 5); o metaestro em pelo menos uma fêmea de quatro duplas $(2,4,5,6)$.

Tabela 2.3. Frequência das fases do ciclo estral nas fêmeas alojadas em dupla durante o $1^{\circ}$ semestre de observação (março-agosto) de um total de 93 medidas

\begin{tabular}{ccccccc}
\hline Dupla & Fêmea & $\mathbf{D}$ & $\mathbf{P}$ & $\mathbf{E}$ & $\mathbf{M}$ & $\mathbf{\%}$ \\
\hline \multirow{2}{*}{$\mathbf{1}$} & 1DA & $\mathbf{9 1}$ & 0 & 0 & 0 & 1 \\
& 1DB & 0 & 0 & 0 & 0 & 0 \\
\hline \multirow{2}{*}{$\mathbf{s 2}$} & 2DA & $\mathbf{8 4}$ & 1 & 0 & 2 & 3 \\
& 2DB & 2 & 0 & 0 & 0 & 0 \\
\hline \multirow{2}{*}{$\mathbf{3}$} & 3DA & $\mathbf{8 5}$ & 3 & 0 & 0 & 3 \\
& 3DB & 16 & 0 & 0 & 0 & 0 \\
\hline \multirow{2}{*}{$\mathbf{4}$} & 4DA & 29 & 0 & 0 & 0 & 0 \\
& 4DB & $\mathbf{6 6}$ & 2 & 2 & 10 & 19 \\
\hline \multirow{2}{*}{$\mathbf{5}$} & 5DA & 25 & 1 & 0 & 1 & 7 \\
& 5DB & $\mathbf{7 2}$ & 2 & 1 & 14 & 20 \\
\hline \multirow{2}{*}{$\mathbf{6}$} & 6DA & 30 & 3 & 0 & 2 & 12 \\
& 6DB & $\mathbf{5 1}$ & 0 & 0 & 2 & 4 \\
\hline
\end{tabular}

Fases: Diestro (D), Proestro (P), Estro (E), Metaestro (M), Porcentagem (\%) de fases não-diestro. Em destaque a fêmea que apresentou a vagina sempre aberta ou selada

Quando se analisa os estados vaginais o teste U de Mann Whitney mostra que há diferença significativa nas seis duplas entre as fêmeas que compartilham a mesma caixa (tabela 2.4). Nesse sentido, é observável um padrão de dominância de uma fêmea sobre a outra, uma vez que, uma delas apresenta maior ocorrência do estado vagina selada ou aberta e a outra de vagina fechada. 
Tabela 2.4. Frequência de estados vaginais de fêmeas em dupla durante o $1^{\circ}$ semestre de observação (março-agosto) em um total de 93 medidas

\begin{tabular}{|c|c|c|c|c|c|c|}
\hline Dupla & Fêmea & $\mathbf{F}$ & $\mathbf{S}$ & $\mathbf{A}$ & $\mathbf{U}$ & $\mathbf{P}$ \\
\hline \multirow{2}{*}{1} & $1 D A^{*}$ & 1 & 89 & 3 & \multirow{2}{*}{46,5} & \multirow{2}{*}{0,0001} \\
\hline & $1 \mathrm{DB}$ & 93 & 0 & 0 & & \\
\hline \multirow{2}{*}{2} & $2 D A^{*}$ & 6 & 82 & 5 & \multirow{2}{*}{372} & \multirow{2}{*}{0,0001} \\
\hline & $2 \mathrm{DB}$ & 91 & 2 & 0 & & \\
\hline \multirow{2}{*}{3} & $3 D A^{*}$ & 5 & 85 & 3 & \multirow{2}{*}{1023} & \multirow{2}{*}{0,0001} \\
\hline & $3 \mathrm{DB}$ & 76 & 15 & 2 & & \\
\hline \multirow{2}{*}{4} & $4 D A^{*}$ & 64 & 27 & 2 & \multirow{2}{*}{1906,5} & \multirow{2}{*}{0,0001} \\
\hline & $4 \mathrm{DB}$ & 12 & 74 & 7 & & \\
\hline \multirow{2}{*}{5} & $5 D A^{*}$ & 65 & 25 & 3 & \multirow{2}{*}{1395} & \multirow{2}{*}{0,0001} \\
\hline & $5 \mathrm{DB}$ & 2 & 88 & 3 & & \\
\hline \multirow{2}{*}{6} & $6 D A^{*}$ & 52 & 41 & 0 & \multirow{2}{*}{3720} & \multirow{2}{*}{0,057} \\
\hline & $6 \mathrm{DB}$ & 39 & 54 & 0 & & \\
\hline
\end{tabular}

Há diferença significativa do estado vaginal (fechada vs. não fechada) entre as $\uparrow_{\text {s de cada }}$ dupla (*), a com mais eventos não-fechado do ciclo em destaque. Teste de Mann-Whitney. Fechada (F); Selada (S); Aberta (A).

No geral o grupo de fêmeas pareadas com fêmeas apresentou durante um semestre de observações $10 \%$ de fases não diestro e $55 \%$ de observações dos estados vaginais selado ou aberto, indicativos de atividade reprodutiva (figura 1.1 a e b e Anexo 3).

Figura 2.1 Estados vaginais (a) e fases do ciclo estral (b) de fêmeas pareadas com fêmeas (grupo A) durante o $1^{\circ}$ semestre de observação

a)

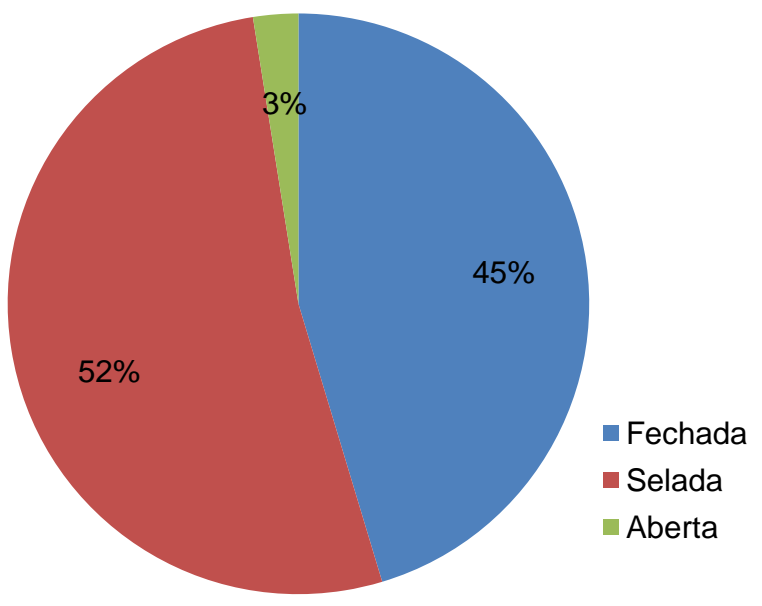

b)

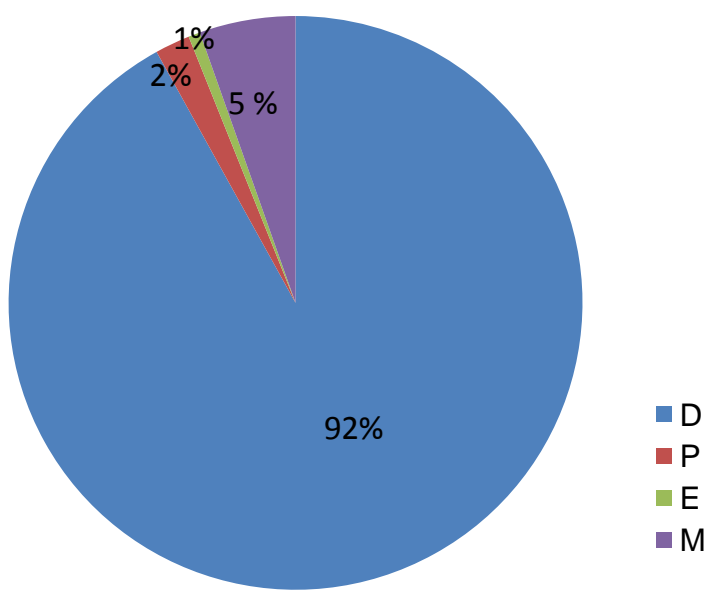




\subsubsection{Ciclo estral das fêmeas alojadas em gaiolas individuais (grupo B)}

Considerando-se um ano de observação que foi realizada nas fêmeas do grupo B, é possível afirmar que todas as fases do ciclo estral ocorrem e que a frequência de eventos é maior do que nos outros dois grupos.

Para essas fêmeas o estado vaginal predominante durante o ano todo é o selado, correspondendo a 67\% das observações (Tabela 2.2.7 e Anexo 4). O estado fechado aparece em $28 \%$ e o aberto em $5 \%$. Em todas as fêmeas a fase do ciclo mais observada foi o diestro, em média 90\% (figura 2.2 b Anexo 4), padrão observado nos três grupos de fêmeas (duplas, individualizadas e em casal).

Tabela 2.5. Fases do ciclo estral, em frequência, de fêmeas alojadas em gaiolas individuais de um total de 177 medidas (93 medidas $1^{\circ}$ semestre e 84 no $2^{\circ}$ )

\begin{tabular}{ccccc|ccccc}
\hline \multirow{2}{*}{ Fêmea } & \multicolumn{3}{c|}{$\mathbf{1}^{\mathbf{0}}$ sem. (março-ago) } & \multicolumn{3}{c}{$\mathbf{2}^{\mathbf{o}}$ sem. (set-abril) } & $\%$ \\
& D & $\mathbf{P}$ & $\mathbf{E}$ & $\mathbf{M}$ & $\mathbf{D}$ & $\mathbf{P}$ & $\mathbf{E}$ & $\mathbf{M}$ & ano \\
\hline $7 \mathrm{I}$ & 2 & 0 & 0 & 0 & $\mathbf{4 9}$ & 0 & 0 & 0 & 0 \\
$8 \mathrm{I}$ & $\mathbf{6 3}$ & 6 & 0 & 0 & $\mathbf{4 7}$ & 4 & 0 & 0 & 8 \\
$9 \mathrm{I}$ & $\mathbf{6 3}$ & 4 & 0 & 5 & $\mathbf{6 1}$ & 2 & 0 & 0 & 8 \\
$10 \mathrm{I}$ & $\mathbf{6 9}$ & 9 & 1 & 7 & $\mathbf{6 8}$ & 5 & 1 & 1 & 15 \\
$11 \mathrm{I}$ & 20 & 0 & 0 & 6 & $\mathbf{4 7}$ & 0 & 0 & 1 & 10 \\
$12 \mathrm{I}$ & $\mathbf{5 9}$ & 5 & 1 & 3 & $\mathbf{7 6}$ & 3 & 0 & 1 & 9 \\
$13 \mathrm{I}$ & $\mathbf{8 5}$ & 2 & 1 & 4 & $\mathbf{8 1}$ & 0 & 1 & 1 & 5 \\
$14 \mathrm{I}$ & $\mathbf{6 6}$ & 6 & 2 & 9 & $\mathbf{6 7}$ & 3 & 0 & 1 & 14 \\
\hline
\end{tabular}

Observações no $1^{\circ}$ semestre (março a agosto) diariamente ou em dias intercalados; no $2^{\circ}$ (agosto a abril) em intervalos de 2 a 4 dias. Diestro (D), Proestro (P), Estro (E), Metaestro (M). \% fases não-diestro

Em três fêmeas foi possível observar a ocorrência de estro, correspondendo de 1 a $2 \%$ dos eventos (Tabela 6 e Anexo 4). Apenas uma fêmea (7I) não apresenta nenhuma ocorrência de proestro, estro ou metaestro como mostra a tabela 2.6, mesmo permanecendo a maior parte do $2^{\circ}$ semestre com a vagina selada ou aberta. 
Tabela 2.6. Frequência de estados vaginais de fêmeas alojadas em gaiolas individuais em um total de 177 medidas ( 93 medidas $1^{\circ}$ semestre e 84 no $2^{\circ}$ )

\begin{tabular}{cccc|ccc}
\hline \multirow{2}{*}{ Fêmea } & \multicolumn{1}{c|}{$\mathbf{1}^{\mathbf{0}}$ semestre (março-ago) } & \multicolumn{4}{c}{$\mathbf{2}^{\mathbf{0}}$ semestre (set-abril) } \\
& $\mathbf{F}$ & $\mathbf{S}$ & $\mathbf{A}$ & $\mathbf{F}$ & $\mathbf{S}$ & $\mathbf{A}$ \\
\hline 7I & $\mathbf{9 1}$ & 2 & 0 & 35 & $\mathbf{4 8}$ & 1 \\
8I & 24 & $\mathbf{6 5}$ & 4 & 33 & $\mathbf{4 9}$ & 2 \\
9I & 21 & $\mathbf{6 9}$ & 3 & 20 & $\mathbf{6 4}$ & 0 \\
10I & 7 & $\mathbf{8 1}$ & 5 & 9 & $\mathbf{7 4}$ & 1 \\
11I & $\mathbf{6 7}$ & 26 & 0 & 36 & $\mathbf{4 8}$ & 0 \\
12I & 24 & $\mathbf{5 9}$ & 10 & 4 & $\mathbf{7 2}$ & 8 \\
13I & $\mathbf{0}$ & $\mathbf{8 1}$ & 12 & 1 & $\mathbf{7 0}$ & 13 \\
14I & 9 & $\mathbf{7 8}$ & 6 & 13 & $\mathbf{6 6}$ & 5 \\
\hline Fechada (F); Selada (S); Aberta (A). Em destaque fêmea que não apresentou \\
nenhum evento de vagina fechada.
\end{tabular}

A fêmea 13I que apresentou um único evento de vagina fechada não mostrou a maior atividade reprodutiva do grupo. No ano essa fêmea teve $5 \%$ das observações de fases reprodutivas, sendo, no $1^{\circ}$ semestre, $14 \%$ de ocorrências de vagina aberta e $8 \%$ de fases reprodutivas $\left(2,2 \%\right.$ de proestro, $1 \%$ estro, $4,3 \%$ metaestro), e no $2^{\circ}$ semestre $16 \%$ de ocorrências de vagina aberta com $2 \%$ de fases reprodutivas (1\%proestro e $1 \%$ metaestro Anexo 3). Outras fêmeas, como a 10I apresentaram maior porcentagem de proestro (9\%), estro (1\%) e metaestro (5\%) (Anexo 3), totalizando 15\% no ano (Tabela 2.5) mesmo com maior porcentagem de observações da vagina fechada (tabela 2.6). Estes fatos reforçam o argumento de que a vagina aberta não é bom indicativo de atividade reprodutiva nesta espécie, diferentemente do que ocorre com a maioria dos histricomorfa (WEIR, 1974).

No geral as fêmeas do grupo B apresentam 10\% de fases não diestro e $72 \%$ de vagina selada ou aberta durante o ano de observações (figura 2.2 a e b). 
Figura 2.2 Estados vaginais (a) e fases do ciclo estral (b) de fêmeas alojadas em gaiolas individuais (grupo B) durante um ano de observação

a)

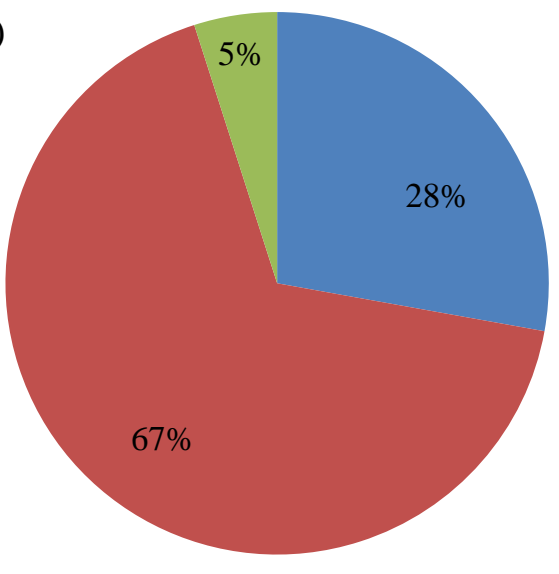

- Fehada

- Selada

Aberta b)

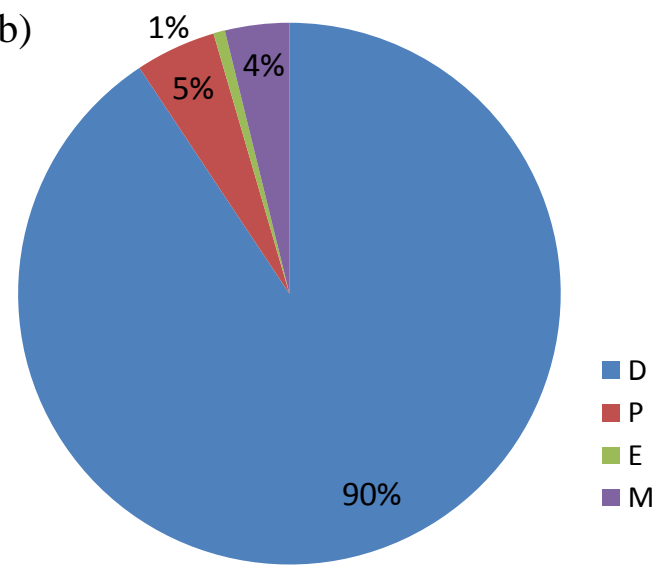

\subsubsection{Ciclo estral nas fêmeas alojadas com machos (grupo C)}

O ciclo estral das fêmeas do grupo $\mathrm{C}$ foi acompanhado durante um ano, sendo no $1^{\circ}$ semestre com coletas em dias intercalados e diários (apenas no quinto mês) e no $2^{\circ}$ semestre com coletas semanais. Estas fêmeas estiveram grávidas durante parte das coletas, sendo por isso, o resultado aqui apresentado dividido em períodos gravidez e fora dele. Neste capítulo será abordado apenas o ciclo estral fora da gravidez. No capítulo 3 serão apresentados os dados referentes ao ciclo estral durante o período de gestação.

O estado vaginal mais observado quando as fêmeas não estão grávidas é vagina selada com $80 \%$ (figura 2.3a) e a fase de diestro (tabela 2.7). As fases de proestro e metaestro foram observadas em todas as fêmeas e somam $4 \%$ da atividade reprodutiva no ano. O estro foi observado em três fêmeas ( $1 \mathrm{CF}, 5 \mathrm{CF}$ e $6 \mathrm{CF})$, incluindo a que permaneceu nulípara (1CF), sendo um deles seguido do nascimento de uma ninhada 93 dias depois (fêmea 6CF). Mesmo não se observando estro cinco fêmeas ficaram grávidas durante o período de observação. 
Tabela 2.7. Fases do ciclo estral, em frequência, de fêmeas alojadas com machos quando não prenhas

\begin{tabular}{ccccc|ccccc}
\hline \multirow{2}{*}{ Fêmea } & \multicolumn{3}{c|}{$\begin{array}{c}\mathbf{1}^{\mathbf{0}} \text { semestre } \\
\text { (março-ago) }\end{array}$} & \multicolumn{5}{c}{$\begin{array}{c}\mathbf{2}^{\mathbf{0}} \text { semestre } \\
\text { (set-abril) }\end{array}$} & $\begin{array}{c}\text { \% } \\
\text { ano }\end{array}$ \\
\cline { 2 - 7 } & $\mathbf{D}$ & $\mathbf{P}$ & $\mathbf{E}$ & $\mathbf{M}$ & $\mathbf{D}$ & $\mathbf{P}$ & $\mathbf{E}$ & $\mathbf{M}$ & \\
\hline $1 \mathrm{CF}$ & 85 & 1 & 2 & 2 & 57 & 0 & 0 & 2 & 6 \\
$2 \mathrm{CF}$ & 47 & 2 & 0 & 0 & 54 & 0 & 0 & 1 & 4 \\
$3 \mathrm{CF}$ & 9 & 1 & 0 & 1 & 39 & 0 & 0 & 0 & 4 \\
4CF & 34 & 0 & 0 & 1 & 48 & 0 & 0 & 2 & 7 \\
$5 \mathrm{CF}$ & 36 & 0 & 0 & 0 & 56 & 2 & $\mathbf{1}$ & 2 & 11 \\
$6 \mathrm{CF}$ & $\mathbf{a}$ & $\mathbf{a}$ & $\mathfrak{a}$ & 31 & 1 & $\mathbf{1}$ & 1 & 9 \\
\hline
\end{tabular}

Observações feitas no $1^{\circ}$ semestre (março a agosto) diariamente ou em dias intercalado; no $2^{\circ}$ semestre (agosto a abril) semanal. Fases: Diestro (D), Proestro (P), Estro (E), Metaestro (M). incluída só no $2^{\circ}$ semestre. Porcentagem no ano $(\%)$ de fases não-diestro

Figura 2.3 Estado vaginal (a) e fases do ciclo estral (b) em fêmeas pareadas com machos $(\mathrm{n}=4$ a 5$)$ fora do período de gravidez

a) Estados vaginais fêmeas não grávidas

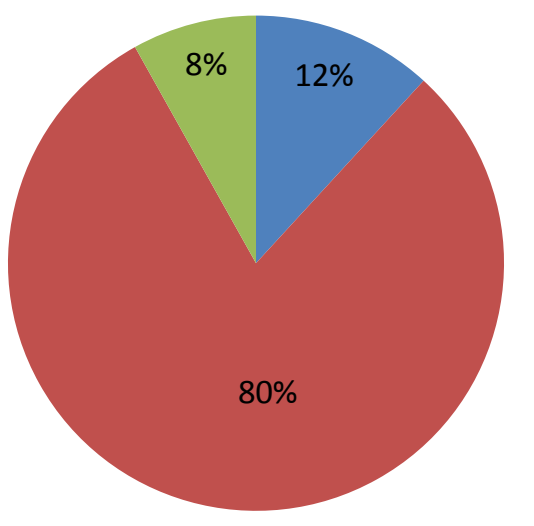

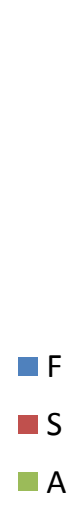

b) Fases do ciclo fêmeas não grávidas

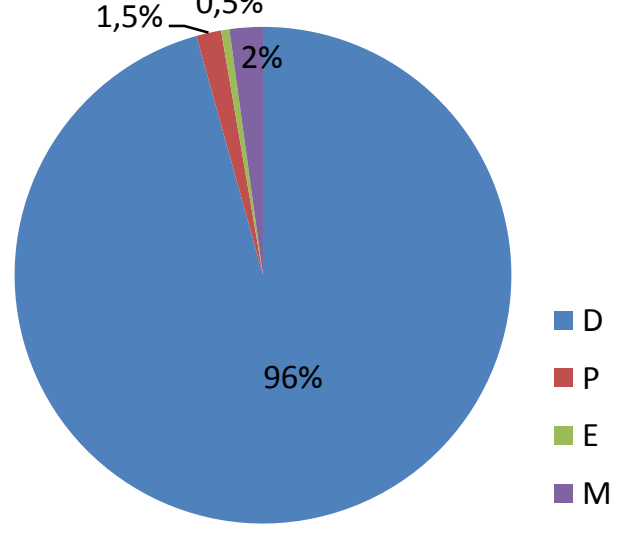

Apenas uma fêmea permanece nulípara (1CF) no grupo $\mathrm{C}$, e sua atividade reprodutiva está representada na figura 2.4 e tabela 2.7. É possível observar que essa fêmea, mesmo apresentando o estado vagina-selada durante a maior parte do ano (89\%), permanece praticamente todo ele em diestro (94\%), com uma ocorrência de proestro, duas de estro e quatro de metaestro (1\% cada e 3\% metaestro). Essa frequiência é maior do que nas fêmeas 
que ficaram grávidas pelo menos uma vez. Já os valores observados para vagina fechada (6\%) e aberta (5\%) são menores do que naquelas fêmeas (14\% e 7\%, respectivamente).

Comparada com as fêmeas alojadas em gaiolas individuais (grupo B), essa fêmea teve a mesma porcentagem de ocorrência de vagina aberta (5\%), sendo diferentes as ocorrências de vagina fechada ( $6 \%$ e $28 \%$ isoladas) e selada ( $89 \%$ e $67 \%$ isoladas). As fases não diestro do ciclo $50 \%$ menos do que se observou nas isoladas do grupo B $(5 \%$ e $10 \%$, respectivamente).

Figura 2.4 Estados vaginais (a) e fases do ciclo estral (b) na fêmea nulípara (1CF) durante um ano de observação

a)

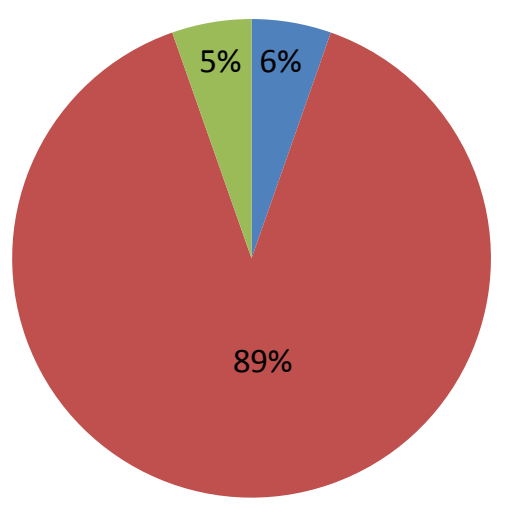

b)

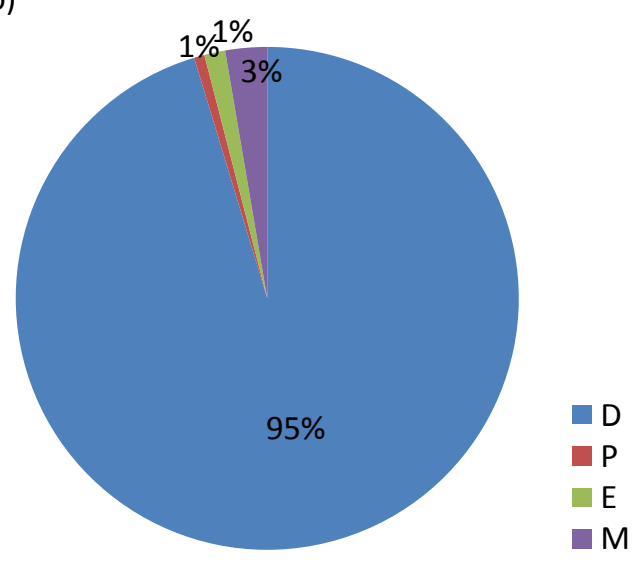

\subsection{Discussão}

As fêmeas em duplas tiveram uma frequiência quase duas vezes maior de VF do que o observado nas fêmeas isoladas. A diferença entre estes dois grupos quanto à frequiência dos três estados vaginais pode ser uma indicação da influência do co-específico sobre o ciclo sexual (LUCHESI et al 2008). O estado VA foi o menos observado nas fêmeas sem contato com os machos, indicando que, embora não garanta a gravidez, o macho pode exercer algum tipo de influência sobre o ciclo das fêmeas. Em casal, elas apresentaram uma freqüência de abertura vaginal de duas a três vezes maior do que nos outros grupos. 
Em animais com o ciclo induzido, como na Galea musteloides, a vagina apresenta-se completamente aberta após três dias em contato com um macho. E naquelas em que ele é espontâneo, como no porquinho-da-índia (Cavia porcellus), há um ciclo de abertura e fechamento, que varia de 2 a 20 dias, independente de contato com o macho (TouMA et al 2001). Em algumas espécies é necessário que ocorra o ato da cópula, para então se seguir a ovulação, como no roedor fossorial sul-africano Cryptomys hottentotus, o rato-toupeira (JACKSON, et al 2005). Em Trinomys yonenagae, a abertura e fechamento do orifício vaginal ocorreram tanto em fêmeas com machos como naquelas em sala isolada da influência deles, dado indicativo de ciclo estral espontâneo.

A observação de fêmeas alojadas em duplas permitiu identificar a existência de influência do co-específico do mesmo sexo sobre o outro, como já observado por Kleiman (1987) em Peromyscus leucopus. Uma relação que parece ser independente dos animais serem aparentados ou não, uma vez que metade das duplas $(n=3)$ era formada por fêmeas irmãs e metade por não-irmãs e a dominância foi constatada em todas as seis duplas (tabela 2.3). Entretanto, o tempo/estação do ano parece não exercer influência sobre o ciclo destas fêmeas uma vez que foi observado alternância das fases do ciclo estral durante os dois semestres de observações.

As fases do ciclo no rabo-de-facho não são de fácil identificação como relatado em Cavia porcellus por Stockard \& Papanicolau (1919). Uma diferença é a presença de linfócitos na maioria dos esfregaços e de alguns leucócitos polimorfonucleares, mesmo nas fases onde há predomínio de células queratinizadas características do estro. Este fato indica uma curta duração das fases de proestro e estro, com isso, um esfregaço realizado $24 \mathrm{~h}$ antes da ocorrência do estro não foi capaz de revelar este com antecedência o acontecimento, como é corriqueiro nos protocolos feitos com ratos da linhagem Wistar. Esta dificuldade de predição da fase de estro com antecedência de $24 \mathrm{~h}$ foi relatada para outro histricomorfo, o Myocastor 
coypus por Felipe e colaboradores (2001). Labyak (1995) já havia relado dificuldade na identificação das fases de proestro e estro em Octodon degus, pois as fêmeas freqüientemente encontravam-se em fase de transição. Além disso, a ruptura da membrana vaginal não é indicativo de estro (SPINELLI OLIVEIRA et al, 2007), o mesmo acontece com Myocastor coypus (FELIPE, 2001). A baixa freqüência de estro em T. yonenagae pode ser também em consequência à definição utilizada nesse trabalho, que só considerou estro a predominância de células epiteliais queratinizadas, com ou sem a presença de muco, seguindo o proposto por Stockard \& Papanicolau (1919).

Através da técnica de esfregaço vaginal e subsequente observação do ovário Breed (1967) observou que o rato-do-campo (Microtus agrestis) apresenta um ciclo estral do tipo induzido pela presença do macho. Breed também observou que o ciclo estral das fêmeas desta espécie pode ser do tipo longo ou curto variando de dois a cinco dias a até quatro semanas em uma única fase. $\mathrm{O}$ autor chama a atenção ao fato de que as mudanças observadas nos esfregaços destas fêmeas não são tão óbvias quanto em ratos e camundongos e que o fato de ser espontânea ou induzida a ovulação varia entre as espécies deste gênero.

Existem relatos entre os caviomorfos, como Trinomys yonenagae, de que o reaparecimento de leucócitos no esfregaço vaginal (que caracteriza o metaestro) não necessariamente indica que houve ovulação. Em chinchilas os leucócitos estão presentes durante todo o tempo em que a membrana vaginal permanece aberta e o acasalamento ocorre em qualquer momento do ciclo (WEIR, 1974). O mesmo ocorre com o murídeo Microtus agrestis onde a detecção das diferentes fases do ciclo também não é tão simples quanto em Cavia (BREED, 1967).

Trinomys yonenagae, portanto, segue os padrões de abertura vaginal e ciclo estral dos histricomorfa já conhecidos, com influência de co-específicos, presença de membrana vaginal, ciclo poliéstrico e fases de difícil identificação. 


\subsection{Bibliografia}

ASDell, S. A. Patterns of Mammalian Reproduction. Ithaca: Cornell University Press, 2. Ed, 1964.

Avery, G. T. Notes of reproduction in guinea pigs. Journal of Comparative Psychology, v.5, pp. 373-396, 1925.

Barbosa, L. P.; Rodrigues, M. V.; Neves, M. M.; Morais, D. B.; Melo, B. E. dos S.; BAlARINI, M. K.; CoElHO, C. D. P.; MENDONÇA, C. Caracterização da colpocitologia em capivaras (Hydrochoerus hydrochaeris). Revista Brasileira de Saúde e Produção Animal, v. 8, n. 4, 258-266, 2007.

Bergallo, H. G. Comparative life-history characteristics of two species of rats, Proechimys iheringi and Oryzomys intermedius, in an Atlantic forest of Brazil. Mammalia, v. 59, 51-64, 1995.

BREED, W. G. Ovulation in the genus Microtus. Nature, v. 214, 896, 1967.

BRONNER, G.; RAUTENBACH, I. L.; MEESTER, J. Environmental influence on reproduction in the Natal multimammate mouse Mastomys natalensis. Suid-Afrikaanse tydskrif vir natuurnavorsing, v. 18, n. 4, pp.142-148. 1988.

Bronson, F. H. Mammalian Reproductive Biology. The University of Chicago Press, Chicago, 1989.

DELlias, P. M. Dados citológicos do ciclo estral da Cavia aperea aperea (Rodentia). Revista da Faculdade de Odontologia de São José dos Campos, v 2, 77-83, 1973.

ECKert, R.; RANDAll, D. AUGUSTINE, G. Animal Physiology: Mechanisms and adaptations. W. H. Freeman and Co., New York, 1998, 683p.

FeliPe, A.; Cabodevila, J.; Callejas, S. Characterization of the estrous cycle of the Myocastor coypus (coypu) by means of exfoliative colpocytology. Journal of Neotropical Mastozoology, v. 8, pp. 129-137, 2001.

JACKSON, C. R.; BENNETT, N. C. Is the natal mole-rat (Cryptomys hottentotus natalensis) a spontaneous or induced ovulator? Journal of Mammalogy, v. 86, 1-6, 2005.

Kleiman, D. G. Reproductive inhibition of female Peromyscus leucopus: female competition and behavioral regulation. American Zoology, v.27, pp. 867-878, 1987.

LABYAK, S. E.; LEE, T. M. Estrus and steroid-induced changes in circadian rhythms in a diurnal rodent, Octodon degus. Physiology \& Behavior, v. 58, n. 3, 573-585, 1995. 
LONG, J. A.; EvANS, H. M. The oestrous cycle in the rat and its associated phenomena. Memoir of the University of California, v. 6, 148, 1922.

LuCHeSI, L. C.; Milan, D. L.; SPINElLi OliVeIRA, E. Dominância entre fêmeas de Trinomys yonenagae (Rodentia:Echimyidae) quanta à abertura vaginal. In: XVI Congresso interno do NaP/NeC, 39, 2008.

NELSON, J. N. An introduction to Behavioral Endocrinology. Sinauer Associates Inc. Publishers, 1995, 611p.

Oliveira SPinelli, E.; SAntos, J. W. A.; MAnAF, P.; Rocha, P. L. B. Utilização da técnica de esfregaço vaginal para o estudo de uma população de Proechimys yonenagae (Rodentia: Echimyidae). In: XII Reunião Anual da Federação de Sociedades de Biologia Experimental - FeSBE, Caxambu: 1997, p. 276.

Oliveira Spinelli, E.; Perry, S. F.; Monea, N. M.; Barbosa, F. L.; LuCheSi, L. C. Does vaginal opening coincide with reproductive activity in a dune-living spiny rat? In:

Comparative Biochemistry and Physiology Part A: Molecular \& Integrative Physiology, n. 148, Suplement 1, S22, 2007.

StOCKARD, C. R.; PAPANICOLAU, G. N. The vaginal closure membrane, copulation, and the vaginal plug in the guinea-pig, with further considerations of the oestrous rhythm. Biological Bulletin, v. 37, 222-245, 1919.

Tobin, M. E.; KoEHLER, A. E.; \& Sugihara, R. T. Seasonal patterns of fecundity and diet of roof rats in Hawaiian academia orchards. Wildlife Research, v. 21 pp. 519-526, 1994.

TOUMA, C.; PALME, R. SACHSER, N. Different types of oestrus cycle in tow closely related South American rodents (Cavia aperea and Galea musteloides) with different social and mating systems. Reproduction, v. 121, 791-801, 2001.

WEIR, B. J. Another hystricomorph rodent: keeping casiguara (Proechimys gauairae) in captivity. Laboratory animal, v.7, 125-134, 1973.

WEIR, B. J. Reproductive characteristics of Hystricomorph rodents. Symposia of the zoological Society of London, n. 34, 264-301, 1974. 


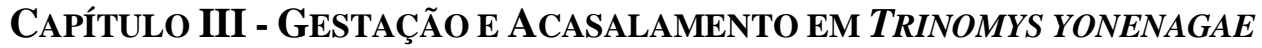

\subsection{Introdução}

\subsubsection{Comportamentos reprodutivos}

Talvez nenhum outro parâmetro fisiológico tenha sofrido mais pressão adaptativa do que a reprodução. As soluções para tais pressões mostram uma vasta gama de padrões reprodutivos. Acredita-se que eles reflitam a distribuição de alimento, locais de reprodução e parceiros em potencial.

O estudo dos comportamentos reprodutivos também é usado como um critério para se caracterizar o ciclo estral em mamíferos, incluindo-se os roedores. Espécies com fase de estro muito curta, em geral, apresentam comportamentos de corte elaborados e/ou persistentes por parte dos machos. Por outro lado, fêmeas mantidas com machos vasectomizados apresentam a persistência da abertura vaginal, nas espécies que têm membrana vaginal. A ocorrência de estro pós-parto também é de interesse diagnóstico do tipo de ciclo estral. O estro pós-parto faz parte do repertório reprodutivo de várias espécies de roedores (Cavia porcellus, Meriones unguiculatus, etc.) e permite aumentar a produtividade e as chances de continuidade da espécie.

Os histricognatas apresentam padrão de acasalamento altamente especializado, e de duração variável, fato relacionado com a duração do ciclo estral (KLEIMAN 1974). No histricomorfo Hystrix cristata, sabe-se que há acasalamento apenas durante a fase de estro (FeliCioli, 1997), diferente do que é observado para outra espécie do mesmo gênero $H$. indica (SEVER e MENDELSON, 1988 e 1992 apud FELICIOLI, 1997). O período de receptividade da fêmea também pode variar de poucas horas (2-3h) como em Galea (RoOD, 1972) até várias horas como em Octodon (KLEIMAN, 1974). 


\subsubsection{Gestação}

O período de gestação também é muito variável e, em geral, reflete relações com o ambiente externo. Em histricognatas o período é geralmente longo variando de 52 dias na Galea até 222 dias em Dinomys. O período mais longo conhecido em um murídeo é do roedor australiano Mesembriomys gouldii com gestação de 46 dias (CRICHTON, 1969 apud WEIR, 1974). Longos períodos de gestação podem ser associados a estratégias como retardo na fertilização ou na implantação. O grupo dos histricognatas, com exceção de Lagostomus (RoBERTS, 1973 apud WeIR, 1974), não adotou nenhum tipo de retardo na gestação, mas as espécies do grupo evoluíram para gestações longas onde o primeiro quarto é tomado pela proliferação de tecidos placentais e o restante do tempo representado por um lento crescimento fetal (WEIR, 1974).

É possível calcular o período de gestação através de diversos sinais, como presença de plug vaginal e de espermatozóides no esfregaço. Intervalos entre gestações consecutivas também podem revelar a periodicidade da gestação e a ocorrência de estro pós-parto (WEIR, 1974).

\subsection{Objetivos}

Os objetivos destes experimentos são caracterizar o ritual de acasalamento; o tempo de gestação, a evolução da massa corporal durante a gestação e as características das ninhadas em Trinomys yonenagae.

\subsection{Material e Métodos}

\subsubsection{Animais}

Neste experimento 15 fêmeas $(125+33 \mathrm{~g})$ tiveram as características da gestação analisadas durante os últimos 10 anos (Anexo 6). Cinco delas eram pertencentes ao grupo $\mathrm{C}$ do 
experimento de ciclo estral (capítulo 2), o que permitiu a análise da citologia vaginal durante a gravidez. As outras nove fêmeas foram analisadas a partir dos registros históricos do biotério do LECO, o que possibilitou o estudo em longo prazo, principalmente para gestações consecutivas e do tamanho das ninhadas. Além delas, em duas fêmeas foi possível analisar os comportamentos associados ao estro pós-parto ${ }^{3}$, a partir de registros filmados por 30 minutos.

\subsubsection{Manutenção dos animais}

As condições de alojamento estão descritas na parte introdutória do trabalho. Em resumo os animais foram em gaiolas do tipo duna em sala com condições controladas.

\subsubsection{Procedimentos}

\subsubsection{Procedimentos e equipamentos dos estudos das características da gestação}

Um levantamento de dez anos permitiu estimar o período de gestação (duração, estado vaginal e citologia esfoliativa), a idade em que as fêmeas apresentaram a primeira concepção, e as características das ninhadas de Trinomys yonenagae geradas (número de filhotes e ninhadas por estação do ano).

Os dados foram obtidos a partir de observações dos casais durante a realização dos experimentos de acompanhamento do ciclo estral e abertura vaginal e/ou pelo histórico do biotério, onde cada animal possui uma ficha com toda a sua vida, como data de nascimento, pais, pareamentos, ninhadas e data de baixa.

A evolução da massa corporal durante a gestação foi acompanhada por pesagens semanais das fêmeas pareadas em casal que participaram do experimento sobre ciclo estral (capítulo 2).

\footnotetext{
${ }^{3}$ Filmagens cedidas pelo Dr. Paulo Manaf.
} 
3.3.3.2 Procedimentos e equipamentos dos estudos do padrão do comportamento

$\underline{\text { reprodutivo }}$

Após o nascimento dos filhotes de dois casais os pais foram filmados por 30min no período imediatamente pós-parto, na fase de transição claro/escuro, buscando-se registrar a ocorrência de estro pós-parto e a caracterização do repertório comportamental de acasalamento na espécie.

Foram quantificadas as freqüências e duração de categorias comportamentais, escolhidas a partir de etograma (MANAF \& OliveIRA, 2000; MANAF, 2000) e da tabela de ocorrência de categorias comportamentais de acasalamento de histricognatas (KLEIMAN, 1974); a latência de montas e a presença ou não de lordose da fêmea pareada com macho, foi obtida seguindo-se o método de amostragem instantânea "Scan" (AltMANN, 1974). E o método de quantificação das unidades comportamentais utilizado foi "Animal Focal" combinado com "Todas as Ocorrências" (ALTMANN, 1974).

Os casais foram filmados com uma câmera de vídeo marca Sony modelo Handycam Vision CCD-TRV15, e as filmagens analisadas em um VCR Samsung VM-K87 acoplado a um monitor Toshiba TV-2066 SU 20”. Toda a quantificação comportamental foi feita através do programa Etholog versão 2.2 (OTTONI, 2000).

\subsection{Resultados}

\subsubsection{Gravidez em Trinomys yonenagae}

Durante 10 anos das 93 ninhadas nascidas 24 (25,8\%) ocorreram em gestações seguidas após o nascimento de uma ninhada. A partir delas foi possível calcular a duração média da gestação $91 \pm 2,5$ dias. O maior intervalo observado sem o nascimento de filhotes até o presente é de 592 dias na fêmea $15 \mathrm{CF}$. Esta fêmea, que não teve nenhuma gestação seguida gerou em média uma ninhada por ano nos cinco anos em que pariu filhotes, ela foi 
também a fêmea mais velha a dar a luz a uma ninhada, com 8 anos e 7 meses de vida no laboratório (animal capturado em campo). A fêmea nascida no biotério que foi a mais nova a ter filhotes (12CF) ficou prenhe aos 111 dias de vida e teve dois filhotes nesta gestação.

Dentre as 14 fêmeas apenas uma (9CF) teve todas as cinco gestações seguidas (duração 91,5 \pm 1 dia) sempre com o mesmo macho. Esta fêmea morreu com 2 anos e 9 meses de vida.

Tabela 3.1. Número de ninhadas e filhotes nascidos no biotério nas quatro estações do ano em dez anos de acompanhamento em cativeiro $\quad(n=13$ fêmeas)

\begin{tabular}{ccc}
\hline $\begin{array}{c}\text { Estação } \\
\text { do ano }\end{array}$ & $\begin{array}{c}\mathbf{N}^{\mathbf{o}} \\
\text { ninhadas }\end{array}$ & $\begin{array}{c}\mathbf{N}^{\mathbf{o}} \\
\text { filhos }\end{array}$ \\
\hline Primavera & 26 & 55 \\
Verão & 21 & 39 \\
Outono & 27 & 47 \\
Inverno & 19 & 34 \\
\hline Total & $\mathbf{9 3}$ & $\mathbf{1 7 5}$ \\
\hline
\end{tabular}

O acompanhamento dos nascimentos (tabela 3.1) mostra que não há um padrão sazonal na ocorrência das ninhadas (primavera 26; verão 21; outono 27; inverno 19) nesta espécie. Sendo as ninhadas espalhadas por todo o ano $[\mathrm{F}=0,51 ; \mathrm{df}=51 ; \mathrm{p}=0,67]$; assim como, o número de filhotes nascidos nas quatro estações é semelhante $[\mathrm{F}=0,65 ; \mathrm{df}=51 ; \mathrm{p}=0,58]$, como mostra a ANOVA com medidas repetidas. O inverno é a estação com menos filhotes nascidos (34) e a primavera com mais (55).

A média de filhotes por ninhada é de $2 \pm 0,6$ filhotes e a razão nos nascidos é de 1,1 macho:fêmea (Anexo 7). 


\subsubsection{Ganho de peso durante a gestação}

Oito gestações foram acompanhadas com pesagens semanais por um período de 15 semanas. Tomando a gestação com 90 dias ou 12 semanas iniciou-se a análise três semanas antes do início dela.

O peso inicial dessas fêmeas era em torno de $134 \pm 15,8 \mathrm{~g}$. Durante a gestação as fêmeas ganharam em média $25 \%$ de sua massa corporal inicial $33 \pm 11,9 \mathrm{~g}$ (tabela 3.2 ). É possível observar uma variação nesse ganho entre $11 \mathrm{~g}$ e $47 \mathrm{~g}$. Onde a fêmea com maior massa corporal foi a que ganhou menos durante os três meses ( $7 \%$ do peso inicial) e a com menor massa $16 \%$ do peso inicial, ambas tiveram um filhote ao final da gestação.

Tabela 3.2. Massa corporal, ganho de peso e \% de ganho das fêmeas de Trinomys yonenagae em 8 episódios de gestação

\begin{tabular}{ccccc}
\hline fêmea & $\mathbf{p}$ inicial & $\mathbf{p}$ final & ganho $(\mathbf{g})$ & \%ganho \\
\hline 2CF & 161 & 172 & 11 & 7 \\
3CF & 145 & 188 & 43 & 30 \\
3CF & 149 & 196 & 47 & 31 \\
4CF & 130 & 163 & 33 & 25 \\
4CF & 131 & 167 & 36 & 28 \\
$5 \mathrm{CF}$ & 110 & 128 & 18 & 16 \\
$5 \mathrm{CF}$ & 116 & 148 & 32 & 28 \\
$6 \mathrm{CF}$ & 132 & 176 & 44 & 33 \\
\hline Média & 134 & 167 & 33 & 25 \\
dp & 15,8 & 20,3 & 11,9 & \\
\hline
\end{tabular}

O aumento da massa corporal durante os três meses se dá de forma contínua, porém discreta no início da gestação nos oito episódios acompanhados. Esse aumento não é significativo no primeiro terço da gestação e só é perceptível no último estágio de gestação (figura 3.1). A partir da análise de variância com medidas repetidas e o teste post hoc de Tukey é possível dizer que o peso da $12^{\mathrm{a}}$ semana de gestação é diferente daqueles do primeiro mês $[F=3,04 ; \mathrm{df}=84, \mathrm{p}=0,0018]$. 
Figura 3.1. Evolução da massa corporal das fêmeas de Trinomys yonenagae em 15 semanas de observação ( $\mathrm{n}=8$ episódios)

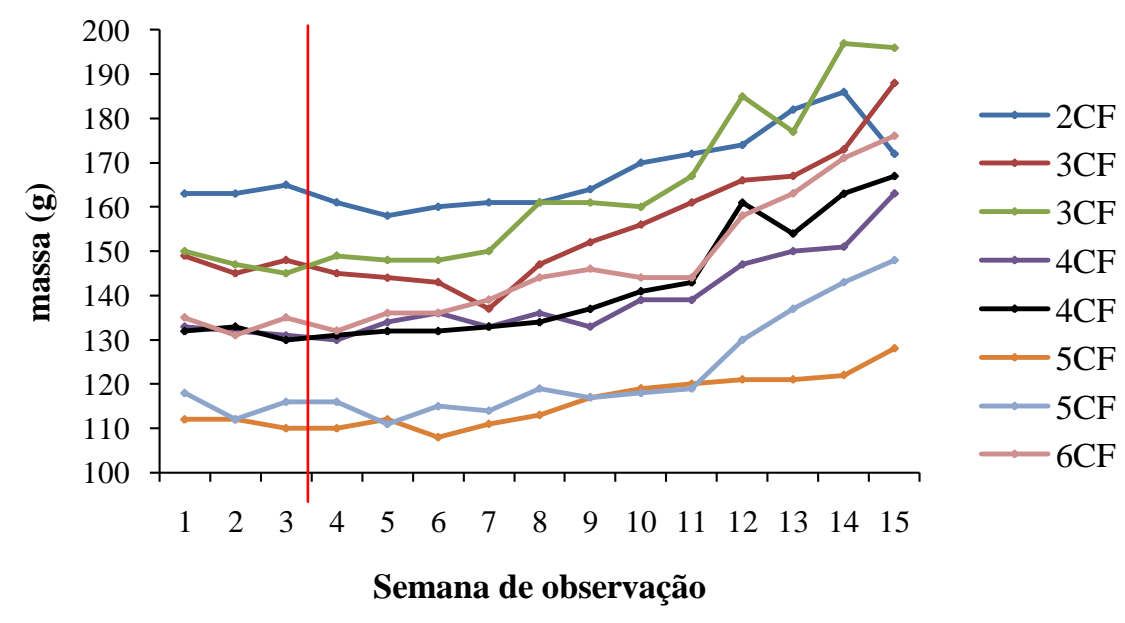

A linha vermelha marca o início do período de gestação. Na $15^{\text {a }}$ semana ocorreram os nascimentos das ninhadas

\subsubsection{Nascimentos durante o desenvolvimento do estudo}

Durante o tempo em que foram coletados os esfregaços vaginais das fêmeas em casal houve três nascimentos dentre aquelas cinco que estavam alojadas com machos e que tiveram pelo menos uma ninhada, representando $60 \%$ dos casais.

A fêmea 3CF, alojada com o macho 3CM, apresentou a fase de proestro com VA após dois dias do início do experimento (13/03). Após 24 dias desse evento observou-se o macho em comportamento de acasalamento, tentando a monta, entretanto a fêmea mostrou-se pouco receptiva e, a fase do ciclo observada foi diestro com VS, que persistiu por mais 20 dias, quando se observou que o macho cheirou a região anogential dela após ser devolvida a gaiola tentando montar novamente (AV selada e diestro o material coletado apresentou sangue).

Com os sangramentos observados a fêmea não teve material coletado por 15 dias. Nesse período ocorreu apenas a pesagem semanal dela que se mantinha estável em torno de 145g. Quando foi incluída de volta a fêmea apresentou apenas a fase de diestro por todo o restante do período observado. 
E no dia 29/06/08 ela deu a luz a dois filhotes machos. Observou-se o estado vaginal e foi feito o esfregaço buscando-se visualizar estro pós-parto, o que não foi detectado. A fêmea estava com VS e em diestro. Assim como no dia seguinte ao nascimento, quando a vagina estava inchada, avermelhada e com presença de sangue no esfregaço vaginal. $O$ casal foi filmado no dia 29/6 por 1h, na tentativa de pegar o estro pós-parto.

$\mathrm{Na} 20^{\mathrm{a}}$ semana de experimento outro casal deu a luz a um filhote pesando $15 \mathrm{~g}$ no dia 25/07, a fêmea 4CF e macho 4CM. Nesta fêmea foi observado a ocorrência de VA cinco dias antes do parto estando em diestro com presença apenas de leucócitos e um pouco de muco.

Durante o acompanhamento do ciclo estral e abertura vaginal esta fêmea apresentou-se de forma cíclica para os estados vaginais, variando entre selado e aberto. O período observado com a vagina aberta variou entre um e cinco dias (em média 1,67 dia). Com um intervalo médio de cinco dias entre cada abertura (mínimo um e máximo 22 dias). Cerca de 90 dias antes do nascimento, a fêmea estava em uma fase de transição entre diestro e proestro com VS.

Outro casal deu a luz a filhote natimorto em 18/07/08, a fêmea 5CF alojada com o macho 5CM. No dia anterior ao parto, a fêmea estava com a vagina aberta e em diestro. $\mathrm{Na}$ coleta pós-parto, ela estava em diestro com a VA e com muito sangue.

O filhote era uma fêmea, pesando $14 \mathrm{~g}$ e que foi encontrada morta na gaiola ainda com o cordão umbilical preso a placenta, sem nenhum ferimento aparente. Não se observou estro nesta fêmea antes do nascimento, mas três meses antes do nascimento o esfregaço mostrou uma fase de transição entre diestro e proestro.

Este casal durante todo o experimento mostrou-se bastante particular apresentando resposta ao menor sinal de ruído na sala em que se encontram. A resposta era caracterizada por corridas em círculos na caixa, ficar parado em sinal de alerta e tamborilar no chão de gaiola. O macho é advindo de uma colônia com muitos casos de epilepsia, já a fêmea não. 


\subsubsection{Ciclo estral e abertura vaginal durante a gestação}

Durante os três meses de gestação, nas cinco fêmeas acompanhadas, se observa a ocorrência dos três estados vaginais (Figura 3.2 e Anexo 8). O estado vagina-selada (média $82 \%$ do tempo) foi o mais observado nos três meses. Durante o $1^{\circ}$ mês de gestação há um predomínio de vagina selada $(88,2 \%)$ com $5,9 \%$ de ocorrências de cada um dos estados vaginais selado e fechado. No segundo mês de gestação não se observa vagina fechada em nenhuma fêmea, ocorrendo $24 \%$ dos eventos de vagina aberta. Os valores observados no $3^{\circ}$ mês para o estado aberto estão próximos aos daqueles de quando as fêmeas não estão prenhas $10 \%$ grávidas, $12 \%$ não grávidas e vagina-selada com $84 \%$ e $70 \%$, respectivamente. Padrão diferente do que era esperado na nossa hipótese inicial de ocorrência somente de vagina fechada na gestação.

Figura 3.2. Estados vaginais das fêmeas grávidas durante os três meses de gestação ( $n=5)$

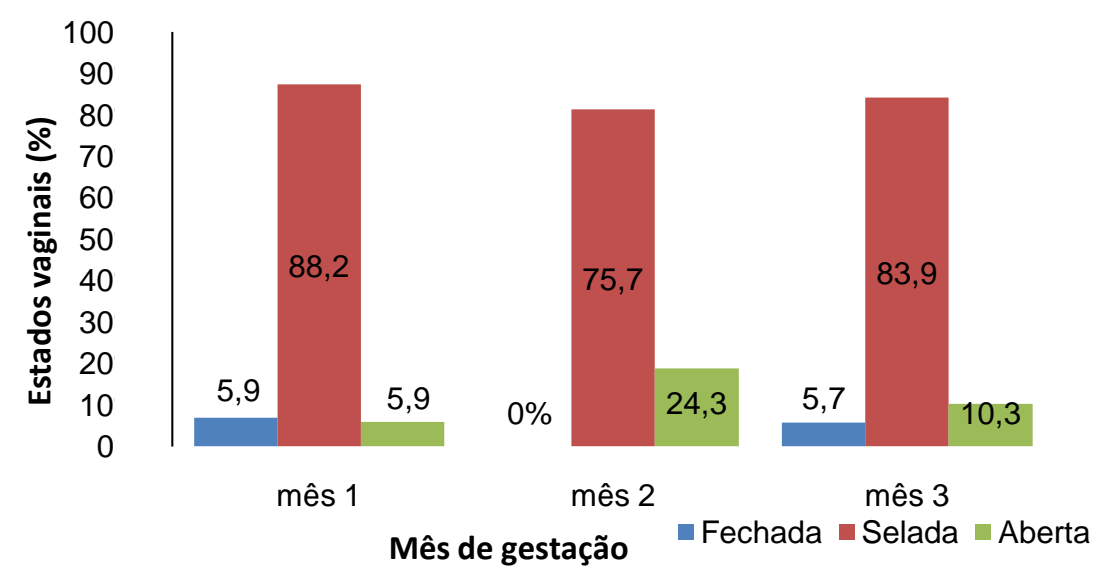

Ocorrências de metaestro foram observadas durante a gravidez, embora tenha ocorrido proestro e estro (figura 3.3). No primeiro mês há 3\% de ocorrência de metaestro; no segundo mês se observa $1 \%$ de cada uma das fases metaestro e não identificada; no terceiro mês há $1 \%$ 
de metaestro, observado quatro dias antes do nascimento da ninhada, respectivamente, o restante do tempo se observou a fase de diestro.

Figura 3.3. Fases do ciclo estral observadas nas fêmeas grávidas durante os três meses de gestação $(n=5)$

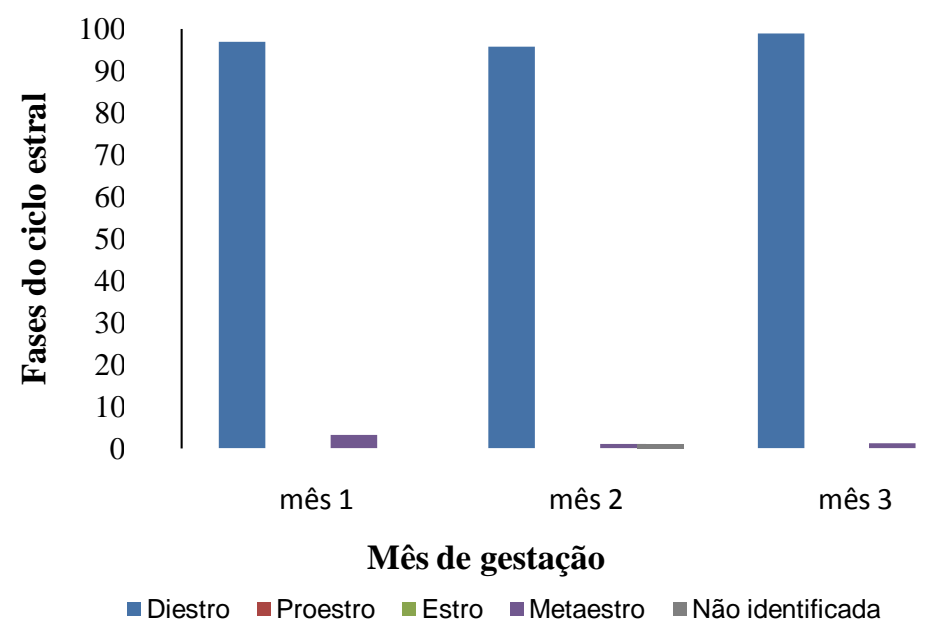

\subsubsection{O padrão de acasalamento}

A corte e acasalamento do rabo-de-facho mostraram-se violentos, com o macho mordendo e segurando a fêmea pelo pescoço quando montado sobre ela nos dois casais que foram filmados (denominados A e B).

Durante as filmagens foi possível observar a ocorrência de cópula pós-parto, no casal A onde o macho passou cerca de $77 \%$ do tempo exibindo comportamentos afiliativos, mesmo com a fêmea não interagindo com ele. A monta representou o maior investimento de tempo do macho para com a fêmea representando $34 \%$ do tempo, $17,8 \%$ ele a seguiu e passou $8 \%$ em grooming genital. Apenas $1 \%$ do tempo realizou monta com movimentos pélvicos (4 ocorrências, de duração média de 12,8 s), sendo que $80 \%$ delas foram seguidas de autolimpeza (grooming) genital, comportamentos indicativos de ejaculação.

No casal B a filmagem foi parcial, mas foi possível observar que o Macho B apresentou comportamentos afiliativos em $27 \%$ do tempo de observação. Sendo $20 \%$ do 
tempo em monta; $5 \%$ seguindo a fêmea; $1 \%$ em grooming genital; e apenas $2 \%$ em monta com movimentos pélvicos (uma ocorrência de duração de 2,24s), que também foi seguida de autolimpeza genital.

A duração das montas não seguiu um padrão crescente ou decrescente nos dois machos. No macho A o maior tempo montado sobre a fêmea foi de 94,8 s e o menor 1,7s. Esta ocorrência de menor tempo foi seguida de monta com movimentos pélvicos, e da monta de maior tempo. No macho B foram observados 22,9s e 1,37s (mediana 15,8s), que ocorreram em seguência, sendo estas, a segunda e terceira tentativas. Esta última(1,37s) seguida da monta com movimentos pélvicos.

As fêmeas passaram mais tempo em comportamentos não afiliativos, $61 \%$ fêmea A e $75 \%$ fêmea B. Quanto ao tempo dispensado nas categorias afiliativas a fêmea A passou 26\% do tempo se afastando do macho, $8 \%$ em grooming genital (assim como o macho) e apenas $1 \%$ do tempo se aproximando do macho. Já a fêmea B dispendeu $17 \%$ do seu tempo se afastando do macho, e 3\% se aproximando do macho, não foi possível observar grooming genital.

Tendo estes acasalamentos ocorridos num período pós-parto esperava-se observar um alto índice de contato com os filhotes tanto dos machos quanto das fêmeas, entretanto, isso não ocorreu, sendo muito baixa a frequência de contato com os filhotes nos dois casais (média 3,25 vezes). No casal A o macho ficou $5 \%$ do tempo com os filhotes e a fêmea $3 \%$. O macho B não exibiu contato com os filhotes e a fêmea passou com os filhotes apenas $2 \%$ do tempo de filmagem.

Observações prévias, mostram que o macho pode vocalizar e tamborilar para a fêmea durante a corte.Afêmea não tem a iniciativa do acasalamento. A corte é longa, sendo possível observar tentativas de monta do macho durante dias, quando a fêmea era devolvida a gaiola após a coleta do lavado vaginal. Ainda, reforçam a ocorrência de estro curto, uma vez que, se 
observa oacasalamento mesmo não se observando a fase de estro no esfregaço vaginal no perído pós-parto.

\subsubsection{Maturação sexual e reprodução da fêmea 080398 (6CF)}

Uma fêmea é acompanhada desde o nascimento neste projeto de pesquisa. Esta fêmea (6CF) nasceu em 12/2/2008, e ficou alojada com os pais e um irmão até os três meses de vida (12-17/5/2008) quando então foi separada. Aos 121 dias de vida (4 meses), já alojada numa gaiola individual em sala isolada da influência de machos, a fêmea apresentou o primeiro episódio de vagina selada. Passados 20 dias dessa observação (4,5 meses) a fêmea foi colocada em uma gaiola duna com um macho (6CM) para procriar (2/7/08). Mesmo não se observando proestro e estro ao redor dos 253 dias de vida (8,4 meses) ocorreu a fecundação de sua primeira ninhada (considerando-se a gestação de 90 dias). A presença do macho, portanto, não garantiu a fertilização da fêmea nos primeiros 122 dias (4 meses) alojados na mesma gaiola. Aos 343 dias de vida sua primeira ninhada nasceu (11,4 meses de vida - dia 19/01/2009), 90 dias após a fecundação.

Um dia após o nascimento do filhote, o esfregaço vaginal foi diestro com presença de espermatozóides e vagina selada com sangue. Passados 28 dias, novamente se observou presença de espermatozóides no esfregaço (Figura 3.4) e a segunda ninhada nasceu 93 dias depois (20/5/2009). 
Figura 3.4. Esfregaço vaginal com espermatozóides da fêmea 6CF em janeiro de 2009

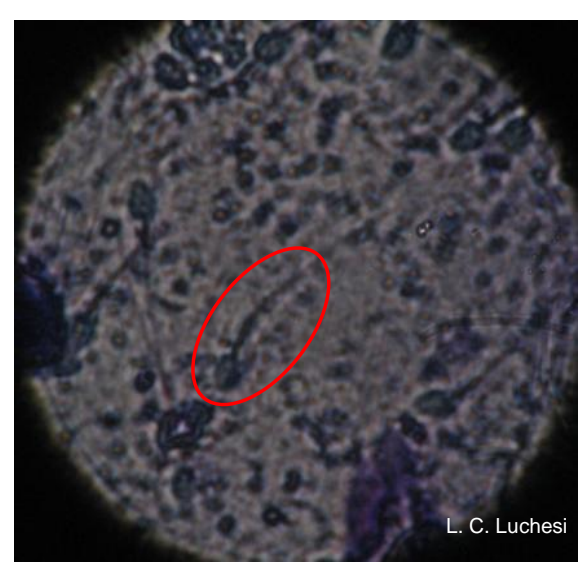

Em destaque espermatozóide

\subsection{Discussão}

A ocorrência de abertura vaginal esporadicamente durante a gestação já foi observada em outras espécies de roedores histricognatas, como no tuco-tuco e no degu, pertencentes à superfamília Octodontoidea (WoODS, 1993) assim como Trinomys yonenagae (WeIR, 1974). Em Lagostomus maximus Weir (1971a, apud WeIR 1974) observou que no segundo terço da gestação ( $62^{\circ}$ dia) há ocorrência de abertura vaginal. A maior ocorrência de vagina aberta e a ausência de fechada nas fêmeas de Trinomys yonenagae no $2^{\circ}$ terço da gestação estão de acordo com o observado anteriormente por Weir. Um padrão semelhante também foi observado por Ford (1951, apud WEIR, 1974) em Cavia porcellus, pertencente à outra superfamília de histricomorfa, a Cavioidea. Nesta espécie, 80\% dos animais também apresentam episódios de vagina aberta no segundo terço da gestação.

Muitos roedores apresentam estro pós-parto, dentre eles representantes dos histricognata, como a Cavia porcellus. O rabo-de-facho apresenta cópula pós-parto, o que indica a existência de estro, embora não tenha sido detectado no esfregaço vaginal (LUCHESI et al, 2007). Entretanto, especula-se que ele ocorra em um intervalo de até $24 \mathrm{~h}$ após o nascimento, uma vez que foi possível filmar o acasalamento nesse intervalo, e por 
observações dos nossos casais que apresentam intervalos entre ninhadas com um mínimo de três meses (MANAF et al, 2008; LUCHESI, et al 2009).

Em roedores sociais de hábito fossorial espera-se que a fêmea inicie a cópula (JARVIS, 1991; BENNETT \& JARVIS, 1988b apud BENNETT et al 2000). Entretanto, esse padrão não foi observado até o momento no rabo-de-facho. A fêmea não se mostra receptiva se distanciando do macho enquanto ele despende atenção à fêmea durante a maior parte das filmagens.

O macho dedica bastante energia na tentativa de copular e a fêmea passa cerca de $60 \%$ do tempo se esquivando dele. Os filhotes não recebem muita atenção de nenhum dos pais nesse momento (média de $1 \%$ do tempo das filmagens). As montas seguem um padrão irregular de tempo e a receptividade da fêmea não se altera durante elas, que permanece pouco tempo receptiva durante todo o período de filmagem.

O acasalamento segue o padrão dos histricomorfos com múltiplas intromissões durando de um a 95s (KLEIMAN,1974, VENANCIO et al, 2006). O Trinomys yonenagae como o gênero Proechimys relatado por Kleiman (1974) não apresenta marcação de urina na fêmea, aproximação bípede, ou o girar a cauda. Muitos parâmetros ainda não foram observados, portanto, não é possível afirmar que eles não ocorram, mas filmagens posteriores em conjunto com estudo da citologia esfoliativa ajudarão a compreender melhor o padrão reprodutivo do rabo-de-facho (T. yonenagae).

A gestação nesta espécie tem um período ao redor de 90 dias (LUCHESI, 2009), um período longo se considerar-se seu tamanho $(125 \mathrm{~g} \pm 33 \mathrm{~g})$. Longos períodos de gestação são associados a animais de grande porte; entre os roedores aqueles de maior tamanho são os caviomorfos, a capivara maior representante do grupo tem um período de gestação de 149 dias (ZARA, 1973, apud WEIR, 1974). Proechimys guairae, roedor da mesma família de Trinomys yonenagae apresenta gestação de 62 dias (WEIR, 1973b). 
O tamanho da prole nessa espécie também segue o padrão histricomorfa com ninhadas pequenas, ao redor de dois filhotes e filhotes precoces e o ganho de peso durante a gestação não permite a identificação de gravidez nos primeiros estágios.

A presença do macho numa mesma caixa não garante a fertilização da fêmea, mesmo com a ocorrência de estro pós-parto (LUCHESI et al, 2007), como na fêmea 6CF que permaneceu na mesma caixa que o macho por 120 dias sem ocorrência de gravidez.

Não se observa um padrão sazonal de reprodução, com filhotes nascendo em todas as estações do ano. Padrão já relatado na literatura para outros caviomorfos de clima tropical, como a Cavia aperea (TRILlmich, 2000). E na família Echimyidae sabe-se que Proechimys semispinosus (ADLER, 1997) também se reproduz de forma não sazonal.

Apesar de seu pequeno porte a espécie parece seguir o padrão de reprodução dos histricomorfa já discutido em detalhes por Kleiman (1974) e Weir (1974) e nesta espécie de forma parcial por Luchesi (2007 e 2009) e Manaf (2008). 


\subsection{Bibliografia}

ADLER, G. H.; BEATTY, R. P. Changing reproductive rates in a Neotropical forest rodent, Proechimys semispinosus. Journal of Animal Ecology, v. 66, n.4, pp. 472-480, 1997.

ALtMAnN, J. Observational study of behavior: sampling methods. Behaviour, v. 49, pp. 227267, 1974.

CRICHTON, E. Reproduction in pseudomyine rodent Mesembriomys gouldii (Gray) (Muridae). Australian Journal of Zoology, v. 17, pp. 785-797, 1969.

FELICIOLI, A., A. GRAZZINI, SANTINI, L. The mounting behaviour of a pair of crested porcupine Hystrix cristata L. Mammalia, v. 61, n.1, pp.119-123, 1997.

FORD, D. H.; WEBSTER, R. L.; YOUNG, W. C. Rupture of the vaginal closure membrane during pregnancy in the guinea-pig. Anatomic Record, v.109, pp. 707-714, 1951.

KLEIMAN, D. G. Patterns of behaviour in hystricomorph rodents. Symposia of the Zoological Society of London, n. 34, pp. 171-209, 1974.

LARA, M. C.; PATTON, J. L.; DA Silva, M. N. F. The simultaneous diversification of South American echimyid rodents (Hystricognathi) based on complete cytocrome b sequences. Molecular Phylogenetics and Evolution, v.5, pp. 403-413, 1996.

LARA, M. C.; PATTON, J. L. Evolutionary diversification of spiny rats (genus Trinomys, Rodentia: Echimyidae) in the Atlantic Forest of Brazil. Zoological Journal of the Linnean Society, v. 130, pp. 661-686, 2000.

LUCHESI, L. C.; MANAF, P.; SPINElli OliVEIRA, E. Caracterização comportamental do acasalamento pós-parto em Trinomys yonenagae. In: XXV Encontro Anual de Etologia 25 Anos, v. 25, p. 267, 2007.

LUCHESI, L. C.; SPINELLI OLIVEIRA, E. K selection in Trinomys yonenagae (Rodentia: Echimyidae). In: 46 $^{\text {th }}$ Meeting of the Animal Behavior Society. 22-26 June, 2009. Pirenópolis - Brazil, p. 104, 2009.

MANAF, P. Behavioral repertoire of Proechimys [Trinomys] yonenagae (Rodentia: Echimyidae) in captivity. Revista de Etologia, v. 2, n. 1, pp. 1-15, 2000.

MANAF, P; SPINELli OliVeira, E. Behavioral repertoire of the spiny rats Proechimys (Trinomys) yonenagae (Rodentia: Echimyidae) in captivity. Revista de Etologia, v.2, pp. 3$15,2000$. 
MANAF, P; SPINELLI OlIVEIRA, E. Reproductive parameters of the Brazilian caviomorph rodent Trinomys yonenagae (Rocha, 1995) in captivity. In: I Congreso Latinoamericano de Etologia Aplicada, p. 108, 2008.

OTTONi, E. B. Etholog 2.2 - A tool for the transcription and timing of behavior observations. Behavior Research Methods, Instruments, \& Computers, v. 32, n.3, pp. 446-449, 2000.

Sever e Mendelson, Sever, Z. \& Mendelssohn, H. Copulation as a possible mechanism to maintain monogamy in porcupines, Hystrix indica. Animal Behaviour, v.36, pp. 1541-1542, 1988.

SEVER, Z. \& MENDELSSOHN, H. The use of shelters by Indian porcupines (Hystrix indica). Israel Journal of Zoology, v.38, n. 3-4, p. 423, 1992.

RoBerTS, C. M.; WeIR, B. J. Implantation in the plains viscacha Lagostomus maximus. Journal of Reproduction and Fertility, v.33, pp. 333-360, 1973.

RoOD, J. P. Ecological and behavioral comparisons of three genera of Argentine cavies. Animal Behavior Monographs, v. 5, pp. 1-83, 1972.

TRILLMICH, F. Effects of low temperature and photoperiod on reproduction in the female wild guinea pig (Cavia aperea). Journal of Mammalogy, v. 81, n. 2, pp. 586-594, 2000.

Venancio, D. C.; Barbosa, L. P.; Ferreira, G. C. M.; Rodrigues, M. V.; Pires, V. B.; NeVES, M. M.; COElHo, C. D. P.; BorgeS, J. M. Estudo do comportamento reprodutivo de capivaras (Hydrochaeris Hydrochaeris) criadas em cativeiro. In: VII Semana de Iniciação Científica - PIC/UnilesteMG, 2006.

WEIR, B. J. The reproductive physiology of the plains viscacha, Lagostomus maximus. Journal of Reproduction and Fertility, v.24, pp. 355-363, 1971

WEIR, B. J. Another hystricomorph rodent: keeping casiragua (Proechimys gauairae) in captivity. Laboratory Animal, v.7, pp. 125-134, 1973 b.

Woods, C.A. Suborder Hystricognathi. In: Wilson, D.E., Reeder, D.M. (Eds.), Mammals Species of the World: A Taxonomic and Geographic Reference. Smithsonian Institution Press, Washington, pp. 771-806, 1993.

ZARA, J. L. Breeding and husbandry of capybara Hydrochoerus hydrochaeris, at Evansville Zoo. International Zoo Yearbook, v.13, pp. 137-139, 1973. 


\section{CAPÍtUlo IV - RITMO DE TEMPERATURA CORPORAL}

\subsection{Introdução}

A temperatura corporal $\left(\mathrm{T}_{\mathrm{c}}\right)$ apresenta um ritmo circadiano que se estabelece precocemente. Em Rattus norvegicus, por exemplo, é observado ao redor dos 24 dias de vida.

Este ritmo é bem conhecido em várias espécies e sabe-se que ele está em relação positiva de fase com o ritmo de atividade e repouso. Nos ratos Wistar, uma espécie noturna os picos de temperatura corporal são noturnos e em humanos, que são diurnos, os picos de temperatura são diurnos.

Em hamsters, o ciclo da temperatura ser um zeitgeber pode arrastar ciclos de atividade (Sulzman et al, 1977, Aschoff \& TOKURA, 1986; TOKURA \& OISHI, 1985, apud MARQUeS, 1997). O mesmo acontece em Octodon degus e nos gerbilos (Pachyuromys duprasi) que apresentam um robusto ritmo circadiano de temperatura (REFINETTI, 1998).

Em T. yonenagae o ritmo de temperatura é desconhecido apesar de ser um parâmetro de grande importância para a compreensão da biologia desse pequeno roedor, que habita o semi-árido, onde as temperaturas da superfície das dunas durante o dia são extremamente altas.

Sabe-se que o valor da $T_{c}$ dos rabos de facho pode ser significativamente reduzido (anapirexia) por aumento das concentrações de gás carbônico no sangue (hipercapnia), segundo resultados do LECO realizados em colaboração com o laboratório do Prof. L. G. S. Branco (BARROS et al, 1998). É importante se considerar que esses animais se abrigam em galerias, onde a concentração de gás carbônico pode estar elevada em comparação com a concentração encontrada em ambientes abertos e mais ventilados.

Em inúmeras espécies de mamíferos ocorre uma variação da $T_{c}$ durante o ciclo estral. Essa relação está estabelecida em várias espécies de roedores Sciurognathi. Entre os Caviomorpha esta associação é conhecida em Octodon degus (LABYAK, 1995). 
É justificável, portanto, a investigação da ritmicidade da temperatura corporal em $T$. yonenagae.

\subsection{Objetivos}

Os objetivos desse estudo são identificar e caracterizar o ritmo de temperatura corporal no roedor Trinomys yonenagae.

\subsection{Material e Métodos}

\subsubsection{Animais}

Foram estudadas 16 fêmeas alojadas em gaiolas individuais, nascidas no biotério do LECO, que foram colocadas em sala sem influência de machos por pelo menos três meses antes das medidas.

Os animais foram divididos em dois grupos contendo oito fêmeas cada (grupos A e B). O grupo A também pertence ao experimento sobre ciclo estral e o B apenas participa desse experimento.

\subsubsection{Manutenção}

As fêmeas foram mantidas em gaiolas individuais de propileno em sala isolada da influência de machos, como apresentado na parte introdutória, e com temperatura controlada $\left(22 \pm 1,4^{\circ} \mathrm{C}, \mathrm{UR} 67 \pm 4,8 \%\right)$.

\subsubsection{Procedimento e equipamentos do estudo do ritmo de temperatura corporal}

Para conhecer o padrão do ciclo de temperatura de $T$. yonenagae fêmeas alojadas individualmente foram estudadas durante 72 horas. As coletas foram realizadas em janelas de 3 horas. O delineamento transversal (cada indivíduo representa um ponto de coleta) foi 
utilizado como medida para minimizar a manipulação dos animais e, com isso, diminuir erros de interpretação do padrão rítmico dessa espécie.

A temperatura corporal foi obtida através de um termômetro digital (BD, DT 203, importado por Becton Dickinson Indústrias cirúrgicas Ltda.) inserido no reto das fêmeas. Este protocolo foi testado em um projeto-piloto com 20 fêmeas e verificou-se a viabilidade e reprodutibilidade do procedimento experimental.

Foram analisados os seguintes parâmetros: porcentagem rítmica, mesor, amplitude do ritmo e acrofase de acordo com NELSON et al, 1979. Primeiramente analisaram-se os dados nos dois grupos, A e B, em separado e depois unindo todos os animais se fez uma análise geral.

\subsubsection{Análise dos dados}

A análise do padrão do ritmo de temperatura corporal foi feita pelo ajuste dos dados a uma curva co-seno através do software Cossana (BENEDITO-SiLvA, 1996). Os horários apresentados referem-se ao horário do Zeitgeber (ciclo claro-escuro do Biotério) assim 0h ZT corresponde ao início da fase de claro (02:00h) e 12h ZT ao início da fase de escuro (14:00h).

\subsection{Resultados}

4.4.1 Ritmo de temperatura nos dois grupos de fêmeas

Nas oito fêmeas do grupo $\mathrm{A}$, a $\mathrm{T}_{\mathrm{c}}$ apresenta um padrão circadiano altamente significativo $p=0,002$, com porcentagem rítmica de 45,01\%. A acrofase $(\varphi)$ do ritmo de temperatura é observada na primeira metade da fase de escuro $17 \mathrm{~h} 11 \mathrm{~min} \mathrm{ZT}\left(35,4 \pm 0,55^{\circ} \mathrm{C}\right)$ e a temperatura média (mesor) é de $33,93 \pm 0,16^{\circ} \mathrm{C}$. Valores semelhantes aos reportados por Barros (1998) com variação 33,4 a $35,7^{\circ} \mathrm{C}$, menores do que é conhecido para outros roedores. A figura 4.1 mostra a oscilação da temperatura, o mesor, os valores medidos e os ajustados à 
curva co-seno em $24 \mathrm{~h}$, a barra negra representa a fase de escuro e a clara, o claro (ver também Anexo 9).

Figura 4.1 Oscilação de temperatura nas fêmeas do grupo A $(\mathrm{n}=8)$ de Trinomys yonenagae em 24 horas. A barra preta representa a fase de escuro

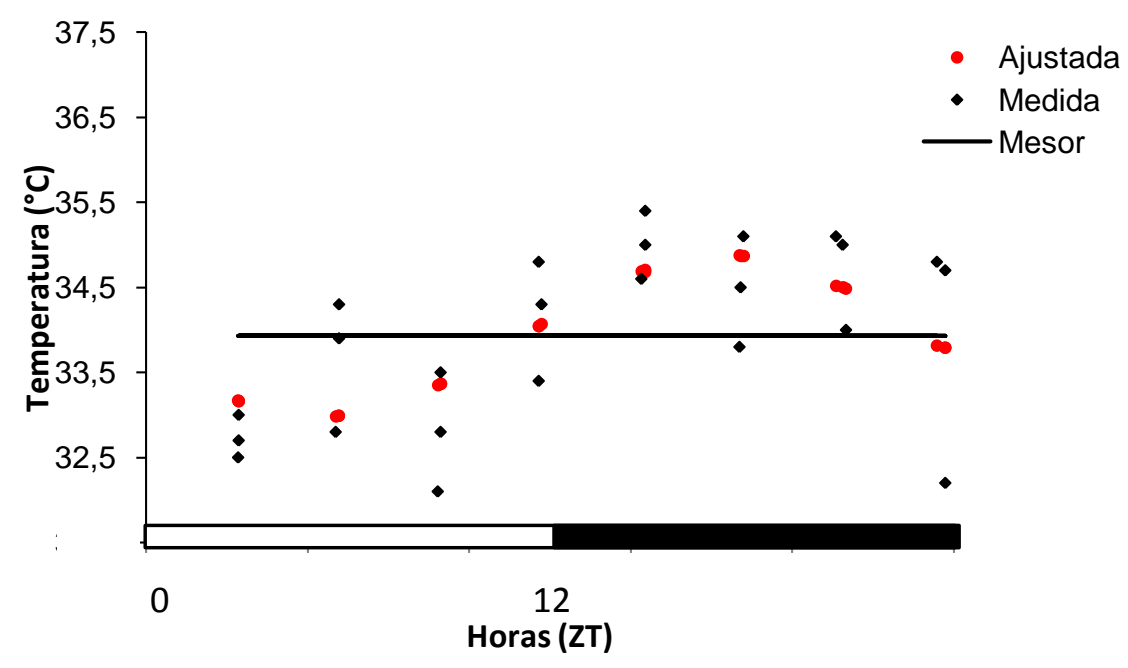

Figura 4.2 Oscilação de temperatura nas fêmeas do grupo B $(\mathrm{n}=8)$ de Trinomys yonenagae em 24 horas. A barra preta representa a fase de escuro

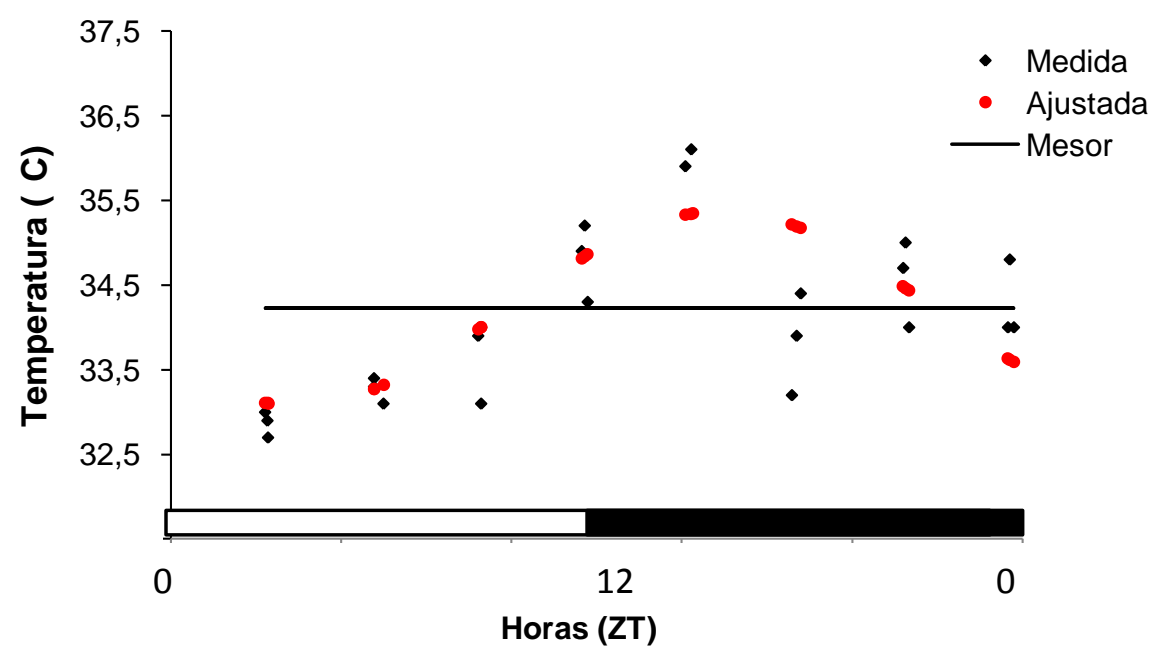

Para o grupo B (figura 4.2), a porcentagem rítmica foi 48,42\%; $\mathrm{p}=0,001$. A amplitude do ritmo de temperatura nessas 8 fêmeas foi de $1,14 \pm 0,26^{\circ} \mathrm{C}$, com mesor de $34,23{ }^{\circ} \mathrm{C}$. Como no grupo $\mathrm{A}$, temperaturas baixas se comparadas a outros roedores. A acrofase ocorreu às $15 \mathrm{~h} 30 \mathrm{~min} . \mathrm{ZT}$ duas horas antes do que a observada no grupo A (17h11 min). 
O padrão de temperatura nesta espécie parece ter dois picos noturnos, um que começa com o aumento gradual da $\mathrm{T}_{\mathrm{c}}$ no início da fase escura, atingindo o valor máximo no meio da noite e o segundo pico na segunda metade da fase de escuro (figuras 4.1 e 4.2 e anexo 9).

\subsubsection{Ritmo de temperatura geral}

A figura 4.3 apresenta o padrão de temperatura obtido das 16 fêmeas que participaram deste estudo sendo, portanto, uma união dos dados obtidos. O padrão circadiano de temperatura mostrou-se de forma robusta (porcentagem rítmica 43,52\%; $\mathrm{p}=0,001$ ), a acrofase foi observada às $16 \mathrm{~h} 15 \mathrm{~min}$. ZT. A amplitude do ritmo foi de $1,02 \pm 0,17{ }^{\circ} \mathrm{C}$, com mesor de $34,08 \pm 0,12{ }^{\circ} \mathrm{C}$. Valores que ficam entre os obtidos em cada um dos grupos separadamente.

Figura 4.3 Oscilação de temperatura das fêmeas de Trinomys yonenagae $(\mathrm{n}=16)$ em 24 horas. A barra preta representa a fase de escuro

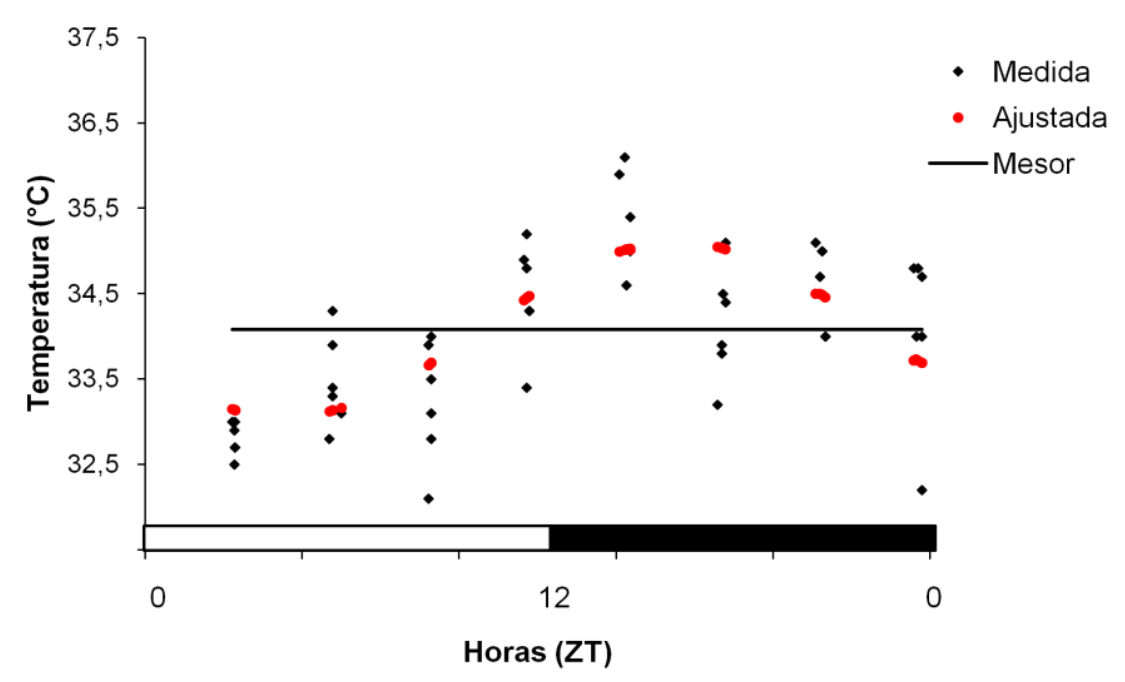

\subsection{Discussão}

O ritmo de temperatura corporal em geral, segue o mesmo padrão que o ritmo de atividade. Sabe-se que apresenta relação de fase positiva com o ritmo de atividade e repouso. 
Os gerbilos apresentam acrofase na fase escura com uma variação de $3^{\circ} \mathrm{C}$ ao longo do dia e amplitude de $2^{\circ} \mathrm{C}$, assim como foi observado nas fêmeas de Trinomys yonenagae. Castilho e colaboradores (2005) estudando duas linhagens de camundongos Mus musculus, roedores Sciurognathi que fazem dois tipos de ninhos, grandes ou pequenos, observou que a temperatura corporal média é de $36,72 \pm 0,07^{\circ} \mathrm{C}$ no primeiro grupo e $36,90 \pm 0,21^{\circ} \mathrm{C}$, no segundo. A amplitude do ritmo também é diferente nestes dois grupos, sendo de 1,95 \pm 0,05 e $2,31 \pm 0,08^{\circ} \mathrm{C}$, respectivamente. Estes valores de amplitude são semelhantes aos que foram observados nas fêmeas de rabo-de-facho $\left(1,02 \pm 0,17^{\circ} \mathrm{C}\right)$. Essa variação de $\mathrm{T}_{\mathrm{c}}$ ao longo do dia está de acordo com o que é conhecida na literatura para mamíferos, uma variação diária entre $1^{\circ}-4^{\circ} \mathrm{C}($ BROWN, 2002).

Além do ritmo de claro/escuro sabe-se que o ritmo de temperatura também é ajustado pelo ritmo de atividade e repouso. Estudos com o roedor crepuscular Octodon degus (KAS, 2001) mostraram que o ritmo de temperatura corporal em livre curso é de 23,39h. Quando há acesso a uma roda de atividade (um Zeitgeber) durante um intervalo fixo de tempo ele é ajustado para um período de 24h. Labyak (1995) estudando a mesma espécie de roedor mostrou que a temperatura e o ritmo de atividade estão em relação positiva de fase e que ainda, a $\mathrm{T}_{\mathrm{c}}$ é mais elevada nas fases de proestro e estro do que nas outras fases do ciclo estral, o que ainda não foi estudado em T. yonenagae.

Nos rabos-de-facho os ritmos de temperatura e atividade/repouso mostraram-se sincronizados, com uma correlação positiva de fase, uma vez que o pico de atividade desses animais ocorre na metade da fase escura, às 18h36min ZT (MARCOMINI, 2003), com o ritmo de atividade antecedido em uma hora pelo pico de temperatura (17h11min ZT). O padrão rítmico observado nas fêmeas de T. yonenagae está de acordo com o exposto por Kas (2001) para $O$. degus, um histricognata, da família Octodontidae, que como os Echimyidae fazem parte dos Octodontoidea. 
A diferença entre os dois grupos de fêmeas quanto à acrofase e a amplitude pode ser conseqüência limitante da metodologia adotada, uma vez que, o método transversal não permite um acompanhamento da expressão rítmica dentro dos limites da variabilidade intraindividual.

Embora os valores de temperatura observados nesta espécie estejam abaixo dos conhecidos para outras espécies de roedores, como já relatado por Barros (1998), Trinomys yonenagae segue o mesmo padrão rítmico e de oscilações que os ritmos conhecidos para outras espécies de roedores noturnos, apresentando picos noturnos de temperatura corporal. 


\subsection{Bibliografia}

AsCOFF. J.; ToKURA, H. Circadian Activity Rhythms in Squirrel Monkeys: Entrainment by temperature Cycles. Journal of Biological Rhythms, v.1, pp-91-100, 1986.

BARROS, R. C. H.; OliveIRA, E. S.; RochA, P. L. B.; BRANCO, L. G. S. Respiratory and metabolic responses of the spiny rats Proechimys yonenagae and Proechimys iheringi to $\mathrm{CO}_{2}$. Respiration Physiology, v. 111, pp. 223-231, 1998.

Brown, S. A.; Zumbrunn, G.; Fleury-Olela, F.; Preitner, N.; Schibler, U. Rhythms of mammalian body temperature can sustain peripheral circadian clocks. Current Biology, v. 12, 1574-1583, 2002.

CAstillo, M. R.; Hochstetler, K. J.; Greene, D. M.; Firmin, S. I.; TAVERnier, R. J.; RAAP, D. K.; BulT-ITO, A. Circadian rhythm of core body temperature in two laboratory mouse lines. Physiology \& Behavior, v. 86, 538-545, 2005.

KAS, M. J. H.; EDGAR, D. M. Scheduled voluntary wheel running activity modulates freerunning circadian body temperature rhythms in Octodon degus. Journal of Biological Rhythms, v. 16, n.1, 66-75, 2001

LABYAK, S. E.; LEE, T. M. Estrus and steroid-induced changes in circadian rhythms in a diurnal rodent, Octodon degus. Physiology \& Behavior, v. 58, n. 3, 573-585, 1995.

MARComini, M.; SPINELli OliveIRA, E. Activity pattern of echimyid rodent species from the Brazilian Caatinga in captivity. Biological Rhythm Research v. 34, pp. 157-166, 2003.

Marques, M. D.; GolombeK, D.; Moreno, C. Adaptação temporal. In: Marques, N. \& MennA-BARRETo, L. (orgs). Cronobiologia: Princípios e aplicações. São Paulo, EDUSP/FioCruz, 2003, pp. 55-98.

NELSON, W.; TONG, Y. L.; LEE, J. K.; HALBERG, F. Methods for cosinor-rhythmometry. Chronobiologia, v. 6, 305-323, 1979.

REFINETTI, R. Homeostatic and Circadian control of body temperature in the fat-tailed gerbil. Comparative Biochemistry and Physiology, v.119A, n. 1, 295-300, 1998.

Sulzman, F. M.; Fuller, C. A.; MoORE-EdE, C. Environmental synchronizers of Squirrel Monkey Circadian rhythms. Journal of Applied Physiology, v. 43, pp.795-806, 1977.

TOKURA, H.; OISHI, T. Circadian locomotor activity rhythm under the influences of temperature cycle in the Djungarian Hamnster, Phodopus sungorus, entrained by 12 hours light-12 hour dark cycle. Comparative Biochemistry and Physiology, v.81A, pp. 271-275, 1985 . 


\section{CONCLUSÕES FINAIS}

Os resultados apresentados trazem novas e importantes informações para o conhecimento da biologia desse roedor de ambiente semi-árido. Pode-se então concluir que:

A VA não necessariamente indica o estado de estro tendo sido observadas ocorrências de VA+diestro; VA+proestro; VS+proestro. Os pesquisadores de campo devem, portanto, ser cautelosos ao utilizar este critério como indicativo de atividade reprodutora em rabos-defacho.

Embora marque o início da vida reprodutiva o estado vaginal não pode ser usado como único indicativo de atividade reprodutiva uma vez que, há raras coincidências de vagina aberta com as fases de proestro ou estro (fases reprodutivas).

As fases de proestro e metaestro são curtas, com menos de um dia de duração. A fase de estro é inferior à $24 \mathrm{~h}$, pois houve dificuldade de observá-la mesmo realizando coleta de material poucas horas após ter sido observado um proestro (oito ocorrências). Tendo sua ocorrência confirmada também pela observação de gestações seguidas.

O ciclo estral parece ser espontâneo nas fêmeas de T. yonenagae uma vez que, observou-se ocorrência de estro em fêmeas em sala livre da influência de macho. E a duração do ciclo estral é variável. Das 26 fêmeas nenhuma apresentou regularidade do ciclo estral, independente das condições de alojamento (individual, pareada com fêmea ou pareada com macho). A existência de um co-específico influencia o ciclo estral, podendo ate chegar ao ponto de inibi-lo (dupla de irmãs). Além disso, existem diferenças no ciclo de fêmeas alojadas em gaiola individual ou pareada com outra fêmea quanto à frequência de observação das fases do ciclo e dos estados vaginais.

T. yonenagae apresenta estro pós-parto. E apesar de haver atividade reprodutiva a presença do macho não garante a gravidez uma vez que, foi possível observar casais em que o intervalo entre o nascimento de duas ninhadas foi 591 dias. 
Em roedores em que o estro é curto o período de corte é longo e elaborado, como pudemos observar nos rabo-de-facho. As fêmeas não apresentam a iniciativa do acasalamento, padrão observado em roedores sociais e fossoriais. O comportamento de acasalamento, com tentativas de monta e contato naso-anal por parte do macho são observados no início da gravidez.

Durante a gestação a vagina pode estar episodicamente aberta, com predomínio do estado vagina selada $\mathrm{O}$ ganho de peso na fêmea só é perceptível no último mês. Além disso, a gestação tem duração de aproximadamente 90 dias, com ninhadas pequenas. Não se observando efeito de sazonalidade em cativeiro, com nascimentos espalhados ao longo do ano. Seguindo o que está na literatura de campo sobre esta espécie.

E para encerrar, Trinomys yonenagae apresenta um ritmo circadiano de temperatura corporal em sincronia com o ritmo de atividade/repouso, acrofase na fase escura.

Os resultados sugerem que esta espécie segue o padrão da família Echimyidae, como gestação longa e ciclo estral longo e de duração variável sem relação com o estado vaginal. A presença de co-específicos influencia a reprodução em Trinomys yonenagae modulando o ciclo estral, e que a temperatura corporal apresenta um ritmo circadiano com picos noturnos de acordo com o seu ritmo de atividade, uma vez que, a espécie que vive nas dunas de areia da Caatinga se encontra ativa durante a noite. 


\section{BIBLIOGRAFIA}

AB'SABER, A. N. Províncias geológicas e domínios morfoclimáticos no Brasil.

Geomorfologia, v.20, pp. 1-26, 1970.

AB'SABER, A. N. O domínio morfoclimático semi-árido das caatingas brasileiras.

Geomorfologia, São Paulo, 1974.

ASCHOFF, J. Die 24-Stunden-Periodik der Maus unter kontanten Umweltbedingungen.

Naturwissenschaften, n. 35, pp. 2326-2332, 1951.

Tierische Periodik unter der aktivitätsperiodik bei Mäusen in Dauerdunkel und

Dauerlicht. Arc. Ges. Physiol., v. 255, pp. 197-203.

Barros, R. C. H.; Oliveira, E. S.; Rocha, P. L. B.; BranCO, L. G. S. Respiratory and metabolic responses of the spiny rats Proechimys yonenagae and Proechimys iheringi to $\mathrm{CO}_{2}$. Respiration Physiology, v. 111, pp. 223-231, 1998.

Benedito-Silva, A. A. Programa Cossana para Análise Ritmo métrica de Séries Temporais Individuais. Version 3.1, 1996.

Bennett, N. C.; FAulKes, C. G.; Molteno, A. J. Reproduction in subterranean rodents. In: LACEY, E. A.; PATTON, J. L.; CAMERON, G. N. (eds.) Life underground: the biology of subterranean rodents. Chicago University Press; 2nd Ed, pp. 145-177, 2000.

BENNETT, N. C.; JARVIS, J. U. M. The social structure and reproductive biology of colonies of the mole-rat Cryptomys damarensis (Rodentia: Batergidae). Journal of mammalogy, v. 69, pp.293-302, 1988 b.

Bergallo, H. G. Comparative life-history characteristics of two species of rats, Proechimys iheringi and Oryzomys intermedius, in an Atlantic Forest of Brazil. Mammalia, v. 59, n. 1, pp. 51-64, 1995.

Carleton, M. D.; Musser, G. G. Order Rodentia. In: Wilson, D. E. \& ReEder, D. M. (eds.). Mammal Species of the World: A Taxonomic and Geographic Reference. $3^{\text {rd }}$ ed. Baltimore: The Johns Hopkins University Press, pp. 745-752, 2005.

DAVIDSON, A. J. Search for the feeding-entrainable circadian oscillator: a complex proposition. American Journal of Physiology Regulatory, Integrative and comparative Physiology, v. 290, pp. R1524-R1526, 2006.

Dias-Munoz, M.; VaZQueZ-Martinez, O.; Aguilar-Roblero, R.; Escobar, C. Anticipatory changes in liver metabolism and entrainment of insulin, glucagon, and corticosterone in food-restricted rats. American Journal of Physiology. Regulatory Integrative and Comparative Physiology, v. 279 pp. 2048-2056, 2000. 
EMMONS, L. H. Neotropical rainforest mammals (A field guide). Chicago, the University of Chicago Press, 1997, 307p.

EscobAR, C.; DíAZ-MunõZ, N.; EnCINAS, F; AguILAR-Roblero, R. Persistence of metabolic rhythimicity during fasting and its entrainment by restricted feeding schedules in rats. The American Journal of Physiology, v. 274, pp. 1309-1316, 1998.

FONSECA, A. P. Comparação do comportamento de ingestão de sacarina, sacarose e frutose em roedores de Caatinga e Mata Atlântica. 1998. 54p. Monografia (Iniciação Científica) - Departamento de Biologia da Faculdade de Filosofia, Ciências e Letras de Ribeirão Preto, Universidade de São Paulo, São Paulo, 1998.

Freitas, J. N. S.; El-HAni, C. N.; RochA, P. B. L. Affiliation in the Torch Tail Rat, Trinomys yonenagae (Rodentia: Echimyidae), a Sand-dwelling rodent from Brazilian Semiarid Caatinga: Evolutionary Implications. Revista de Etologia, v.5, n.2, pp. 61-73, 2003.

Affiliation in four Echimyid rodent species based on intrasexual dyadic encounters: evolutionary implications. Ethology, v.114, pp. 389-397, 2008.

Freitas, J. N. S.; Carvalho, L. A. da S.; El-Hani, C., N.; Rocha, P. L.B. Affiliation in the social interactions in captivity of the torch tail rat, Trinomys yonenagae (Rodentia: Echimyidae). Journal of Ethology, v. 28, n.1, pp. 105-112, 2010.

Galewski T, J; Mauffrey, J-F.; Leite, Y. L. R.; PAtTon, J. L.; DouZery, E. J. P. Ecomorphological diversification among South American spiny rats (Rodentia; Echimyidae): a phylogenetic and chronological approach. Molecular Phylogenetics and Evolution, v. 34, n. 3, pp. 601-615, 2005.

GolombeK, D.; CARdinali, D.; Aguilar-Roblero, R. Mecanismos de temporarização em vertebrados. In: MARQues, N. \& MENnA-BARRETO, L. (orgs). Cronobiologia: Princípios e aplicações. São Paulo, EDUSP/FioCruz, 2003, pp. 163-190.

Groot, J. De. The rat forebrain in Stereotaxic coordenates. Trans Royal Neth Academy of Sciences, v. 52, n. 4, 1959.

HILDEBRAND, M. Digging of quadrupeds. In: HiLdEBRAND, M.; LIEM, K. F. \& WAKE, D. B. (eds.). Functional vertebrate morphology. London: Belknap Press, pp 89-109, 1985.

HuCHON, D; DouZERY, E. J. P. From the Old World to the New World: A Molecular Chronicle of the Phylogeny and Biogeography of Hystricognath Rodents. Molecular Phylogenetics and Evolution, v. 20, n. 2, pp. 238-251, 2001.

IWASAKI, H.; DUNLAP, J.C. Microbial circadian oscillatory systems in Neurospora and Synechococcus: models for cellular clocks. Current Opinion in Microbiology, v. 3, 189196, 2000. 
JARVIS, J. U. M. Reproduction of the naked mole-rats. In: SHERMAN, P. W.; JARVIS, J. U. M.; ALEXANDER, R. D. (eds.) The biology of the naked mole-rat. Princeton, NJ: Princeton University Press, pp. 384-426, 1991.

KLEIMAN, D. G. Patterns of behaviour in hystricomorph rodents. In: RowlandS W. I.; WEIR B. (Orgs.). The biology of hystricomorph rodents. London: Academic Press, pp.171-209, 1974.

KONDO, T.; ISHIURA, M. The circadian clock of cyanobacteria. BioEssays , v.22, pp. 10-15, 2000 .

LARA, M. C.; PAtTON, J. L.; DA Silva, M. N. F. The simultaneous diversification of South American echimyid rodents (Hystricognathi) based on complete cytocrome b sequences. Molecular Phylogenetics and Evolution, v.5, pp. 403-413, 1996.

LARA, M. C.; PATTON, J. L. Evolutionary diversification of spiny rats (genus Trinomys, Rodentia: Echimyidae) in the Atlantic Forest of Brazil. Zoological Journal of the Linnean Society, v. 130, pp. 661-686, 2000.

MACDONALD, D. (ed.). The encyclopedia of mammals. Facts on File: Andromeda Oxford Limited, 4. reimpressão, 1995, 895p.

MANAF, P.; Spinelli OliveIRA, E. Roedores com cheiro de tutti-frutti. Ciência hoje, v. 38, pp. 68-70, 2006.

Female choice in Trinomys yonenagae, a spiny rat from the Brazilian Caatinga.

Revista Brasileira de Zoociências, v. 11, n. 3, pp. 200-207, 2009.

Behavioral repertoire of the spiny rats Proechimys (Trinomys) yonenagae (Rodentia:

Echimyidae) in captivity. Revista de Etologia, v.2, pp. 3-15, 2000.

MANAF, P. Efeitos do bloqueio de receptores opióides sobre o comportamento social de Trinomys yonenagae (Rodentia: Echimyidae) em cativeiro. 2005, 104p. Tese (Doutorado em psicologia) - Instituto de Psicologia da Universidade de São Paulo, Núcleo de pesquisa em Neurociência e Comportamento, São Paulo, 2005.

Estudo do comportamento social de uma população de Proechimys yonenagae (Rodentia: Echimyidae) em cativeiro. 2000, 114p. Dissertação (Mestrado em psicologia) Instituto de Psicologia, Universidade de São Paulo, São Paulo, 2004.

MANAF, P.; BRITO-GITIRANA, L.; SPINELLI OlIVEIRA, E. Evidence of chemical communication in the spiny rat (Trinomys yonenagae, Echimyidae): anal scent gland and social interactions.

Canadian Journal of Zoology, v. 81, pp. 1-6, 2003 (b). 
Manaf, P.; Morato, S.; SPinelli Oliveira, E. Profile of wild Neotropical spiny rats (Trinomys, Echimyidae) in two behavioral tests. Physiology \& Behavior, v. 79, pp. 129-133, 2003 (a).

MARComini, M. Cronobiologia de duas espécies de Trinomys (Rodentia, Echimyidae). 2004. 73p. Dissertação (Mestrado em psicologia) - Instituto de Psicologia, Universidade de São Paulo, São Paulo, 2004.

MARCOMIni, M.; SPINELli OliveIRA, E. Activity pattern of echimyid rodent species from the Brazilian Caatinga in captivity. Biological Rhythms Research v. 34, pp. 157-166, 2003.

MARCONATO, D. A. Escavação de tocas e armazenamento de alimentos: suas implicações na biologia de espécies filogeneticamente próximas de ratos-de-espinho neotropicais (Rodentia: Echimyidae). 2003. 81p. Dissertação (Mestrado em psicologia) - Instituto de Psicologia, Universidade de São Paulo, São Paulo, 2003.

Mares, M. A.; OJeDA, R. A. Patterns of diversity and adaptation in South American histricognath rodents. In: MARES, M. A.; GEnOwAYs, H. H. (ed.) Mammalian biology in South America, University of Pittsburgh, Pymatuning Laboratory of Ecology, pp. 393-432, 1982.

MARES, M. A.; WiLling, M. R.; STREILEIN, K. E.; LACHER, T. E., JR. The mammals of Northeastern Brazil: a preliminary assessment. Annals of Carnegie Museum, v. 50, n. 4, pp. 81-237, 1981.

Marques, N.; Menna-Barreto, L. (orgs). Cronobiologia: Princípios e aplicações. São Paulo, EDUSP/FioCruz, 2003.

MARTIN, T. Schmelzmikrostruktur in den Inzisiven alt-und neuweltlicher hystricognather Nagetiere. Paleovertebrata, Montpellier, Mémoire Extraordinaire, pp. 1-168, 1992.

MENDES, L. A. F. Estudo da Biologia de Roedores Silvestres Brasileiros: aspectos do balanço hídrico e do consumo alimentar. 1998. 67p. Monografia (Iniciação Científica) Departamento de Biologia da Faculdade de Filosofia, Ciências e Letras de Ribeirão Preto, Universidade de São Paulo, São Paulo, 1998.

Mistlberger, R. E.; SKENE, D. J. Social influences on mammalian circadian rhythms: animal and human studies. Biological Reviews of the Cambridge Philosophical Society, v. 79, pp. 533-556, 2004.

Moore-Ede, M. C.; Sulzaman, F. M.; Fuller, C. A. The clocks that time us. Harvard University Press, Cambridge, 1982, p. 448.

MONEIA, N. M. Comentários sobre a biologia de Trinomys yonenagae com observações sobre o seu ciclo estral. 2004, 37p. Monografia (Iniciação Científica) - Departamento de 
Biologia da Faculdade de Filosofia, Ciências e Letras de Ribeirão Preto, Universidade de São Paulo, Ribeirão Preto, 2004.

NeVes, E. L.; VianA, B. F. Comunidade de machos de Euglossinae (Hymenoptera: Apidae) das matas ciliares da margem esquerda do Médio Rio São Francisco, Bahia. Anais da Sociedade Entomológica Brasileira, v.28, n.2 [online], Londrina, pp201-210, 1999.

NEVES, E. S. Avaliação de risco de predação e comportamento de tamborilar em Trinomys yonenagae (Rodentia: Echimyidae). Dissertação (Mestrado) - Instituto de Biologia, Universidade Federal da Bahia, 49p. 2007.

NOWAK, R. M. Walker's mammals of the world. Baltimore. The Johns Hopkins University Press, v. 2, 6. ed., 1629p, 1999.

Oliveira SPINElli, E.; CoIMBRA, T. M.; RochA, P. L. B. Determinação de alguns parâmetros fisiológicos do roedor Proechimys sp. In: X Reunião Anual da Federação de Sociedades de Biologia Experimental - FeSBE, São Paulo, 1995.

PERRY, S. F.; SPINELli OlIVEIRA, E. Respiration in a changing environment. Respiratory Physiology \& Neurobiology, 2010. No prelo.

RIBEIRO, M. F. S. Encéfalos de espécies de roedores Trinomys de diferentes habitats e seu correlato ecoetológico. 2004. 48p. Dissertação (Mestrado em psicologia) - Instituto de Psicologia, Universidade de São Paulo, São Paulo, 2004.

RochA, P. L. B. Ecologia e morfologia de uma nova espécie de Proechimys (Rodentia: Echimyidae) das dunas interiores do rio São Francisco (BA). 1992. Dissertação (Mestrado em zoologia) - Depto. de Zoologia do Instituto de Biociências da Universidade de São Paulo, São Paulo,154p. 1992.

Proechimys yonenagae, a new species of spiny rat (Rodentia: Echimyidae) from fossil sand dunes in the Brazilian Caatinga. Mammalia, v. 59, n. 4, pp. 537-549, 1995.

Rocha, P. L. B; Renous, S. AbOuRAChID, A.; HöFling, E. Evolution toward asymmetrical gaits in Neotropical spiny rats (Rodentia: Echimyidae): evidences favoring adaptation.

Canadian Journal of Zoology (Online), v. 85, pp. 709-717, 2007.

Rodrigues, M. T. Herpetofauna das dunas interiores do Rio São Francisco, Bahia, Brasil. I. Introdução à área e descrição de um novo gênero de microteídeo (Calyptommatus) com notas sobre sua ecologia, distribuição e especiação (Sáuria, Teiidae). Papéis Avulsos de Zoologia, v. 37, n. 20, pp. 321-327, 1991. 
REIS, A. C. S. Contribuição ao conhecimento das floras nordestinas. Rodriguesia, v.41, pp. 137-193, 1976.

RoDRIGUES, M. T. Lizards, Snakes, and Amphisbaenians from the Quaternary Sand Dunes of the Middle Rio São Francisco, Bahia, Brazil. Journal of Herpetology, v. 30, n. 4, pp. 513523, 1996.

RotenberG, L.; MARQues, N.; Menna-BARReto, L. História e perspectivas da cronobiologia. In: Marques, N.; Menna-BarReto, L. (orgs). Cronobiologia: Princípios e aplicações. São Paulo, EDUSP/FioCruz, pp. 31-53, 2003.

SAntos, E. M. R. Teor de água em itens disponíveis a Proechimys yonenagae (Rodentia:Echimyidae) das dunas interiores do rio São Francisco com discussão da evolução do balanço hídrico no gênero. 1997, 49p. Trabalho de conclusão de curso, Universidade Federal da Bahia, Salvador, 1997.

SANTOS, J. W. A. Ecologia da socialidade do roedor psamófilo Trinomys yonenagae (Rodentia: Echimyidae) em uma área das dunas do rio São Francisco na caatinga. 2004. 119p. Dissertação (Mestrado) - Instituto de Biociências, Universidade de São Paulo, São Paulo. 2004.

SCHMIDT-NIELSEN, K. Desert animals: Physiological problems of heat and water. Dover Publications. New York. 1964.

SPINELli OliVEIRA E, Social behavior of spiny rats (Trinomys, Echimyidae) that differ with respect to habitat. Revista de Etologia, v. 5, pp. 24-25, 2003.

SPinelli Oliveira, E.; Perry, S. F.; Monea, N. M.; Barbosa, F. L.; LuChesi, L. C. Does vaginal opening coincide with reproductive activity in a dune-living spiny rat? In:

Comparative Biochemistry and Physiology Part A: Molecular \& Integrative Physiology, n. 148, Suplement 1, S22, 2007.

VARLINSKA, E. I.; SPEAR, L. P.; SPEAR, N. E. Social behavior and social motivation in adolescent rats: role of housing conditions and partner's activity. Physiology \& Behavior, v. 67, pp. 475-482, 1999.

VIVO, M. DE. Mammalian evidence of historical ecological change in the Caatinga semiarid vegetation of northeastern Brazil. Journal of Comparative Biology, v.2, pp. 65-73, 1997.

WEIR, B. J. Reproductive characteristics of hystricomorph rodents. Symposium of Zoological Society of London. n. 34, p. 265-301, 1974.

Wilson, D. E. \& REEDER, D. M. (eds.). Mammal Species of the World: A Taxonomic and Geographic Reference. $3^{\text {rd }}$ ed. Baltimore: The Johns Hopkins University Press, 2005. 
Wood, A. E. Eocene radiation and phylogeny of the rodents. Evolution, v. 13, pp. 354-361, 1959.

Wood, A. E. The relationship, origin and dispersal of the Hystricognathous rodents. In: LUCKETT, W. P.; HARTENBERGER, J. L. Evolutionary relationship among rodents: a multidisciplinary analysis. New York: Nato ASI series A: Life Sciences, v. 92, 1985.

YounG, M. W. Life's 24-hour clock: molecular control of circadian rhythms in animal cells Trends in Biochemical Sciences, v. 25, n.12, pp. 601-606, 2000.

ZAR, J. H., Biostatistical analysis. 3 ed., New Jersey: Prentice-hall. Inc., 1996, 662p.

$\underline{\text { Redigido de acordo com as diretrizes: }}$

ASSOCIAÇÃO BRASILEIRA DE NORMAS TÉCNICAS. NBR 6023: Informação e documentação: Referência -Elaboração; Rio de Janeiro, 2002.

NBR 10520: Informação e documentação: citações em documentos - apresentação. Rio de Janeiro, 2002.

NBR 6024: Informação e documentação - Numeração progressiva das seções de um documento escrito - Apresentação, Rio de Janeiro, 2003.

MALERBO, M. B. Referências e citações bibliográficas: Manual de orientação, Ribeirão Preto, PCARP - USP (Serviço de Biblioteca e documentação), 1996.

UNIVERSIDADE DE SÃo PAUlo. Sistema Integrado de bibliotecas. Grupo DiTesis. In: FuRANO, V.M. B. de O. (coord.). Diretrizes para apresentação de dissertações e teses da USP: documento eletrônico e impresso. São Paulo: SIBi-USP, 110p., 2004. 
Anexos 
Anexo 1 - Descrição do grupo de fêmeas de Trinomys yonenagae que participam do experimento de idade da abertura vaginal (AV)

Tabela 1. Grupo de fêmeas que tiveram a idade da abertura vaginal acompanhada $\quad n=12$

\begin{tabular}{lcccc}
\hline Gaiola & $\begin{array}{c}\mathbf{n}^{\mathbf{0}} \\
\text { experimental }\end{array}$ & animal & mãe & Pai \\
\hline 21 & 1 & 060370 & 020222 & 010207 \\
22 & 2 & 060372 & 030281 & 030273 \\
23 & 3 & 060376 & 010211 & 010199 \\
24 & $4 \mathrm{e}$ & 070390 & 010211 & 010199 \\
25 & $5 \mathrm{e}$ & 070394 & 060381 & 060380 \\
26 & 6 & 070395 & 020222 & 010207 \\
27 & $7 \mathrm{e} 6 \mathrm{c}$ & 080398 & 030284 & 030272 \\
28 & 8 & 080405 & 020233 & 030292 \\
29 & 9 & 090446 & 060381 & 060380 \\
30 & 10 & 090447 & 080398 & 030311 \\
31 & 11 & 090451 & 080398 & 030311 \\
32 & 12 & 090456 & 020233 & 030292 \\
\hline
\end{tabular}

Tabela 2. Idade da AV em Trinomys yonenagae acompanhada desde o nascimento $\quad(n=12)$

\begin{tabular}{cccccc}
\hline \multirow{2}{*}{ Fêmea } & \multirow{2}{*}{ Nascimento } & Data & \multirow{2}{*}{ AV } & \multicolumn{2}{c}{ Idade na abertura } \\
& & abertura & & Meses & Dias \\
\hline 1 & $29 / 3 / 2006$ & $21 / 7 / 06$ & $\mathrm{~S}$ & 3,5 & 105 \\
2 & $22 / 5 / 2006$ & $28 / 8 / 06$ & $\mathrm{~S}$ & 2,5 & 75 \\
3 & $31 / 5 / 2006$ & $21 / 9 / 06$ & $\mathrm{~S}$ & 3,0 & 90 \\
4 & $31 / 10 / 2007$ & $14 / 2 / 08$ & $\mathrm{~S}$ & 3,5 & 105 \\
5 & $27 / 11 / 2007$ & $3 / 3 / 08$ & $\mathrm{~S}$ & 3,1 & 94 \\
6 & $17 / 12 / 2007$ & $18 / 2 / 08$ & $\mathrm{~A}$ & 2 & 61 \\
7 & $12 / 2 / 2008$ & $12 / 6 / 08$ & $\mathrm{~S}$ & 4 & 121 \\
8 & $25 / 7 / 2008$ & $22 / 10 / 08$ & $\mathrm{~S}$ & 3 & 89 \\
9 & $7 / 1 / 2009$ & $1 / 4 / 09$ & $\mathrm{~S}$ & 2,8 & 84 \\
\hline
\end{tabular}


Anexo 2 - Descrição dos animais utilizados no estudo do ciclo estral (EV) e abertura vaginal (AV) de acordo com o grupo experimental ao qual pertencem

Tabela 3. Grupo A fêmeas alojadas com fêmeas nn=12

\begin{tabular}{cccccc}
\hline Gaiola & $\mathbf{N}^{\mathbf{o}}$ & Animal & Mãe & Pai & Parentesco \\
\hline 1 & $1 \mathrm{DA}$ & 050356 & $030284 \mathrm{D} 13 / \mathrm{C} 3$ & $030272 \mathrm{C} 1 / \mathrm{D} 13$ & irmãs \\
& $1 \mathrm{DB}$ & 050357 & $030284 \mathrm{D} 13 / \mathrm{C} 3$ & $030272 \mathrm{C} 1 / \mathrm{D} 13$ & \\
2 & 2DA & 050358 & $000189 \mathrm{E} \mathrm{D} 13$ & $990167 \mathrm{C} 3$ & irmãs \\
& 2DB & 050359 & $000189 \mathrm{E} \mathrm{D} 13$ & $990167 \mathrm{C} 3$ & irmãs \\
3 & 3DA & 060378 & $010211 \mathrm{C} 1 / \mathrm{D} 13$ & $010199 \mathrm{C} 3$ & não irmãs \\
& 3DB & 060379 & $010211 \mathrm{C} 1 / \mathrm{D} 13$ & $010199 \mathrm{C} 3$ & não irmãs \\
& 4DA & 030297 & $010201 \mathrm{C} 1$ & $010207 \mathrm{E} \mathrm{D13/C2}$ & \\
& 4DB & 030298 & 960034 & 960019 & não irmãs \\
\hline
\end{tabular}

E - animal com epilepsia; $C n$ colônias originárias: $\mathrm{D} n$ duna originária

Tabela 4. Grupo B fêmeas alojadas sozinhas nas gaiolas $\quad n=8$

\begin{tabular}{|c|c|c|c|c|c|}
\hline Gaiola & $\mathbf{N}^{\mathbf{o}}$ & Animal & Mãe & Pai & Histórico \\
\hline 7 & $7 \mathrm{I}$ & 030263 & $960030 \mathrm{C} 1$ & $960038 / 970009 \mathrm{C} 1$ & Já esteve com + \\
\hline 8 & $8 \mathrm{I}$ & 060371 & $030284 \mathrm{D} 13 / \mathrm{C} 3$ & 030272 C3/D13 & Isolada aos $3 \mathrm{~m}$ \\
\hline 9 & 9I & 070390 & $010211 \mathrm{C} 1 / \mathrm{D} 13$ & 010199 C3 & Isolada aos $3 \mathrm{~m}$ \\
\hline 10 & $10 \mathrm{I}$ & 070394 & 060381C1/C4 & $060380 \mathrm{C} 1 / \mathrm{C} 4$ & Isolada aos 3m; pais irmãos \\
\hline 11 & $11 \mathrm{I}$ & 010208 & 000189E D13 & $990167 \mathrm{C} 3$ & Já esteve $\mathrm{c} / \hat{\sigma}$ \\
\hline 12 & $12 \mathrm{I}$ & 070387 & $030284 \mathrm{D} 13 / \mathrm{C} 3$ & 030272 C3/D13 & Esteve com irmão até $6 \mathrm{~m}$ de vida \\
\hline 13 & $13 \mathrm{I}$ & 070385 & $010211 \mathrm{C} 1 / \mathrm{D} 13$ & 010199 C3 & Esteve com irmão ate $6 \mathrm{~m}$ de vida \\
\hline 14 & 14I & 040329 & $030271 \mathrm{C} 5 / \mathrm{C} 2$ & $030272 \mathrm{D} 13 / \mathrm{C} 3$ & Esteve na sala com $\hat{\jmath}$ \\
\hline
\end{tabular}

E- Animal com epilepsia; $\mathrm{C} n$ colônias originárias: $\mathrm{D} n$ duna originária 
Tabela 5. Grupo C fêmeas alojadas em casal

$\mathrm{n}=6$

\begin{tabular}{ccccccccc}
\hline Gaiola & $\mathbf{N}^{\mathbf{0}}$ & Fêmea & Mãe & Pai & Macho & $\mathbf{N}^{\mathbf{0}}$ & Mãe & Pai \\
\hline $1 \mathrm{C}(15)$ & $1 \mathrm{CF}$ & 020250 & $000190 \mathrm{C} 1$ & $000188 \mathrm{D} 13$ & $010209 \mathrm{E}$ & $1 \mathrm{CM}$ & $000193 \mathrm{C} 1$ & $000177 \mathrm{C} 4$ \\
$2 \mathrm{C}(16)$ & $2 \mathrm{CF}$ & 030284 & $010196 \mathrm{D} 13$ & $010205 \mathrm{C} 3$ & 030272 & $2 \mathrm{CM}$ & $010211 \mathrm{C} 1 / \mathrm{D} 13$ & $010199 \mathrm{C} 3$ \\
3C (17) & $3 \mathrm{CF}$ & 060381 & $030281 \mathrm{C} 1$ & $030273 \mathrm{C} 3 / \mathrm{D} 13$ & 060380 & $3 \mathrm{CM}$ & $030281 \mathrm{C} 1$ & 030273 \\
$4 \mathrm{C}(18)$ & $4 \mathrm{CF}$ & 020233 & $9700071 \mathrm{C} 4$ & $970020 \mathrm{C} 4$ & $030292 \mathrm{E}$ & $4 \mathrm{CM}$ & $000193 \mathrm{C} 1$ & $000177 \mathrm{C} 4$ \\
$5 \mathrm{C}(19)$ & $5 \mathrm{CF}$ & 050365 & $010201 \mathrm{C} 1$ & $010199 \mathrm{C} 3$ & 030285 & $5 \mathrm{CM}$ & $010203 \mathrm{C} 1 / \mathrm{C} 5$ & $030266 \mathrm{D} 13 / \mathrm{C} 3$ \\
$6 \mathrm{C}(20)$ & $6 \mathrm{CF}$ & 080398 & $030284 \mathrm{D} 13 / \mathrm{C} 3$ & $030272 \mathrm{C} 3 / \mathrm{D} 13$ & 030311 & $6 \mathrm{CM}$ & $030281 \mathrm{C} 1$ & $030276 \mathrm{C} 3 / \mathrm{D} 13$ \\
\hline
\end{tabular}

E - Animal com epilepsia; $\mathrm{C} n$ colônias originárias: $\mathrm{D} n$ duna originária

Fêmea 080398 inserida no experimento a partir de julho /08

O código Do animal é dado pelo número da gaiola seguido de código de alojamento: D

duplas, seguido de A $e \mathbf{B}$ para identificação intra-dupla; I fêmeas alojadas individualmente; e

$\mathbf{C}$ animais alojados em casal, seguido de $\mathbf{F}$ para fêmea e $\mathbf{M}$ para macho. 
Anexo 3 - Dados do ciclo estral das fêmeas alojadas em duplas $(n=12)$

Tabela 6. Porcentagem das fases do ciclo estral nas fêmeas alojadas em duplas (grupo A) durante o $1^{\circ}$ semestre de observação (março-ago/2008)

\begin{tabular}{cccccc}
\hline Dupla & Fêmea & $\mathbf{D}$ & $\mathbf{P}$ & $\mathbf{E}$ & $\mathbf{M}$ \\
\hline \multirow{2}{*}{$\mathbf{1}$} & 1DA & 99 & 0 & 0 & 1 \\
& 1DB & 0 & 0 & 0 & 0 \\
\hline \multirow{2}{*}{$\mathbf{2}$} & 2DA & 97 & 1 & 0 & 2 \\
& 2DB & 100 & 0 & 0 & 0 \\
\hline \multirow{2}{*}{$\mathbf{3}$} & 3DA & 97 & 3 & 0 & 0 \\
& 3DB & 100 & 0 & 0 & 0 \\
\hline \multirow{4}{*}{$\mathbf{4}$} & 4DA & 100 & 0 & 0 & 0 \\
& 4DB & 81 & 2,5 & 2,5 & 12 \\
\hline \multirow{2}{*}{5} & 5DA & 92 & 4 & 0 & 4 \\
& 5DB & 80 & 2 & 2 & 16 \\
\hline \multirow{2}{*}{6} & 6DA & 88 & 7 & 0 & 5 \\
& 6DB & 96 & 0 & 0 & 4 \\
\hline D- Diestro; P-Proestro; E-Estro; M-Metaestro
\end{tabular}

Tabela 7. Porcentagem dos estados vaginais nas fêmeas alojadas em duplas (grupo A) durante o $1^{\circ}$ semestre de observação (março-ago/2008)

\begin{tabular}{ccccc}
\hline Dupla & Fêmea & $\mathbf{F}$ & $\mathbf{S}$ & $\mathbf{A}$ \\
\hline \multirow{2}{*}{1} & 1DA & 1,1 & $\mathbf{9 6}$ & 3,2 \\
& 1DB & $\mathbf{1 0 0}$ & 0 & 0 \\
\hline \multirow{2}{*}{2} & 2DA & 6,5 & $\mathbf{8 8}$ & 5,4 \\
& 2DB & $\mathbf{9 8}$ & 2,2 & 0 \\
\hline \multirow{2}{*}{3} & 3DA & 5,4 & $\mathbf{9 1}$ & 3,2 \\
& 3DB & $\mathbf{8 2}$ & 16 & 2,2 \\
\hline \multirow{2}{*}{4} & 4DA & $\mathbf{6 9}$ & 29 & 2,2 \\
& 4DB & 13 & $\mathbf{8 0}$ & 7,5 \\
\hline \multirow{2}{*}{5} & 5DA & $\mathbf{7 0}$ & 27 & 3,2 \\
& 5DB & 2,2 & $\mathbf{9 5}$ & 3,2 \\
\hline \multirow{2}{*}{6} & 6DA & $\mathbf{5 6}$ & 44 & 0 \\
& 6DB & 42 & $\mathbf{5 8}$ & 0 \\
\hline
\end{tabular}

F- Fechada; S-Selada; A-Aberta Em destaque estado vaginal mais observado em cada fêmea. E aquela que apresentou somente vagina fechada 
Anexo 4 - Tabelas com frequência dos eventos do ciclo estral nas fêmeas alojadas em gaiolas individuais $(\mathrm{n}=8)$

Tabela 8. Fases do ciclo estral, em porcentagem, de fêmeas alojadas em gaiolas individuais (grupo B), $1^{\circ}$ semestre de observação (março-ago/08); $2^{\circ}$ semestre (set-março/09)

\begin{tabular}{|c|c|c|c|c|c|c|c|c|c|}
\hline \multirow{2}{*}{ Fêmea } & \multicolumn{4}{|c|}{$1^{\circ}$ semestre } & \multicolumn{4}{|c|}{$2^{\circ}$ semestre } & \multirow{2}{*}{$\begin{array}{c}\text { Total } \\
\%\end{array}$} \\
\hline & D & $\mathbf{P}$ & $\mathbf{E}$ & $\mathbf{M}$ & D & $\mathbf{P}$ & $\mathbf{E}$ & $\mathbf{M}$ & \\
\hline 7I & 100 & 0 & 0 & 0 & 100 & 0 & 0 & 0 & 0 \\
\hline $8 \mathrm{I}$ & 91 & 9 & 0 & 0 & 92 & 8 & 0 & 0 & 8 \\
\hline 9I & 88 & 6 & 0 & 7 & 97 & 3 & 0 & 0 & 8 \\
\hline 10I & 80 & 10 & 1 & 8 & 91 & 7 & 1 & 1 & 15 \\
\hline 11I & 77 & 0 & 0 & 23 & 98 & 0 & 0 & 2 & 9 \\
\hline 12I & 87 & 7 & 2 & 4 & 95 & 4 & 0 & 1 & 9 \\
\hline 13I & 92 & 2 & 1 & 4 & 98 & 0 & 1 & 1 & 6 \\
\hline 14I & 80 & 7 & 2 & 11 & 95 & 4 & 0 & 1 & 4 \\
\hline
\end{tabular}

Observações feitas no $1^{\circ}$ semestre (março a agosto) diariamente ou em dias intercalado; no $2^{\circ}$ semestre (agosto a abril) em intervalos de 2 a 4 dias. Fases: Diestro (D), Proestro (P), Estro (E), Metaestro (M). Total: porcentagem total de eventos não-diestro. Em destaques o $\%$ de estro observado em cada fêmea.

Figura 4.1. Estados vaginais nas fêmeas alojadas em gaiolas individuais (grupo B) no $1^{\circ}$ (março-agosto/08) e $2^{\circ}$ (setembro-abril) semestres

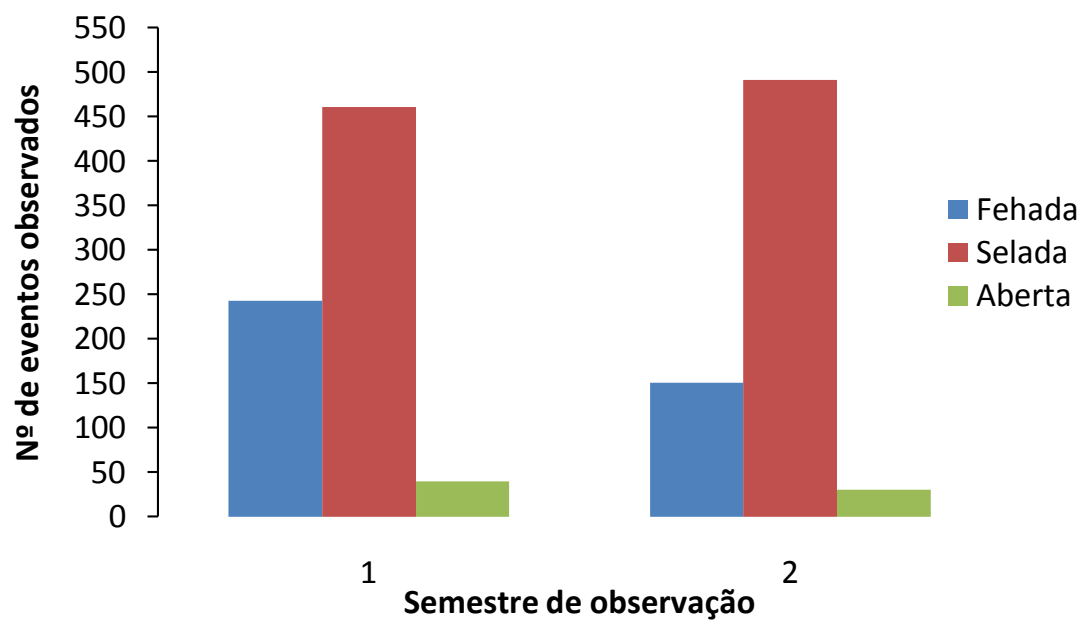


Anexo 5 - Tabelas com frequência dos eventos do ciclo estral nas fêmeas alojadas com machos $(\mathrm{n}=6)$

Tabela 9. Frequência de estados vaginais de fêmeas alojadas com machos quando fora do período de gravidez no $1^{\circ}$ semestre de observação (março-ago/2008); $2^{\circ}$ semestre (setembro-março)

\begin{tabular}{ccccc|cccc}
\hline \multirow{2}{*}{ Fêmea } & \multicolumn{3}{c|}{$\mathbf{1}^{\mathbf{0}}$ Semestre } & \multirow{2}{*}{ Total } & \multicolumn{2}{|c}{$\mathbf{2}^{\mathbf{0}}$ Semestre } & \multicolumn{2}{c}{ Total } \\
& $\mathrm{F}$ & $\mathrm{S}$ & $\mathrm{A}$ & & $\mathrm{F}$ & $\mathrm{S}$ & $\mathrm{A}$ & \\
\hline $1 \mathrm{CF}$ & 5 & $\mathbf{8 3}$ & 5 & 93 & 4 & 58 & 3 & 65 \\
2CF & 10 & 48 & 1 & 59 & 10 & 54 & 1 & 65 \\
$3 \mathrm{CF}$ & 0 & 10 & 1 & 11 & 5 & 59 & 1 & 65 \\
$4 \mathrm{CF}$ & 0 & 19 & 16 & 35 & 16 & 46 & 4 & 66 \\
$5 \mathrm{CF}$ & 1 & 33 & 3 & 37 & 4 & 58 & 2 & 64 \\
$6 \mathrm{CF}$ & 16 & 193 & 26 & $*$ & 21 & 42 & 2 & 65 \\
\hline
\end{tabular}

Observações feitas no $1^{\circ}$ semestre (março a agosto) diariamente ou em dias intercalado; no $2^{\circ}$ semestre (agosto a abril) em intervalos aleatórios Total: porcentagem total de eventos por fêmea fora da gravidez. * Fêmea $6 \mathrm{Cf}$ incluída em julho de 2008. 
Anexo 6 - Descrição do grupo de fêmeas de Trinomys yonenagae que participam do experimento

Tabela 10. Grupo de fêmeas alojadas em casal (grupo C experimento AV e EV) que tiveram a gestação acompanhada

$\mathrm{n}=5$

\begin{tabular}{ccccc}
\hline Gaiola & $\mathbf{N}^{\mathbf{0}}$ & Fêmea & Macho & $\mathbf{N}^{\mathbf{o}}$ \\
\hline $2 \mathrm{C} \mathrm{(16)}$ & $2 \mathrm{CF}$ & 030284 & 030272 & $2 \mathrm{CM}$ \\
$3 \mathrm{C} \mathrm{(17)}$ & $3 \mathrm{CF}$ & 060381 & 060380 & $3 \mathrm{CM}$ \\
$4 \mathrm{C} \mathrm{(18)}$ & $4 \mathrm{CF}$ & 020233 & $030292 \mathrm{E}$ & $4 \mathrm{CM}$ \\
$5 \mathrm{C} \mathrm{(19)}$ & $5 \mathrm{CF}$ & 050365 & 030285 & $5 \mathrm{CM}$ \\
$6 \mathrm{C} \mathrm{(20)}$ & $6 \mathrm{CF}$ & 080398 & 030311 & $6 \mathrm{CM}$ \\
\hline \multicolumn{5}{c}{ E- Animal com epilepsia }
\end{tabular}

Tabela 11. Grupo de fêmeas alojadas em casal que tiveram a gestação acompanhada a partir do histórico do biotério

\begin{tabular}{|c|c|c|c|c|}
\hline Gaiola & $\mathbf{N}^{\mathbf{o}}$ & Animal & Macho & $\mathbf{N}^{\mathbf{o}}$ \\
\hline$*$ & $7 \mathrm{CF}$ & 990169 & 000192 & $7 \mathrm{CM}$ \\
\hline$*$ & $8 \mathrm{CF}$ & 000189 & 990167 & $8 \mathrm{CM}$ \\
\hline$*$ & $9 \mathrm{CF}$ & 000190 & 000188 & $9 \mathrm{CM}$ \\
\hline$*$ & $10 \mathrm{CF}$ & 000193 & 000177 & $10 \mathrm{CM}$ \\
\hline * & $11 \mathrm{CF}$ & 010211 & 010199 & $11 \mathrm{CM}$ \\
\hline$*$ & $12 \mathrm{CF}$ & 030281 & $\begin{array}{c}030276 / 030273 / \\
000177\end{array}$ & $12 \mathrm{CM}$ \\
\hline$*$ & $13 \mathrm{CF}$ & $\begin{array}{c}960012 \\
\text { col }\end{array}$ & 960016 & $13 \mathrm{CM}$ \\
\hline$*$ & $14 \mathrm{CF}$ & $\begin{array}{c}960030 \\
\text { col }\end{array}$ & $960038 / 970009$ & $14 \mathrm{CM}$ \\
\hline$*$ & $15 \mathrm{CF}$ & $\begin{array}{c}960034 \\
\text { col }\end{array}$ & 960019 & $15 \mathrm{CM}$ \\
\hline
\end{tabular}

O código Do animal é dado pelo número da gaiola seguido de código de alojamento em casal $\mathbf{C}$, seguido de $\mathbf{F}$ para fêmea e $\mathbf{M}$ para macho. 
Anexo 7 - Histórico de nascimentos no biotério

Fêmeas que participam do experimento do ciclo estral e que tiveram os nascimentos acompanhados pela experimentadora

Tabela 12. Nascimentos, intervalo entre ninhadas, $n^{\circ}$ de filhotes e relação macho:fêmea da fêmea $2 \mathrm{CF}(030284)$

\begin{tabular}{|c|c|c|c|c|c|c|c|c|}
\hline Fêmea & Macho & Ninhadas & $\begin{array}{c}\text { Inter. } \\
\text { (d) }\end{array}$ & $\begin{array}{c}\mathbf{N}^{\mathbf{0}} \\
\text { filhotes }\end{array}$ & \multicolumn{2}{|c|}{ Identificação } & Macho & Fêmea \\
\hline \multirow{12}{*}{030284} & \multirow{9}{*}{030272} & $13-20 / 7 / 05$ & - & 2 & f050356 & f050357 & 0 & 2 \\
\hline & & 28/4/06 & 283 & 1 & f060371 & & 0 & 1 \\
\hline & & $3 / 10 / 06$ & 158 & 2 & $\mathrm{~m} 060382$ & $\mathrm{~m} 060383$ & 2 & 0 \\
\hline & & $25 / 5 / 07$ & 234 & 2 & $\mathrm{~m} 070386$ & $\mathrm{~m} 07387$ & 2 & 0 \\
\hline & & $12 / 2 / 08$ & 263 & 2 & f080398 & m080399 & 1 & 1 \\
\hline & & $24 / 9 / 08$ & 210 & 2 & $\mathrm{~m} 080406$ & f080407 & 1 & 1 \\
\hline & & $23 / 12 / 08$ & \multirow{3}{*}{91} & & $\mathrm{~m} 080413$ & $\mathrm{~m} 080414$ & \multirow{2}{*}{3} & \multirow{2}{*}{1} \\
\hline & & & & 4 & $\mathrm{~m} 080415$ & f080416 & & \\
\hline & & $15 / 7 / 09$ & & 1 & m090427 & & 1 & 0 \\
\hline & & & Total & 15 & & Total & 9 & 6 \\
\hline & & & Média & 2,0 & & $\%$ & 60 & 40 \\
\hline & & & Dp & 0,9 & & & & \\
\hline
\end{tabular}

f -fêmea; m- macho; ?- sexo desconhecido

Tabela 13. Nascimentos, intervalo entre ninhadas, $n^{\circ}$ de filhotes e relação macho:fêmea da fêmea 3 CF (060381)

\begin{tabular}{|c|c|c|c|c|c|c|c|c|c|}
\hline Fêmea & Macho & Ninhadas & $\begin{array}{c}\text { Inter. } \\
\text { (d) }\end{array}$ & $\begin{array}{c}\mathrm{N}^{\mathbf{o}} \\
\text { filhotes }\end{array}$ & \multicolumn{3}{|c|}{ Identificação } & Macho & Fêmea \\
\hline \multirow{8}{*}{060381} & \multirow{5}{*}{060380} & $27 / 11 / 07$ & - & 2 & m 070393 & f070394 & \multirow{5}{*}{ m 080410} & 1 & 1 \\
\hline & & $29 / 6 / 08$ & 215 & 2 & m 080403 & m080404 & & 2 & 0 \\
\hline & & 2/10/08 & 95 & 3 & f 080408 & \multirow{2}{*}{ m080409 } & & 2 & 1 \\
\hline & & 7/1/09 & 97 & 1 & f 090417 & & & 0 & 1 \\
\hline & & $17 / 6 / 09$ & 161 & 2 & m090424 & $\mathrm{m} 090425$ & & 2 & 0 \\
\hline & & & Total & 8 & & & Total & 7 & 3 \\
\hline & & & Média & 2 & & & $\%$ & 87,5 & 37,5 \\
\hline & & & dp & 0,7 & & & & & \\
\hline
\end{tabular}

Tabela 34. Nascimentos, intervalo entre ninhadas, $n^{\circ}$ de filhotes e relação macho:fêmea da fêmea 3CF (020233)

\begin{tabular}{ccccccccc}
\hline \multirow{2}{*}{ Fêmea } & \multirow{2}{*}{ Macho } & Ninhadas & $\begin{array}{c}\text { Inter. } \\
\text { (d) }\end{array}$ & $\begin{array}{c}\mathbf{N}^{\mathbf{0}} \\
\text { filhotes }\end{array}$ & Identificação & Macho & Fêmea \\
\hline \multirow{2}{*}{020233} & \multirow{2}{*}{030292} & $25 / 7 / 08$ & - & 1 & $\mathrm{f} 080405$ & & 0 & 1 \\
& $22 / 6 / 09$ & & 1 & f090426 & & 0 & 1 \\
\hline & & & Total & 2 & & Total & 0 & 2 \\
& & & Média & 1 & & $\%$ & 0 & 100 \\
\hline
\end{tabular}


Tabela 15. Nascimentos, intervalo entre ninhadas, $n^{\circ}$ de filhotes e relação macho:fêmea da fêmea $5 \mathrm{CF}(050365)$

\begin{tabular}{|c|c|c|c|c|c|c|c|c|}
\hline Fêmea & Macho & Ninhadas & $\begin{array}{c}\text { Inter. } \\
\text { (d) }\end{array}$ & $\begin{array}{c}\mathrm{N}^{\mathbf{0}} \\
\text { filhotes }\end{array}$ & \multicolumn{2}{|c|}{ Identificação } & Macho & Fêmea \\
\hline \multirow[t]{5}{*}{050365} & 030285 & 18/7/08 & - & 1 & natimorta & & 0 & 1 \\
\hline & & $25 / 5 / 09$ & & 2 & m090422 & $\mathrm{m} 090423$ & 2 & 0 \\
\hline & & & Total & 3 & & Total & 2 & 1 \\
\hline & & & Média & 1,5 & & $\%$ & 66,7 & 33,3 \\
\hline & & & dp & 0,7 & & & & \\
\hline
\end{tabular}

Tabela 16. Nascimentos, intervalo entre ninhadas, $n^{\circ}$ de filhotes e relação macho:fêmea da fêmea 6CF (080398)

\begin{tabular}{ccccccccc}
\hline \multirow{2}{*}{ Fêmea } & \multirow{2}{*}{ Macho } & Ninhadas & $\begin{array}{c}\text { Inter. } \\
\text { (d) }\end{array}$ & $\begin{array}{c}\mathbf{N}^{\mathbf{0}} \\
\text { filhotes }\end{array}$ & Identificação & Macho & \multirow{2}{*}{ Fêmea } \\
\hline \multirow{2}{*}{080398} & \multirow{2}{*}{030311} & $19 / 1 / 09$ & - & 1 & $\mathrm{f} 090418$ & & 0 & 1 \\
& $20 / 5 / 09$ & 121 & 2 & f090420 & m090422 & 1 & 1 \\
\hline & & Total & 3 & & Total & 1 & 2 \\
& & & Média & 1,5 & & $\%$ & 33,3 & 66,7 \\
& & & 0,7 & & & & \\
\hline
\end{tabular}

Fêmeas que tiveram os dados de nascimentos levantados pelo histórico do biotério

Tabela 47. Nascimentos, intervalo entre ninhadas, $n^{\circ}$ de filhotes e relação macho:fêmea da fêmea 7CF (990169)

\begin{tabular}{ccccccccc}
\hline Fêmea & \multirow{2}{*}{ Macho } & Ninhadas & $\begin{array}{c}\text { Inter. } \\
\text { (d) }\end{array}$ & $\begin{array}{c}\mathbf{N}^{\mathbf{0}} \\
\text { filhotes }\end{array}$ & \multicolumn{2}{c}{ Identificação } & Macho & Fêmea \\
\hline \multirow{6}{*}{990169} & 000192 & $22 / 3 / 02$ & - & 2 & f020226 & m020227 & 1 & 1 \\
& & $10 / 12 / 02$ & 263 & 2 & m020255 & m020256 & 2 & 0 \\
& $30 / 5 / 03$ & 171 & 2 & m030279 & m030280 & 2 & 0 \\
& $4 / 11 / 03$ & 158 & 2 & f030305 & f030306 & 0 & 2 \\
& $11 / 5 / 04$ & 189 & 2 & f040323 & m040324 & 1 & 1 \\
\hline & & Total & 10 & & Total & 6 & 4 \\
& & & Média & 2 & & \% & 60 & 40 \\
& & dp & 0 & & & & \\
\hline
\end{tabular}

f-fêmea; m- macho; ?- sexo desconhecido 
Tabela 18. Nascimentos, intervalo entre ninhadas, $n^{\circ}$ de filhotes e relação macho:fêmea da fêmea 8CF (000189)

\begin{tabular}{|c|c|c|c|c|c|c|c|c|c|}
\hline \multirow[t]{2}{*}{ Fêmea } & Macho & \multirow{2}{*}{$\begin{array}{c}\text { Ninhadas } \\
16 / 10 / 01\end{array}$} & \multirow{2}{*}{$\begin{array}{c}\begin{array}{c}\text { Inter. } \\
\text { (d) }\end{array} \\
-\end{array}$} & \multirow{2}{*}{$\begin{array}{c}\begin{array}{c}\mathbf{N}^{\mathbf{o}} \\
\text { filhotes }\end{array} \\
2\end{array}$} & \multicolumn{3}{|c|}{ Identificação } & Macho & Fêmea \\
\hline & & & & & $\mathrm{m} 010207$ & f010208 & & 1 & 1 \\
\hline & & 4/3/02 & 139 & 2 & f020223 & f020223 & & 0 & 1 \\
\hline & & $15 / 9 / 02$ & 195 & 2 & m020244 & f020245 & & 1 & 1 \\
\hline & & $31 / 1 / 03$ & 138 & 2 & m030266 & f030267 & & 1 & 1 \\
\hline & & $5 / 5 / 03$ & 94 & 1 & $\mathrm{~m} 030276$ & & & 1 & 0 \\
\hline & & $4 / 8 / 03$ & 91 & 3 & $\mathrm{~m} 030287$ & f030288 & f030289 & 1 & 2 \\
\hline \multirow[t]{11}{*}{000189} & 990167 & $4 / 11 / 03$ & 92 & 3 & $? 030301$ & $? 030302$ & $? 030303$ & 0 & 0 \\
\hline & & $23 / 5 / 04$ & 201 & 2 & m040325 & m040326 & & 2 & 0 \\
\hline & & 25/10/04 & 155 & 3 & f040336 & m040337 & m040338 & 2 & 1 \\
\hline & & $24 / 3 / 05$ & 150 & 3 & m050351 & f050352 & f050353 & 1 & 2 \\
\hline & & $24 / 8 / 05$ & 150 & 2 & f050358 & f050359 & & 0 & 2 \\
\hline & & $22 / 11 / 05$ & 90 & 2 & $\mathrm{~m} 050363$ & m050364 & & 2 & 0 \\
\hline & & $25 / 2 / 06$ & 95 & 2 & m060368 & f060369 & & 1 & 1 \\
\hline & & $25 / 5 / 06$ & 90 & 3 & f060373 & f060374 & f060375 & 0 & 3 \\
\hline & & & Total & 32 & & & Total & 13 & 15 \\
\hline & & & Média & 2,29 & & & $\%$ & 44,8 & 51,7 \\
\hline & & & dp & 0,61 & & & & & \\
\hline
\end{tabular}

Tabela 19. Nascimentos, intervalo entre ninhadas, $n^{\circ}$ de filhotes e relação macho:fêmea da fêmea 9CF (000190)

\begin{tabular}{|c|c|c|c|c|c|c|c|c|}
\hline Fêmea & Macho & Ninhadas & $\begin{array}{l}\text { Inter. } \\
\text { (d) }\end{array}$ & $\begin{array}{c}\mathbf{N}^{\mathbf{0}} \\
\text { filhotes }\end{array}$ & \multicolumn{2}{|c|}{ Identificação } & Macho & Fêmea \\
\hline \multirow{8}{*}{000190} & \multirow{5}{*}{000188} & 27/10/01 & - & 2 & m010209 & f010210 & 1 & 1 \\
\hline & & $29 / 4 / 02$ & 91 & 2 & $\mathrm{~m} 020228$ & f020229 & 1 & 1 \\
\hline & & 29/7/02 & 91 & 2 & $\mathrm{~m} 020241$ & f020242 & 1 & 1 \\
\hline & & $30 / 10 / 02$ & 93 & 1 & f020250 & & 0 & 1 \\
\hline & & $29 / 1 / 03$ & 91 & 2 & $\mathrm{~m} 030264$ & f030265 & 1 & 1 \\
\hline & & & Total & 9 & & Total & 4 & 5 \\
\hline & & & Média & 1,80 & & $\%$ & 44,4 & 55,6 \\
\hline & & & dp & 0,45 & & & & \\
\hline
\end{tabular}

Tabela 20. Nascimentos, intervalo entre ninhadas, $\mathrm{n}^{\mathbf{o}}$ de filhotes e relação macho:fêmea da fêmea 10CF (000193)

\begin{tabular}{|c|c|c|c|c|c|c|c|c|}
\hline \multirow[t]{2}{*}{ Fêmea } & \multirow[t]{2}{*}{ Macho } & \multirow{2}{*}{$\begin{array}{c}\text { Ninhadas } \\
22 / 10 / 01\end{array}$} & \multirow{2}{*}{$\begin{array}{c}\text { Inter. (d) } \\
-\end{array}$} & \multirow{2}{*}{$\begin{array}{c}\mathbf{N}^{\mathbf{o}} \text { filhotes } \\
1\end{array}$} & \multicolumn{2}{|c|}{ Identificação } & \multirow{2}{*}{$\frac{\text { Macho }}{1}$} & \multirow{2}{*}{$\begin{array}{c}\text { Fêmea } \\
0\end{array}$} \\
\hline & & & & & m010209 & & & \\
\hline & & $12 / 3 / 02$ & 141 & 1 & $? 020224$ & Natimorto & 0 & 0 \\
\hline & & $30 / 12 / 02$ & 293 & 1 & $\mathrm{~m} 020257$ & & 1 & 0 \\
\hline \multirow[t]{8}{*}{000193} & 000177 & $1 / 6 / 03$ & 152 & 1 & f030281 & & 0 & 1 \\
\hline & & $2 / 9 / 03$ & 93 & 2 & m030292 & f030293 & 1 & 1 \\
\hline & & 28/9/04 & 392 & 2 & f040332 & m040333 & 1 & 1 \\
\hline & & $28 / 2 / 05$ & 153 & 1 & f050348 & & 0 & 1 \\
\hline & & $1 / 11 / 05$ & 245 & 2 & f050361 & $\mathrm{m} 050362$ & 1 & 1 \\
\hline & & & Total & 11 & & Total & 6 & 5 \\
\hline & & & Média & 1,38 & & $\%$ & 54,5 & 45,5 \\
\hline & & & dp & 0,52 & & & & \\
\hline
\end{tabular}


Tabela 21. Nascimentos, intervalo entre ninhadas, $\mathrm{n}^{\mathbf{o}}$ de filhotes e relação macho:fêmea da fêmea $11 \mathrm{CF}(010211)$

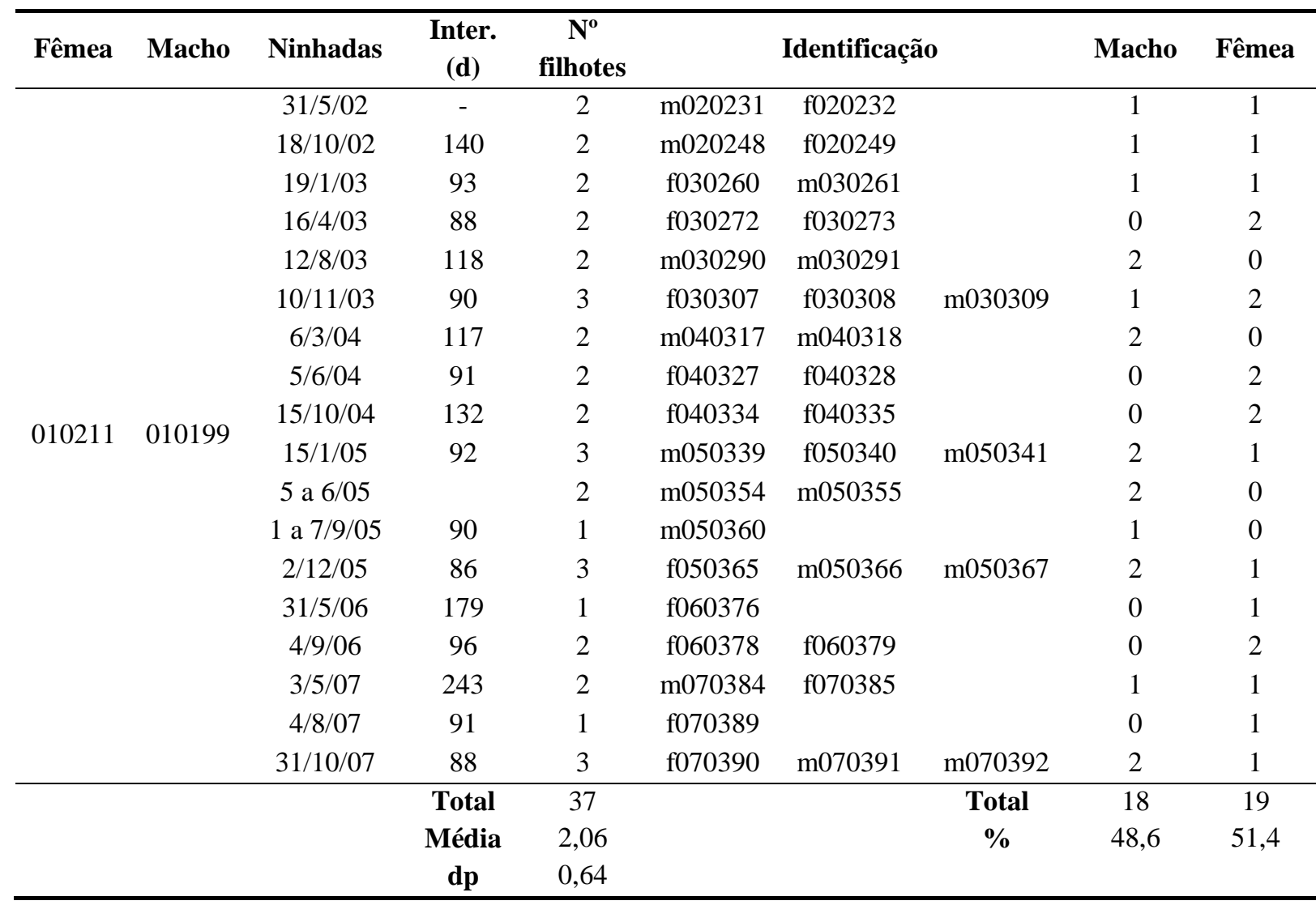

Tabela 22. Nascimentos, intervalo entre ninhadas, $n^{\circ}$ de filhotes e relação macho:fêmea da fêmea 12CF (030281)

\begin{tabular}{ccccccccc}
\hline \multirow{2}{*}{ Fêmea } & \multirow{2}{*}{ Macho } & Ninhadas & $\begin{array}{c}\text { Inter. } \\
\text { (d) }\end{array}$ & $\mathbf{N}^{\mathbf{0}}$ filhotes & Identificação & Macho & Fêmea \\
\hline \multirow{2}{*}{030281} & \multirow{2}{*}{030276} & $17 / 12 / 03$ & & 2 & $\mathrm{~m} 030311$ & $\mathrm{f} 030312$ & 1 & 1 \\
& $17 / 1 / 05$ & 396 & 2 & $\mathrm{f} 050344$ & $\mathrm{f} 050345$ & 0 & 2 \\
\hline \multirow{2}{*}{030281} & \multirow{2}{*}{030273} & $22 / 5 / 06$ & & 1 & $\mathrm{~m} 060372$ & & 1 & 0 \\
& & $18 / 9 / 06$ & 119 & 2 & $\mathrm{~m} 060380$ & $\mathrm{f} 060381$ & 1 & 1 \\
\hline 030281 & 000177 & $12 / 6 / 08$ & & & $\mathrm{~m} 080401$ & $\mathrm{~m} 080402$ & 2 & 0 \\
\hline & & & Total & 7 & & Total & 5 & 4 \\
& & & Média & 1,75 & & $\%$ & 71,4 & 57,1 \\
& & & dp & 0,5 & & & & \\
\hline
\end{tabular}

A linha em negrito é a separação entre os diferentes machos que foram pareados com a fêmea 
Fêmeas capturadas que tiveram os dados de nascimentos levantados pelo histórico do biotério

Tabela 23. Nascimentos, intervalo entre ninhadas, $n^{\circ}$ de filhotes e relação macho:fêmea da fêmea 13CF (960012)

\begin{tabular}{|c|c|c|c|c|c|c|c|c|}
\hline Fêmea & Macho & Ninhadas & $\begin{array}{l}\text { Inter. } \\
\text { (d) }\end{array}$ & $\begin{array}{c}\mathbf{N}^{\circ} \\
\text { filhotes }\end{array}$ & \multicolumn{2}{|c|}{ Identificação } & Macho & Fêmea \\
\hline \multirow{10}{*}{$\begin{array}{l}960012 \\
\text { coletada }\end{array}$} & \multirow{7}{*}{960016} & $15 / 3 / 99$ & & 2 & m990168 & f990169 & 1 & 1 \\
\hline & & $21 / 11 / 99$ & 251 & 2 & m990173 & m990174 & 2 & 0 \\
\hline & & 28/4/00 & 158 & 2 & $\mathrm{~m} 000186$ & f000187 & 1 & 1 \\
\hline & & $5 / 12 / 00$ & 221 & 1 & m000194 & & 1 & 0 \\
\hline & & 20/8/01 & 258 & 2 & f010197 & m010198 & 1 & 1 \\
\hline & & $17 / 11 / 01$ & 89 & 2 & f010213 & $\mathrm{m} 010212$ & 1 & 1 \\
\hline & & $24 / 5 / 02$ & 188 & 1 & $\mathrm{~m} 020230$ & & 1 & 0 \\
\hline & & & Total & 13 & & Total & 9 & 4 \\
\hline & & & Média & 1,9 & & $\%$ & 69,2 & 30,8 \\
\hline & & & Dp & 0,38 & & & & \\
\hline
\end{tabular}

f-fêmea; m- macho; ?- sexo desconhecido

Tabela 24. Nascimentos, intervalo entre ninhadas, $n^{\circ}$ de filhotes e relação macho:fêmea da fêmea 13CF (960030)

\begin{tabular}{|c|c|c|c|c|c|c|c|c|}
\hline Fêmea & Macho & Ninhadas & $\begin{array}{c}\text { Inter. } \\
\text { (d) }\end{array}$ & $\begin{array}{c}\mathbf{N}^{\mathbf{o}} \\
\text { filhotes }\end{array}$ & Iden & :̃̃o & Macho & Fêmea \\
\hline \multirow{12}{*}{$\begin{array}{c}960030 \\
\text { coletada }\end{array}$} & 960038 & $19 / 11 / 99$ &. & 1 & m990172 & & 1 & 0 \\
\hline & ou & 16/3/00 & 117 & 2 & $\mathrm{~m} 000178$ & f000179 & 1 & 1 \\
\hline & 970009 & $14 / 8 / 00$ & 151 & 1 & f000190 & & 0 & 1 \\
\hline & 960038 & $6 / 11 / 00$ & - & 2 & $\mathrm{~m} 000192$ & f00193 & 1 & 1 \\
\hline & \multirow{8}{*}{$\begin{array}{c}960038 \\
\text { ou } \\
970009\end{array}$} & $15 / 9 / 01$ & 397 & 2 & f010201 & $\mathrm{m} 010202$ & 1 & 1 \\
\hline & & 4/7/02 & 292 & 2 & f020237 & f020238 & 0 & 2 \\
\hline & & $21 / 1 / 03$ & 201 & 2 & f030262 & f030263 & 0 & 2 \\
\hline & & $17 / 5 / 03$ & 116 & 2 & $\mathrm{~m} 030277$ & $\mathrm{~m} 030278$ & 2 & 0 \\
\hline & & $17 / 9 / 03$ & 123 & 2 & m030294 & f030295 & 1 & 1 \\
\hline & & $1 / 3 / 04$ & 170 & 2 & $\mathrm{~m} 040315$ & f040316 & 1 & 1 \\
\hline & & $12 / 8 / 04$ & 169 & 1 & f040331 & & 0 & 1 \\
\hline & & $21 / 1 / 05$ & 153 & 2 & $\mathrm{~m} 050346$ & $\mathrm{~m} 050347$ & 2 & 0 \\
\hline & & & Total & 21 & & Total & 10 & 11 \\
\hline & & & Média & 1,7 & & $\%$ & 47,6 & 52,4 \\
\hline & & & Dp & 0,47 & & & & \\
\hline
\end{tabular}

A linha em negrito é a separação entre os diferentes machos que foram pareados com a fêmea 
Tabela 25. Nascimentos, intervalo entre ninhadas, $\mathrm{n}^{\circ}$ de filhotes e relação macho:fêmea da fêmea 14CF (960034)

\begin{tabular}{|c|c|c|c|c|c|c|c|c|}
\hline Fêmea & Macho & Ninhadas & Inter. & $\mathbf{N}$ & \multicolumn{2}{|c|}{ Identificação } & Macho & Fêmea \\
\hline \multirow{9}{*}{$\begin{array}{c}960034 \\
\text { coletada }\end{array}$} & \multirow{6}{*}{960019} & $6 / 5 / 00$ & - & 2 & $\mathrm{~m} 000188$ & f000189 & 1 & 1 \\
\hline & & $15 / 4 / 01$ & 344 & 2 & m010195 & f010196 & 1 & 1 \\
\hline & & 27/7/02 & 468 & 2 & f020239 & $\mathrm{m} 020240$ & 1 & 1 \\
\hline & & $17 / 2 / 03$ & 205 & 2 & $? 030268$ & $? 030269$ & 0 & 0 \\
\hline & & $26 / 9 / 03$ & 221 & 1 & f030298 & & 0 & 1 \\
\hline & & $11 / 5 / 05$ & 592 & 2 & $? \mathrm{~s} / \mathrm{n}^{\mathrm{o}}$ & $? \mathrm{~s} / \mathrm{n}^{\mathrm{o}}$ & 0 & 0 \\
\hline & & & Total & 11 & & Total & 3 & 4 \\
\hline & & & Média & 1,8 & & $\%$ & 27,3 & 36,4 \\
\hline & & & Dp & 0,45 & & & & \\
\hline
\end{tabular}


Anexo 8 - Tabelas de frequência dos eventos do ciclo estral nas fêmeas enquanto grávidas $(\mathrm{n}=5)$

Tabela 26. Frequência dos estados vaginais (AV) durantes os três meses de gravidez em Trinomys yonenagae durante o ano 2008/2009 (grupo C) ${ }^{4}$

\begin{tabular}{cccc|ccc|ccc}
\hline \multirow{2}{*}{ FÊMEA/ AV } & \multicolumn{3}{c|}{ Mês 1 } & \multicolumn{3}{c|}{ Mês 2 } & \multicolumn{3}{|c}{ Mês 3 } \\
& F & S & A & F & S & A & F & S & A \\
\hline 4 CF & 0 & 12 & 3 & 0 & 16 & 3 & 0 & 20 & 5 \\
2 CF & 5 & 23 & 0 & 0 & 0 & 0 & 1 & 11 & 0 \\
5 CF & 0 & 14 & 1 & 0 & 13 & 6 & 1 & 17 & 4 \\
$3 \mathrm{CF}^{2}$ & 1 & 12 & 1 & 0 & 10 & 0 & 1 & 16 & 0 \\
$3 \mathrm{CF}$ & 1 & 28 & 1 & 0 & 0 & 0 & 2 & 10 & 0 \\
\hline Total & 7 & 89 & 6 & 0 & 39 & 9 & 5 & 74 & 9 \\
\% & 7 & 87 & 6 & 0 & 81 & 19 & 6 & 84 & 10 \\
Total Mês & & $\mathbf{1 0 2}$ & & & $\mathbf{4 8}$ & & & $\mathbf{8 8}$ & \\
\hline
\end{tabular}

F- Fechada; S-Selada; A-Aberta

Tabela 27. Frequência das fases do ciclo estral (EV) durantes os três meses de gravidez em Trinomys yonenagae durante o ano 2008/2009 (Grupo C) ${ }^{1}$

\begin{tabular}{|c|c|c|c|c|c|c|c|c|c|c|c|c|c|c|c|}
\hline \multirow{2}{*}{ FÊMEA } & \multicolumn{5}{|c|}{ Mês 1} & \multicolumn{5}{|c|}{ Mês 2} & \multicolumn{5}{|c|}{ mês 3} \\
\hline & D & $\mathbf{P}$ & $\mathbf{E}$ & $\mathbf{M}$ & $?$ & D & $\mathbf{P}$ & $\mathbf{E}$ & $\mathbf{M}$ & ? & D & $\mathbf{P}$ & $\mathbf{E}$ & M & $?$ \\
\hline $4 \mathrm{CF}$ & 14 & 0 & 0 & 1 & 0 & 18 & 0 & 0 & 1 & 0 & 25 & 0 & 0 & 0 & 0 \\
\hline $2 \mathrm{CF}$ & 23 & 0 & 0 & 1 & 0 & 0 & 0 & 0 & 0 & 0 & 11 & 0 & 0 & 0 & 0 \\
\hline $5 \mathrm{CF}$ & 14 & 0 & 0 & 0 & 0 & 18 & 0 & 0 & 0 & 1 & 20 & 0 & 0 & 0 & 0 \\
\hline $3 \mathrm{CF}$ & 12 & 0 & 0 & 1 & 0 & 9 & 0 & 0 & 0 & 0 & 15 & 0 & 0 & 1 & 0 \\
\hline $3 \mathrm{CF}$ & 29 & 0 & 0 & 0 & 0 & 0 & 0 & 0 & 0 & 0 & 10 & 0 & 0 & 0 & 0 \\
\hline total & 92 & 0 & 0 & 3 & 0 & 45 & 0 & 0 & 1 & 1 & 81 & 0 & 0 & 1 & 0 \\
\hline$\%$ & 96,8 & 0 & 0 & 3,2 & 0 & 95,7 & 0 & 0 & 2,1 & 2,1 & 98,8 & 0 & 0 & 1,2 & 0,0 \\
\hline total mês & \multicolumn{5}{|c|}{95,0} & \multicolumn{5}{|c|}{47,0} & \multicolumn{5}{|c|}{82,0} \\
\hline
\end{tabular}

D- Diestro; P- Proestro; E- Estro; M- Metaestro; ?- Fase não identificada

\footnotetext{
${ }^{4}$ Participam apenas as fêmeas do grupo C do experimento de AV e EV que tiveram pelo menos um episódio de gestação. Sendo portanto, apresentadas 5 fêmeas.
} 
Anexo 9 - Oscilação de temperatura corporal nas fêmeas de Trinomys yonenagae nas $72 \mathrm{~h}$ de experimento

Figura 9.1. Oscilação da temperatura corporal nas 8 fêmeas que compõem o grupo A em $72 \mathrm{~h}$

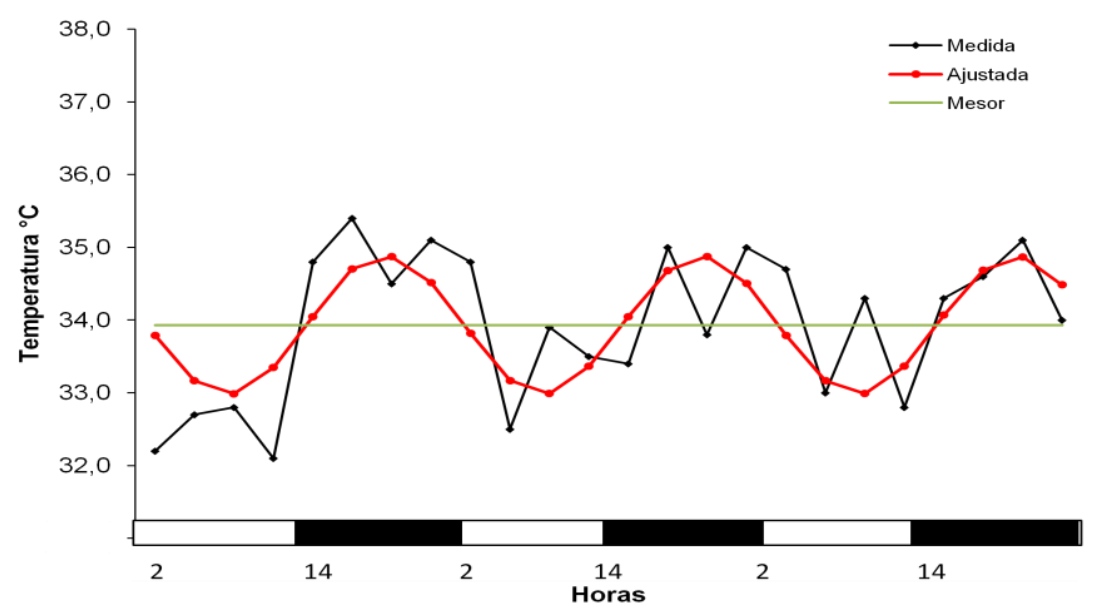

Figura 9.2. Oscilação da temperatura corporal nas 8 fêmeas que compõem o grupo B em $72 \mathrm{~h}$

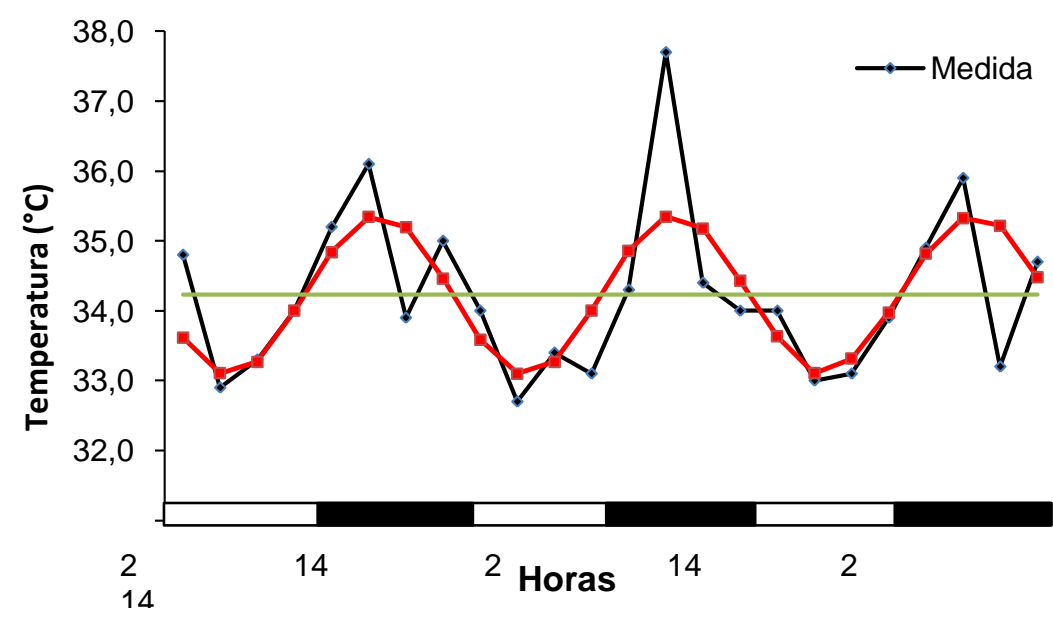

